V.

Aus der Kgl. Universitäts-Ohrenklinik zu Halle a. S. (Geh. Rat Prof. Dr. H. Sehwartze.)

\title{
Jahresbericht über d. Tätigkeit der Kgl. Universitäts-0hren- klinik zu Halle a. S. vom 1. April 1904 bis 31. März 1905.
}

Von

Prof. Dr. K. Grunert und Dr. E. Dallmann.

Im Berichtsjahre 1904/1905 wurden in der Kgl. UniversitätsOhrenklinik zu Halle a. S. 2937 Patienten behandelt, gegen 2719 im Vorjahre, wobei die aus dem vorigen Berichtsjahre verbliebenen nicht eingesehlossen sind.

In der stationären Klinik wurden aus dem Vorjahre übernommen 15 männliche und 9 weibliche Kranke, neu aufgenommen wurden 292 Kranke (gegen 239 im Vorjahre), 175 männliche und 117 weibliche, so daß im ganzen $316 \mathrm{Kranke}$ verpflegt wurden, 190 männliche und 126 weibliche. Von diesen Kranken wurden 261 entlassen, 150 männliche und 111 weibliche; es verstarben 19, 16 männliche und 3 weibliche, so daß am 31. März 1905 ein Krankenbestand von 36 Kranken, und zwar 24 männlichen und 12 weiblichen verblieb. Auf die Gesamtzahl der 316 stationär behandelten Kranken kamen 11053 Verpflegungstage, mithin durchsehnittlieh auf jeden Kranken 34,9 Tage. Der durohsehnittliehe tägliehe Krankenbestand betrug 30,28 Kranke, überstieg also auch in diesem Jahre, und zwar in weit höherem Maße als im Vorjahre, wo er 26,12 Kranke betrug, die Zahl der vorhaudenen etatsmäßigen 25 Betten. Der höchste tägliche Krankenbestand betrug am 23. November 190436 Kranke (gegen 34 Kranke im Vorjahre), der niedrigste am 31. Mai 190421 Kranke. Die durehschnittliehe tägliche Aufnahme betrug 0,8 Kranke, die höchste Zahl der an einem Tage aufgenommenen Kranken betrug 6, und zwar am 3. August 1904.

Obige Zablen beweisen, wie sehr die Ohrenklinik in Zeiten stärkeren Krankenandranges tiberlegt war. Es handelte sich dabei um Fälle schwerer, nur operativ zu beseitigender Ohrerkrankungen, die nieht abgewiesen werden konnten, ohne Verletzung. 
der Humanitätspflicht. Da auch die beiden Filialen der Klinik beständig voll belegt waren und in Zeiten stärkeren Krankenandranges nicht genügten, waren wir gezwungen, eine 3. Filiale anzulegen, ja mehrfach muBten wir Kranke sogar in Gasthöfen unterbringen. Welehe Mißstände sich aus diesen Verhältnissen ergeben, liegt auf der Hand. Der größte Mißstand ist der, daß eine sorgfältige Krankentiberwachung der an so auseinandergelegenen Orten untergebrachten Kranken selbst bei bestem Willen nicht in dem Grade durchfuhrbar ist, wie es dem Interesse der nns anvertrauten Kranken entspricht. Wiederholt mußten wir Kranke, die einer eingreifenden Operation unterzogen worden waren, bereits mehrere Tage nach dem Eingriffe za ambulatorischer Behandlung entlassen. Ja, bei Kranken, die in Halle ansässig sind, haben wir mehrfach große Operationen ambulatorisch ausführen müssen. Auch der Mangel ausreichender Isolierräume für ansteckende Kranke (Scharlach usw.) machte sich wiederholt in der unangenehmsten Weise geltend, und nur dank des Entgegenkommens der Herren Direktoren der inneren und chirurgischen Klinik waren wir in der Lage, derartige Kranke in die innere und chirurgisehe Klinik zu verlegen und dort zu behandeln.

Was die Personalien der Ärzte anbetrifft, so ist die Gesundheit des im Vorjahr beurlaubten Direktors der Klinik, Herrn Geheimrat Prof. H. Schwartze, soweit wieder gekräftigt, daß er am 15. Oktober 1904 die Direktionsgeschäfte wieder übernehmen konnte. Im Laufe des Wintersemesters 1904/1905 wurde dem ersten Assistenten der Klinik, Prof. Dr. C. Grunert, zur Entlastung des klinischen Direktors vom Kgl. Unterrichtsministerium die ärztliche Leitung der Poliklinik übertragen. Außer ihm fungierten während des Berichtsjahres als Assistenten der Klinik Dr. E. Dallmann und der vom Kgl. Kriegsministerium zur Klinik kommandierte Oberarzt im Mansfelder Art.-Rgt. Nr. 75 Dr. Is emer, sowie der etatsmäBige Hilfsassistent Dr. P. Konietzko. Als Volontärassistenten waren im Berichtsjahre tätig Dr. Winter und Dr. P. Laval.

Im Berichtsjahre sind folgende Werke und Arbeiten aus der Kgl. Universitäts-Ohrenklinik hervorgegangen:

1. Grunert, Die operative Ausrăumung des Bulbus venae jugularis (Bulbusoperation) in Fällen otogener Pyämie; bei F. C. W. Vogel, Leipzig 1904.

2. Grunert und Dallmann, Jahresbericht über die Tätigkeit der Kgl. Uníversitäts-Ohrenklinik zu Halle a. S. vom 1. April 1904 bis 31. März 1905. Dieses Archiv. Bd. LXII. S. 74.

3. Konietzko und I semer, Ein Fall von secundärer Otitis media puru- 
lenta im Anschluß an Empyem der Highmorshöble. Ebenda. Bd. LXIV. S. 92 .

4. Grunert, Zur Gefahr der Bulbusoperation; Bildung einer Encepbalocele. Fibenda. Bd. IXIV. S. 95.

5. Laval, Zur regionären Anästbesie des äuleren Gehörganges. Ebenda. Bd. LXIV. S. 142.

6. Dallmann, Beitrag zur Casuistik der Pneumokokkenotitis. Ebenda. Bd. LXIV. S. 147.

7. Kober, Über unkomplizierte otogene Extraduralabszesse. Dissert. inang. Halle 1904.

8. Schwartze-Grunert, Einführung in das Studium der Ohrenheilkunde, ein Grundrib der Otologie in Form von akademischen Vorträgen für Studierende und praktische Arzte; bei F. C. W. Vogel, Leipzig 1905.

9. Grunert, Erfahrungen aus dem Gebiete der Chirurgie der oberen Nebenhöblen der Nase, mit besonderer Berücksichtigung der postoperativen Angenmuskelstörungen. Zeitschr. f. Augenheilk. Bd. XII. H. 6.

10. Derselbe, Zur Arbeit von Stabsarzt Dr. Voss: Zur operativen Freilegung des Bulbus venae jugularis. Zeitschr. f. Ohrenheilk. 1905.

Die Verhältnisse des Alters, der Heimat der Patienten, der Erkrankungen und der ausgefuhrten Operationen ergeben sich aus folgenden Tabellen:

I. Alterstabelle.

\begin{tabular}{c|c|c|c}
\hline $\begin{array}{c}\text { Altersklassen } \\
\text { Jahre }\end{array}$ & $\begin{array}{c}\text { Mannliche } \\
\text { Kranke }\end{array}$ & $\begin{array}{c}\text { Weibliohe } \\
\text { Kranke }\end{array}$ & Summa \\
\hline \hline $0-2$ Jahre & 141 & 90 & 231 \\
$2-10=$ & 437 & 400 & 837 \\
$11-20=$ & 341 & 218 & 559 \\
$21-30=$ & 224 & 101 & 325 \\
$31-40=$ & 366 & 106 & 472 \\
$41-50=$ & 139 & 48 & 187 \\
$51-60=$ & 84 & 52 & 136 \\
$61-70=$ & 67 & 40 & 107 \\
$71-80=$ & 8 & 36 & 44 \\
$81-90=$ & 2 & 30 & 32 \\
Unbekannt & 5 & 2 & 7 \\
\hline Summa: & 1814. & 1123. & 2937.
\end{tabular}

II. Heimatstabelle.

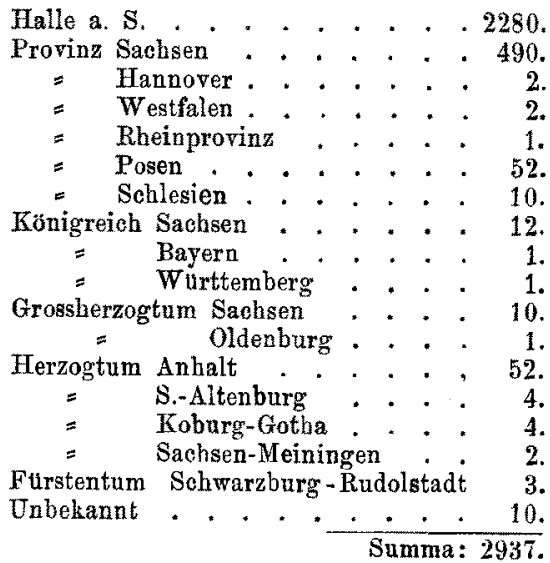


III. Krankheitstabelle.

\begin{tabular}{|c|c|c|c|c|c|c|c|c|}
\hline Nomen morbi & 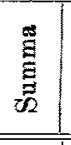 & 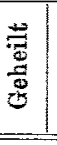 & 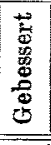 & 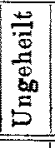 & 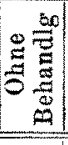 & 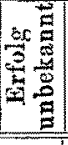 & 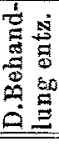 & $\begin{array}{l}5 \\
\frac{5}{5} \\
5 \\
0 \\
0 \\
0 \\
0\end{array}$ \\
\hline Ohrmuschel: & 2 & & - & - & & & & \\
\hline $\begin{array}{l}\text { Neubildungen (Carcinom) } \\
\text { Ekzem. }\end{array}$ & 28 & -4 & - & - & - & $\begin{array}{r}2 \\
14\end{array}$ & - & - \\
\hline Congelatio & 2 & - & - & - & - & - & - & — \\
\hline Missbildung & 2 & - & - & - & 2 & - & _ & - \\
\hline Othatmatom. & 2 & 2 & - & - & - & - & - & - \\
\hline $\begin{array}{l}\text { Ä asserer Gehörgang: } \\
\text { Mißbildung }\end{array}$ & & & & & & & & \\
\hline $\begin{array}{l}\text { Mißbildung } \\
\text { Fremdkörper (durch Spritzen entfernt 91; }\end{array}$ & 1 & -1 & - & - & 1 & - & - & - \\
\hline operativ entf. 3) & 94 & 94 & - & - & - & - & - & - \\
\hline Cerum. obt. (eins. 128, doppels. 60) & 248 & 248 & - & - & - & - & - & - \\
\hline Ekzema acutum & 100 & - & - & - & - & - & - & - \\
\hline$=$ ehronicum .. & 124 & - & - & - & - & - & - & - \\
\hline Furunkel (durch Ineision geheilt 26) & 124 & 124 & - & - & - & - & 一 & - \\
\hline Exostosen & $\begin{array}{r}4 \\
10\end{array}$ & - & - & - & - & - & 一 & - \\
\hline Otomykosis & 12 & 12 & - & - & - & - & - & - \\
\hline Carcinom & 1. & $1 \mid$ & - & - & - & - & - & - \\
\hline Trommelfell: & & & & & & & & \\
\hline Epithelperle & 1 & - & - & - & 1 & - & - & - \\
\hline Ruptur (durch Ohrfeige 4) & 9 & 9 & - & - & - & - & - & - \\
\hline Mittelohr: & & & & & & & & \\
\hline Akuter Catarrh (eins. 240, doppels. 61) & $361] 1$ & 109 & - & $\rightarrow$ & - & 252 & - & - \\
\hline Subakuter Catarrh (eins. 60 , doppels. 42) & 144] & -1 & - & - & - & - & - & - \\
\hline $\begin{array}{l}\text { Chron. Catarrh der Paukenböble (eins, 200, } \\
\text { doppels. } 71 \text {; mit Exsudat } 164 \text {; mit Tuben- }\end{array}$ & & & & & & & & \\
\hline $\begin{array}{l}\text { stenose } 68 \text {; mit Adhaesionen } 42 \text { ) } \\
\text { Otosklerose }\end{array}$ & $\begin{array}{l}342 \\
204\end{array}$ & - & 一 & - & - & - & - & - \\
\hline Aknte Mittelohreiterung (eins. 204, doppel- & & & & & & & & \\
\hline $\begin{array}{l}\text { seitig } 100) \\
\text { Subaknte Mittelohreiterung (eins. } 56 \text {, dop- }\end{array}$ & $404: 5$ & 302 & - & - & - & 88 & - & 14 \\
\hline $\begin{array}{l}\text { Subaknte Mittelonrelterung (eins. } 06 \text {, cop- } \\
\text { pels. 50) }\end{array}$ & 156 & - & - & - & - & - & - & - \\
\hline $\begin{array}{l}\text { Chron. Mittelohreiterung (einseitige } 290 \text {, dop- } \\
\text { pelseit. } 80 \text {; mit Caries } 204 \text {; mit Polypen } \\
70 \text {; mit Cholesteatombildung } 138 ; \text { mit }\end{array}$ & & & & & & & & \\
\hline Entzindung des proe. mast. 52 ) & 450 & 198 & - & - & - & 239 & - & 13 \\
\hline Residuen & 246 & -1 & - & - & - & -1 & - & $\longrightarrow$ \\
\hline $\begin{array}{l}\text { Neuralgia plexus tymp. (Angina 18, Zahn- } \\
\text { karies } 30 \text {, Laes 2, unbek. Ursache 9) }\end{array}$ & 59 & $30]$ & - & - & 29 & - & - & - \\
\hline $\begin{array}{l}\text { Inneres } O \mathrm{hr} \text { : } \\
\text { Chron. Nerventaubheit }\end{array}$ & 59 & - & - & - & - & - & - & 一 \\
\hline Ménière'sche Krankheit & 3 & - & - & - & - & - & - & - \\
\hline Scbläfenbeinfractur & 4 & - & - & - & - & - & - & - \\
\hline Ohrensausen ohne Befund & 12 & - & - & - & - & - & - & - \\
\hline Taubstummheit & 10 & - & - & - & - & - & - & - \\
\hline Negativer Befund im $O \mathrm{hr}^{1}$ ) & 64 & - & - & - & - & - & - & - \\
\hline Anderweitige Erkrankungen ${ }^{2}$ ) & 360 & — & - & - & - & - & - & - \\
\hline Keine Diagnose & 59 & - & - & - & - & - & - & - \\
\hline Summa der Erkrankungsformen: & 3642 & - & -1 & -1 & - & - & 一 & - \\
\hline
\end{tabular}

1) Betrift neist Kranke, welehe von andercn Kliniken zur Aufnabme des Ohrbefundes zugesandt wurden.

2) Betrift vornebmlich Erkrankungen der Nase und ibrer Nebenhöhlen, sowie des Nasenrachenraumes. 
IV. Operationstabelle.

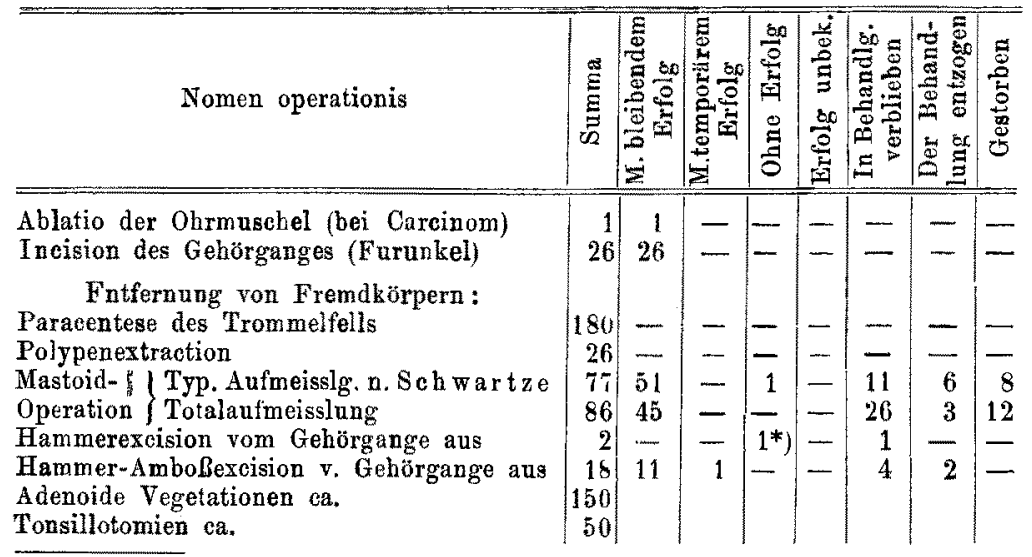

*) Später total aufgemeißelt.

Die Zahl der Mastoidoperationen ist gegen das Vorjahr, wo sie 136 betrug, auf 163 gestiegen. Bei den Hammer-Amboßexcisionen vom Gehörgange aus hat sich uns, wie aus obiger Operationstabelle zu ersehen ist, nach wie vor zur Entfernung des Amboß der Zeronische ösenförmige Haken auf das beste bewährt. Wenn neuerdings Neumann (dieses Arch. Bd. LXIV. S. 167) dieses Instrument zur AmboBextraktion deshalb für "nicht geeignet" erklärt, weil die scharfe Ecke dieses Hakens an der Umbiegungsstelle eine nicht zu unterschätzende Gefahr für den Facialnerven bilden soll, so beweist der Umstand, daß wir bei Anwendung dieses Hakens niemals eine Facialisverletzung haben eintreten sehen, am besten die Unhaltbarkeit dieses ungerechtfertigten Urteiles. Nach der Abbildung zu urteilen, ist das Neumannsche Instrument nur ein $\mathrm{Kretsehmannscher} \mathrm{Haken} \mathrm{mit}$ unwesentlichen Abänderungen, auch die Anwendungsart ist die gleiche und wird deshalb wohl auch dieselben Nachteile haben, die Zeroni gerade zur Construktion seines ösenförmigen Instrumentes geführt haben. Übrigens enthält der Nenmannsche Haken wieder scharfe Ränder am Angriffsteil, die bei falscher Anwendung eine viel größere Gefahr für den Facialis bilden, als die von ihm gerügte scharfe Ecke bei den alten Modellen. Wir halten nach wie vor grundsätzlich für die Mehrzahl der Fälle von Hammer-Amboßextraktion eine tiefe Allgemeinnarkose für unerläßlich. Der Anwendung der Lokalanästhesie, wie sie Nenmann (1. c.) ausübt, steht immer die Tatsache entgegen, daß die dazu notwendige Abhebung der Bekleidung der oberen und hin- 
teren knöchernen Gehörgangswand durch die Injektionsflüssigkeit rom Knochen nicht schmerzlos zu bewerkstelligen ist. Wenn Nenmann sagt: "Obwohl die Injektion in der Mehrzahl der chronisohen Fälle wenig schmerzhaft ist, ist es doch ratsam, dabei den Kopf durch einen Assistenten fixieren zu lassen ", so ermutigt das keineswegs zur Anwendung seiner Methode. Denn mit seinen Worten gibt er zu, daß die Anästhesierung selbst im günstigsten Falle - bei der Mehrzahl der ohronischen Fälle "wenig schmerzhaft" ist. Von der Dehnbarkeit dieses Begriffes abgesehen, enthalten seine Worte indirekt das Geständnis, daß die Anästhesierung in der Minderzahl der Fälle mehr wie "wenig schmerzhaft" ist. Wie kann man aber im Vorans dem einzelnen Falle ansehen, $o b$ er in die erste oder zweite Rubrik fällt? Fernerhin erwähnt Neumann bei der Besprechung der Indikationen der Hammer-Amboßextraktion, daß die von Schwartze aufgestellten Indikationen eine Erweiterung durch Suckstorff erfahren hätten, „der die Extraktion auch bei bloßen Schleimhauteiterungen im Attik ohne Caries der Gehörknöchelchen indiciert findet, weil durch Umwandlung von Attik und Antrum in eine gemeinsame Höhle dem Sekret freier $A b f l u B$, dem Eindringen von Medikamenten freier Zugang geschaffen wird". Hierzu möehten wir bemerken, daß wir in unserer Klinik bereits seit 13 Jahren in einzelnen Fällen von einfachen Schleimhauteiterungen ohne Caries der Ossicula lediglich im Interesse eines besseren Eiterabflusses die Hammer-Ambobexcision vom Gehörgange aus ausgefuhrt haben. Bereits im Jahresberichte 1892/1893 dies.Areh. Bd.XXXVI.S. 282) findet sich der folgende entsprechende Hinweis: "Man kann die Indikation der Hammerextraktion auch auf solche Fälle von chronischer Eiterung ausdehnen, welche nicht wegen der Complikation mit Caries jeder palliativen Therapie trotzen, sondern weil durch Verwachsungszustände des Trommelfells mit der Labyrinthwand der Eiter nicht genügenden Abfluß hat."

Ehe wir zur Schilderung der im Berichtsjahre eingetretenen Todesfälle übergehen, mögen noeh einige Fälle von größerem Interesse vorausgeschickt werden. Unsere neueren Erfalrungen über die Bulbusoperation übergehen wir hierbei, weil sie von Laval in einer besonderen Arbeit publieiert werden sollen.

1. Fall. Akute linksseitige Mittelohreiterang nach Ohrfeigenverletzung des Ohres. Mastoiditis. Sinusverletzung bei der Mastoidoperation. Infeliöse Sinusthrombose mit consecu- 
tiver Pyämie. Jugularisunterbindung oberhalb der Einmündungsstelle der Vena facialis communis. Sinusoperation. Ausgang in Heilung der Pyämie und Ohreiterung.

Otto Planert, 22 Jahre alt, Ziegelarbeiter aus Schkölen; rec. am 20. August, entlassen am 26. Oktober 1904.

A namnese: Ende Juli Schlag auf das linke Obr, wobei einige Tropfen Blut aus dem Ohr geflossen sein sollen; einige Tage später eitriger $\mathrm{Ohr}$ ausfluß.

Status praesens: Krăftig, guter Ernäbrungszustand, Brust- und Baucheingeweide obne Besonderheiten. Mattigkeit, Übelkeit ohne Erbrechen, kein Schwanken. Pupillen und Augenhintergrund normal. Haut- und Sehnenreflexe normal. Drin ohne Zucker und Eiweiß. Temperatur $38,2^{\circ}$.

Umgebung des linken Ohres: Geringes Odem über dem Planum mastoideum mit Druckempfindlichkeit daselbst.

Gehörgang - und Trommelfellbefund links: Stinkender Eiter. Gebörgang in der Tiefe durch Schwellung sehr verengt. Trommelfell gerötet, geschwollen, vorn unten Perforation.

Hörprufung: Flüstersprache links unmittelbar am $0 \mathrm{hr}$, rechts $5 \mathrm{~m}$. $C$ rom Scheitel nach links. Fis 4 links erst beim Nagelanschlag. Rinne links negativ.

Am Tage vor der Aufname, als Patient in einer Filiale der Klinik lag, Temperatur $37,9,39,7,38,4^{\circ}$. Druckempfindlichkeit, besonders in der Gegend des Emissarium mast. und an der Spitze. Paracentese.

Catheterismus tubae: Perforationsgerăusch mit Rasseln.

21. August. Temperatur $38,9,38,9^{\circ}$. Schlechtes Allgemeinbefinden.

22. August. Temperatur $37,5,37,7^{\circ}$. Ty p i s c he A ufm eißelung $n$ ach Schwartze. Eiter und Granulationsmassen in den Hoblräumen des Warzenfortsatzes. Dura und Sinus freigelegt. Blutung aus dem verletzten Sinus sigmoideus.

23. August. Temperatur $37,3-38,2^{\circ}$. Patient klagt über starke Schmerzen in der Wunde. Puls 56.

24. August. Temperatur $37,2-37,6^{0}$. zen geringer.

25. August. Temperatur $36,4-36,7^{\circ}$, Puls zwischen 60 und 70. Schmer-

26. August. Temperatur $36,7-37,7^{\circ}$.

27. August. Temperatur $37,1,39,5,40,1^{\circ}$. Seit gestern Abend wieder stärkere Schmerzen in der Wunde und der linken Stirngegend. Nachmittags $3^{1 / 2}$ Uhr Schüttelfrost von $1 / 4$ Stunde Dauer mit folgender starker Schweißabsonderung. Puls meist 70 . Keine Benommenheit. Geringer Nystagmus borizontalis. Augenhintergrund normal.

28. Angust. Temperatnr $39,0,38,1,38,7,37,4^{\circ}$. Nacht sebr unruhig. Während der Nacht und am Vormittag mehrmals Frösteln. Puls kräftig, wenig beschlennigt. Jugularisunterbindung. Sinusoperation. Vorsichtige Freilegung des mit schlecht aussehenden, nekrotischen Granulationen bedeckten Sinus vom Knie bis fast zum Bulbus venae jugularis. Bis fast an den Bulbus noch eiterbaltige Zellen aufgedeckt. Im Sinus ein gröBeres Loch (Verletzung), durch das vom Bulbus her mit dem scbarfen Löffel eitrig zerfallene Thrombusmassen entleert werden. Spaltung der collabierten sinuswand bis zum Knie. Nit dem scharfen Löffel wird aus dem Sinus transversus ein ca. $4 \mathrm{~cm}$ langer, zum Teil eitrig zerfallener Thrombus ausgespullt.

29. August. Temperatur $36,8-36,7^{\circ}$. Nacht leidlich ruhig. Nachmittags etwas unrubiger. Puls zwischen 60 und 70 , kräftig. Nystagmus nicht mehr wahrnehmbar.

29. und 30. August. Temperatur $36,7-37,30$.

31. August. Temperatur $37-37,3^{\circ}$.

1. September. Temperatur $37,2-38,2^{\circ}$. Verbandwechsel. Vom Bulbus her Eiterabfluß. Spaltung der Jugularis oberbalb der Ligaturstelle, dabei Abtluß einer geringen Menge zersetzten Blutes. Einlegung eines Drain in die Vene. 2. September. Temperatur $37,8-38,6^{0}$.

3. September. Temperatur $37,2-37,1^{\circ}$. Aus dem Venendrain fließt eine 
geringe Menge mißfarbigen Blutes ab, vom Bulbus her etwas Eiter. Bei Lockerung des im Sinus transversus liegenden Tampon Blutung.

4. September. Temperatur $37,0-37,1^{\circ}$.

5. September. Temperatur $37,0-37,1^{\circ}$. Bei Durchspülung der JugularisSinuswunde, wobei nur wenig Flüssigkeit abflieft, wird ein ca. $21 / 2 \mathrm{~cm}$ langer, zum Teil eitrig zerfallener Thrombus ausgespült. Allgemeinbefinden gut.

6 . September. Temperatur $36,7-37,0^{\circ}$.

7. September. Temperatur $37,5-38,6^{\circ}$. Noch zahlreiche Thrombenreste bei der Durchspülung aus dem Bulbus entfernt. Bei Entfernung des Tampon aus dem Sinus transversus nur geringe Blutung.

8. September. Temperatur $36,9-37,3^{\circ}$. Im weiteren Verlauf die Temperatur bis zum 13. September völlig normal.

9. September. Bei der Durchspülung noch Thrombenreste entfernt, ebenso am 11 . September.

13. September. Durchspülung gelingt nicht mehr. Abstoßung der Unterbindungsfäden. Vom Bulbus her noch geringe Eiter menge.

14. September. Temperatur $37,6-38,0^{\circ}$. Drain aus der Vene fortgelassen.

15. und 16 . September. Temperatur normal.

16. September. Wunde sieht gut aus. Weder von der Jugularis noch vom Bubus her Eiterabfuß mehr. Nachts geringes Frösteln.

17. September. Temperatur $37,1-38,7-39,0^{\circ}$ " Schmerzen im rechten Knie und linkem Ellbogengelenk. gelassen.

18. September. Temperatur $36,9-38,0^{\circ}$, Puls 68 . Gelenkschmerzen nach-

19. September. Temperatur $38,5,39.6,38,9^{\circ}$. Starke Schmerzen in der linken Schläfe und Kopfseite, ebenso im linken Ellbogengelenk. Frösteln.

20. September. Temperatur $37,0-38,0^{\circ}$. Linksseitige Kopfschmerzen, Gelenkschmerzen nachgelassen. Puls 74 .

21. September. Temperatur $37,5-38,0^{\circ}$.

22. September. Temperatur $38,4,37,6,38,4^{\circ}$. Nachts Schüttelfrost. Keine Gelenkschmerzen, starke Schmerzen in der linken Schläfe. Herz und Lungen ohne Besonderheiten. Wunde tadellos.

23 . bis 25 . September. Temperatur vollig normal.

24. September. Nachts Schüttelfrost, Schmerzen in der linken Schlăfengegend, die jedoch auf Klopfen nicht zunehmen.

25. September. Schmerzen und geringe Schwellung im linken Akromion.

26. September. Temperatur $36,8,38,1,39,0^{\circ}$. Nachmittags Schüttelfrost. Augenhintergrund normal.

27 . September. Temperatur $36,8,36,6,37,5^{\circ}$. Schmerzen uber beiden Augen und in der Stirngegend

28. September. Temperatur $36,1,38,0,37,5^{\circ}$. Von da an keine Fiebersteigerung mehr.

29. September. Schmerzen und Schwellung in der Akromiongegend völlig geschwunden. Nachts Schmerzen abwechseind in Stirn- und Schläfengegend.

Weiterer Heilungsverlauf normal.

26. Oktober. Retroauriculăre Wunde vollstāndig geschlossen. Gebörgang mäßig weit. Trommelfell getrübt. Flüstersprache beiderseits $5-7 \mathrm{~m}$. $\mathrm{C}$ vom Scheitel nach links lateralisiert. Fis 4 beiderseits gut. Geheilt entlassen.

Epikrise. Vor allem interessiert in diesem Falle die Frage, $o b$ die infektiöse Sinusthrombose als eine traumatische aufaufassen ist, in ursächlichem Zusammenhange stehend mit der bei Vornahme der typisehen Aufmeißelung unbeabsichtigt zustande gekomme ien Verletzung des Sinus sigmoideus, oder ob sie unabhängig von diesem Trauma entstanden ist.

Eine sichere Entscheidung dieser Frage ist natiirlich nicht möglich. Gegen einen ursächlichen Zusammenhang sprechen 
außer der klinischen Erfahrung, daß solche Sinusverletzungen gewöhnlich keine Störung des Heilungsverlanfes zur Folge haben, folgende Momente: Sehon vor der Mastoidoperation bestanden Fieberböhen (bis $39,7^{\circ}$ ), die durch den Operationsbefund keine rechte Erklärung fanden. Einerseits war keine Eiterretention in der Paukenhöhle vorhanden, und andererseits wurde bei der Operation auch kein extrasinöser AbszeB freigelegt, welcher eine genügende Erklärung für das hohe Fieber erbracht hätte. Auch lag der Beginn der akuten Eiterung bereits soweit zurück, daß man das Fieber unmöglich erklären konnte nach Analogie solcher Fälle akuter Mittelohreiterung, bei denen selbst nach Durehbruch des Eiters dureh das Trommelfell noch längere Zeit mittleres oder selbst höheres Fieber fortbesteht, wie man dies bei Kindern nicht allzu selten erlebt. Der Einwand, daß man bei der Sinusverletzung nur eine Blutung habe auftreten seben und nichts von einem Thrombus bemerkt habe, kann mit dem Hinweise darauf bekämpft werden, daB ja der Thrombus zur Zeit der Verletzung vielleicht nur ein wandständiger und daher in. folge der starken Blutung nicht erkennbarer gewesen ist, oder daß er zunächst weiter centralwärts im Bulbus lokalisiert gewesen sein kann. Die Möglichkeit, daß hier ein Thrombus entstehen konnte, war um so mehr gegeben, als hier, ganz centralwärts nach dem Bulbus zu, sich mehrere Zellen mit eitrigem Inhalt befanden, wie sie die Mastoidoperation aufgedeckt hat.

Dab die 6 Tage nach der Mastoidoperation vorgenommene Sinusoperation mit Jugularisunterbindung das Fieber nieht sofort zum Verschwinden brachte, sondern daß es erst allmählich abklang, entspricht ja der alltäglichen klinischen Erfahrung. Es kann dies um so weniger auffallen, als ja der Bulbus nach der Sinusoperation noch längere Zeit der Sitz zerfallener Thrombusmassen war, deren wir schließlich durch Durcbspülungen des Jugularis-Sinusrohres Herr wurden, ohne daß wir gezwungen waren, den Bulbus selbst operativ in Angriff zu nehmen. Als das Fieber bereits fast abgeklungen war und weder aus Bulbus noch Jugularis mehr Eiter abfloh, setzte unter neu auftretenden Sehüttelfrösten eine neue Temperatursteigerung ein (vom 17. September ab), und nun erst traten pyämische Metastasen an Gelenken, Akromion usw. auf. Es ist anzunehmen, daß ihre Aussaat erfolgt ist von einem noch nicht konsolidierten Thrombus in irgend einem der kleineren Sinus. Einen bedrohlichen Charakter nabmen indessen diese pyämisehen Erschei- 
nungen nicht an, insbesondere blieben die Lungen frei von Metastasen. Dieses zweite, erst ausgesprochen pyämische Stadium der Erkrankung dauerte im ganzen nur 11 Tage. Nach cirea zweimonatlichem Aufenthalt konnte der Kranke geheilt entlassen werden, geheilt nicht nur von seiner Pyämie, sondern auch von der ursächlichen Nittelohreiterung, und zwar mit völliger Herstellung seines Gehörs.

2. Fall. Chronische Eiterung beiderseits. Rechtsseitige infektiöse Sinusthrombose; kleiner ExtraduralabszeB in der mittleren Schädelgrabe. TotalanfmeiBelung. Jugularisunterbindung. Sinusoperation.

Nartha Patscb, 16 Jahre alt, Aufwärterin aus Merseburg; rec. am 29. September 1904, entlassen am 2. Januar 1905.

Anamnese: Seit 14 Jahren Eiterung beiderseits aus unbekannter Ursache. Links vor 14 Jahren typisch aufgemeißelt. Seit den letzten Wochen vermehrte Eitersekretion, seit 2 Tagen plötzlich heftige Kopfschmerzen und Druckempfindlichkeit über dem Proc. mastoideus. Am 28. September abends Erbrechen und Fieber. Sensorium etwas benommen Klage über Klopfen im ganzen Kopf. Angeblich soll die Patientin einige Tage vor der Exacerbation der Krankheitserscheinungen eine Obrfeige bekommen haben.

Status praesens: Temperatur 38,8 , Puls 120 . Mittelkräftiges Mădchen. Pupillen gleich groß, reagieren gleichmäßig, kein Nystagmus, keine objektiv nachweisbaren Gleichgewichtsstörungen. Herz und Lungen ohne Besonderheiten. Augenhintergrund zeigt etwas stärker gefüllte Venen.

Umgebung des rechten Ohres: Druckempfindlichkeit an der Spitze des Proc. mast. und in der Gegend des Emissarium.

Gehörgang - und Trommelfell befund: Kechts: Gehörgang nicht stenosiert; profuser übelriechender Ausfluß. Hammergriff schwer ertsennbar. Vorn unten Perforation, kleine Granulationen, beim Sondieren hier cariöser Knochen fühlbar.

Hörprüfung: Flüstersprache rechts dicht am Ohr. C vom Scheitel nicht lateralisiert. Fis 4 gut gehört. Rinn e positiv.

29. September 1904. Die Lumbalpunktion ergab Punctio sicca.

Totalaufmeibelung rechts: Weichteile normal Corticalis osteosklerotisch. Nach den ersten Meißelschlägen quillt aus der Sinusgegend unter hohem Drack stehende, pulsierende, rotbraune Jauche hervor. Ausgedehnte Caries sämtlicher Mittelohrränme. Die Caries reicht bis zur Dura der mittleren Schädelgrube. Bei Freilegung der Dura quillt plötzlich zwischen ihr und der Vitrea dünntiüssiger gelber Eiter hervor. Eröffnung eines ungeführ bohnengroßen Extraduralabszesses. Dura sieht hier grau verfärbt aus. Resektion der mit Eiter gefullten Spitze und der knöchernen Wand des Sulcus sigmoideus in großer Ausdehnung. Hierbei Sinusverletzung und Blutung. Durch die verletzte Sinuswand hindurch läßt sich das Vorhandensein eines wandständigen Thrombus feststellen. Jugularisunterbindung oberhalb der Einmandungsstelle der V. facialis. Breite Sin u öffnung und Entfernung grau verfärbter Thrombenmassen. Schließlich kräftige Blutung aus dem peripheren und mäßige aus dem centralen Sinusende.

Nach der Operation sofortiger Fieberabfall von 38,9 auf $36,9^{\circ}$.

30. September. Temperatur $37,4-37,1^{\circ}$. Befinden gut. Die Kopfschmerzen sind vollständig verschwunden. Puls krâftig und regelmäßig. Geringe Milzvergrößerung. Perkussions- und Auskultationsbefund über der Lunge normal. Gelenke frei.

1. Oktober. Temperatur $37,4-37,1^{\circ}$. 2. Okt. Temperatur $37,3-38,2^{\circ}$.

3. Oktober. Temperatur $37,3-38,1^{\circ}$. Keine Klagen. Verbandwechsel: In der Paukenhohle etwas freier Eiter. Gutes Aussehen der freiliegenden Dura. Bei Lösung des centralen Sinustampon keine Blutung, Lockerung des peripheren Tampon, bis Blutung eintritt. Die Halswunde sieht etwas trocken und in der Tiefe sulzig aus. 
4. Oktober. Temperatur $37,6-40,1^{\circ}$. Befinden gut, gute Nahrungsaufaufnahme. 2 Uhr 10 Minuten p. m. Schüttelfrost, darauf Temperaturanstieg anf $40,1^{\circ}$.

5. Oktober. Temperatur 38,8-38,2 ${ }^{\circ}$. Allgemeinbefinden gut. Verbandwechsel: Im centralen Sinusteil steht dünnflüssige Jauche. Bei Druck auf die seitliche Halsgegend quillt aus dem centralen Sinusende dickflüssiges schwarzes Blut hervor, vermischt mit Thrombenpartikeln. Aũfschlitzung der Jugularis und Durchspülung. Die Durehspülung gelingt von oben nach unten gut. Es werden dabei reichliche Mengen zum Teil zerfallener Thrombenmassen entfernt. Lösung des peripheren Tampons, mittelstarke Blutung.

Langsamer stetigex Temperaturabfall; rom 8. Okt. an völlig fieberfirei.

2. Januar 1905. Die ganze Wundhöhle ist epidermistert bis auf eine hirsekorngroße Stelle an der Tubenmündung. Patientin zu ambulatorischer Behandlung entlassen. gegend.

Hat Halle später verlassen mit noch spärlicher Eiterung aus der Tuben-

Epik $r$ ise. Die Lumbalpunktion wurde vor dem operativen Eingriffe zuerst beabsichtigt, weil uns die Benommenheit recht suspekt im Sinne einer diffusen Meningitis vorkam. Sie gab uns nicht den gew ünschten Aufsehluh (punctio sicca). Die bei der Totalaufmeißelung vorgekommene Sinusverletzung ist auf eine abnorme Brüchigkeit der Sinuswand zu beziehen. Direkt im AnschluB an die Verletzung war in dem durch die Läsion eröffneten Sinusrohr die Anwesenheit wandständiger Thrombose zu konstatieren. Nach der Sinusoperation fiel zunächst die Fiebertemperatur bis zur Norm ab. Die Temperatur blieb zunächst 2-3 Tage völlig normal, zeigte dann 2 Tage eine leicht febrile Erhöhung, um am nächsten Tage nach vorhergegangenem Schutttelfrost zu einer Höhe von 40,10 emporzuschnellen. Die Ursache dieser erneuten hohen Temperatursteigerung wurde sofort klar. Sie bestand in Verhaltung purulenter Thrombenmassen im Jugularvenenbulbus und in dem Jugularisteil oberhalb der Ligatur. Als die Jugularis oberhalb der Ligatur aufgeschlitzt war und durch eine Durchspïlung des Bulbus nach der geöffneten Jugularis hin von dem offenen Sinus sigmoideus aus dje infektiösen Zerfallsmassen aus dem in Rede stehenden venösen Gefäßbezirk ausgespült worden waren, fiel die Temperatur schnell wieder and ging in wenigen Tagen zur Norm zurück. Metastasen sind nicht aufgetreten.

3. Fall. Chronische Eiterung rechts. Cholesteatom. Sinusthrombose. Jugularisunterbindung. Sinusoperation. Heilung.

Curt Kalbitz, 12 Jahre alt, Schuhmachersohn aus Weißenfels; rec. am 15. Mai, entlassen am 26. Juni 1904.

Anamnese: Verdacht auf Tuherkulose. Die Mutter ist mehrmals wegen "Drüsenvereiterung" operiert. Patient selbst leidet in der letzten Zeit an Husten und Nachtschweißen. Seit dem 6. Lebensjabre Ohreiterung rechts, angeblich im Anschluß an Masern. Die Eiterung bat mit geringen Dnterbrechungen fast ununterbrochen bestanden und soll immer sehr fötid gewesen sein. Klage über mäßige Schwerhörigkeit. Seit ungefähr einem Jahre Kopf- 
schmerzen und mitunter Schwindelanfälle. Seit 4 Tagen Schmerzen hinter dem Ohre.

Status praesens: Temperatur $38,2^{\circ}$. Sehr blasser Knabe, Knochenbau grazil, Muskulatur und Fettpolster dürftig. Thorax sçhlecht gewölbt. Uber beiden Lungenspitzen, besonders links, verschärftes Exspirium und Inspirium. Herzdämpfung nicht vergrößert. Yupillen gleích weit, reagieren prompt. Geringer Nystagmus rotatorius beim Blick nach rechts Sehwindel läßt sich objektiv nicht nachweisen.

Umgebung des rechten Ohres: Der ganze Warzenfortsatz ist stark druckempfindlich, besonders in der Gegend des Planum mastoideum. Kein Ödem. Unterhalb der Spitze eine geschwollene Drüse.

Gehörgang- und Trommelfellbefund: Rechts: Gehörgang stenosiert, enthält mäßige Mengen fötiden Eiters und schmieriger Epidermis. Im Hintergrunde einige kleine Granulationen sichtbar. Beim Sondieren kommt man hinten oben auf kranken Knochen. -- Links: Trubung.

Hörpr ü fung: Flüstersprache rechts nicht gehört. Links $5 \mathrm{~cm} . \mathrm{C}_{1}$ vom Scheitel nach links. Fis 4 rechts erst bei Nagelanschlag. Rinne rechts negativ.

16. Mai. Temperatur abends $39,8^{\circ}$.

17. Mai. In der Nacht Frost. Morgentemperatur $37,2^{\circ}$.

Totala fmeißelung wegen großen zerfallenen Cholesteatoms, welches die ganzen Mittelohrräume einnahm und die knöcherne bintere Gehörgangswand bereits zerstört batte. Von Ossiculis nur noch ein Amboßrest vorhanden. Im hinteren unteren Teile der großen Operationshöhle - die ganze Spitze mußte wegen Cholesteatomes reseciert werden - liegt der mit mißfarbenen, ulcerösen Granulationen bedeckte Sinus frei. Mit der Tenotomsonde gelangt man durch eine Fistel in der Sinuswand in den Sinus hinein. Es ergießc sich dabei nur aufällig wenig Blut. Unterbindung der makroskopisch unveränderten Vena jugularis int. Sinus peripher- und centralwärts weit treigelegt. Beim Freilegen zentralwärts möglicherweise ein einmaliger Facialisspasmus bemerkt (nach der Operation Facialislähmung). Breite Spaltung des abnorm dickwandigen Sinus. Enorme Blutung, so daß von deutlichen Thrombenmassen nichts zu sehen war. Tamponade mit Jodoformgaze

Nach der Operation Pals sehr klein, erholt sich bald wieder.

23. Mai. Erster Verbandwechsel; Lösung des Sinustampon ohne Blutnng Abgesehen von nur noch erhöhter Abendtemperatur am 3 . Juni von $38,0^{\circ}$ vollkommen fieberfreier Verlauf nach der Operation.

4. Juni. Verbandwechsel. Aus der Halswunde entleert sich etwas Eiter, Drainage.

6. Juni. Jeden 3. Tag Verbandwechsel. Eiterung aus der Halswunde nur noch gering.

9. Juni Eiterabsonderung aus der Halswunde verschwunden. Allgemeines Woblbefinden.

20. Juni. Halswunde geheilt. Ohroperationshöhle epidermisiert sebr langsam; reichliche Granulationsbildung. In ambulatorische Bebandlung entlassen.

15. August. Sehr langsamer Heilungsverlauf der Ohroperationshöhle, die noch reichliche eitrige Absonderung zeigt.

12. November. Die ganze Ohroperationshöhle epidermisiert. Ohr vollständig trocken. Gehörgang ziemlich eng.

Epikritische Bemerkung. Der rapide Abfall des Fiebers $\left(39,8^{\circ}\right)$ zur Norm in direktem Anschluß an die Sinusoperation - nur an einem Abend, $17 \mathrm{Tage}$ nach der Operation, trat noch eine einmalige Temperatursteigerung auf $38^{\circ}$ ein - charakterisiert den Verlauf des vorliegenden Falles als einen ungewöhnlich günstigen. Störungen traten nur ein in der Epidermisierung der Ohroperationshöhle, die eine Nachbehandlung von weit über 
Durehschnittsdauer nötig machten und in der schlechten Eroährung (Pthisis pulmonum) des Knaben ihre Erklärung fanden.

Bei der Operation selbst trat uns ein Ereignis entgegen, welches wir nun schon ein zweites Mal erlebt haben. Der freigelegte Sinus sigmoideus war mit ulcerösen Granulationen bedeckt. An einer makroskopisch fistelverdächtigen Stelle gelangte man mit der Tenotomsonde tatsächlich in das Sinusrohr. Es ergoß sich dabei eine anffällig geringfügige Blutung aus dem Sinus, die uns annehmen ließ, daß das GefäBrohr zum größten Teil thrombosiert sein müsste. Wie groß war nun unsere Verwunderung über das Ergebnis der breiten Sinusspaltung! Es zeigte sieh, daß die Sinuswand um das Vielfache ihrer normalen Dicke verdickt war. Bei der Incision quoll ein so enorm starker Blutstrom hervor, dab zunächst von einem Thrombus nichts zu sehen war. Wie ist es nun zu erklären, daß bei dem vorbergebenden Sondieren des Sinus mit der Tenotomsonde nur eine spärliche Blutung eintrat? Doeb wohl nur aus der enormen Dicke der Sinuswand, die es zuließ, daß der intravenöse Blutdruck die Fistelwände so fest aneinanderpressen konnte, daß bei dem Wiederherausführen der Tenotomsonde aus dem Sinus nur eine kleine Menge Blutes zum Abfließen kam.

4. Fall. Aknte linksseitige Mittelohreiterung mit folgender Sinusthrombose nach Nasenoperation. Jugularisnnterbindung. Sinusoperation. Heilung.

Minna Seidel, 23 Jahre alt, Dienstmädchen aus Trebitz. Aufgenommen am 1. Mai, entlassen am 29. Juli 1904.

Patientin war wegen starker Deviatio septi narium und hochgradiger papillärer Hypertrophie der linken unteren Nasenmuschel mit völliger Verlegung der Nase in die Filiale der Klinik aufgenommen. Amputation der unteren Muschel. Danach mehrfache Nachblutung im Zeitraume mehrerer Tage, so daß schließlich mit Hülle der Belocqueschen Röhre tamponiert werden mußte. Am 1. Mai Kopfschmerzen. Trommelfell nicht entzündet, trübe. 3. Mai. Aknte Eiterung links. Ödem und Druckempfindlichkeit hinter dem Ohre.

Stat. praesens: Sehr anämisches Mädchen, Herz und Lungen gesund.

Umgebung des linken Ohres: Ödem über dem ganzen Proc. mastoideus. Druckschmerzhaftigkeit besonders über dem Planum mast. und über der Spitze.

Gebörgang- und Trommelfellbefund links: Im Gehörgang pulsierender Eiter. Frische Trommelfellperforation Beim Catheterismus tubae Perforationsgerănsch.

Therapie: Paracentese. Eisblase binter das Obr. Bettruhe.

Temperatur zwischen 1 . und 6 . Mai zwischen 36,7 und $39,9^{\circ}$.

7. Maí. Typische Aufmeißelung links: Weichteile ödematös. Corticalis normal, linea temporalis steht sehr tief. Nach Fortnahme des Planum mastoid. erweisen sich sämtliche Zellen des Warzenfortsatzes als sehr groß und mit Eiter erfüllt. Um das Antrum erreichen zu können, mul die sehr tief stehende Dura der mittleren Schädelgrube ziemiich weit freigelegt werden. Die ganze Spitze des Warzenfortsatzes wird reseciert, weil sie mit Eiter erfüllt ist. Freilegung des Sinus in großer Ausdehnung. Bei Weiter- 
abtragung der eitrig infiltrierten Zellen ziemlich starke Blutung aus dem Emissarium mastoideum. Tamponade.

8. Mai. Temperatur $37,5-38,2^{\circ}$. Woblbetinden.

9. Mai. Temperatur $37,3-37,9^{\circ}$. 10. Mai. Temp. 37,2-37,9 . 11. Mai.

Temperatur $36,6-37,1^{\circ}$. 12. Mai. Temperatur $36,5-36,8^{\circ}$.

13. Mai. Temperatux $36,7-39,1^{\circ}$. Verbandwechsel. Wunde sieht gut aus.

14. Mai. Temperatur $38,2-38,3$. Geringe Kopfschmerzen in der rechten Stirngegend. Puls beschleunigt, regelmäBig.

15. Mai. Temperatur $37,2-38,5^{\circ}$. Wunde sieht gut aus. S inus w eit freigelegt and eroffnet, kleine Thromben darin. Jugularisunterbindung. Puls sehr schwach. Ätherinjektion im rechten Unterarm.

16. Mai. Temperatur $38,3-39,9^{\circ}$. Große Mattigkeit, Puls kräftiger. Klagen aber Schmerzen in der Gegend der Injektionsstelle am rechten Unterarm, daselbst unter der Haut das Gefühl von Knistern.

17. Mai. Temperatur $38,2-38,8^{\circ}$. An der Vorderseite des rechten Armes, handbreit oberhalb des Handgelenkes beginnend, heraufreichend bis handbreit unterhalb der Schulterhöhe füblt sich die Haut gespannt an, zeigt auf Druck Knistern und an einzelnen Stellen Flnktuation. Spaltung im ganzen Bereich der infiltrierten Partie, wobei sich etwas schmieriger Eiter and Luft. entleert. Gegenincision $8 \mathrm{~cm}$ oberhalb des Ellenbogengelenkes.

18. Mai. Temperatur $37,9-37,6^{\circ}$. Armwunde mit schmierigem Belage, der mit Scheere und scharfem Löffel entfernt wird; breite Tamponade, Hochlagerung des Armes.

Seit dem 19. Mai fieberfreier Verlauf.

23. Mai. Wunde am Obr und am Arm zeigen ein frisches Aussehen.

25. Mai. Verkleinerung der Armwande durch Zusammenziehen der Wundränder durch sechs Nähte.

30. Mai. Die Hautlappen am Arm sind anf der Unterlage angeheilt, die Wunde dadurch verkleinert. Sie ist von frischrotem Aussehen. Methodische Bewegungen im Eillenbogengelenk beim Verbandwechsel.

10. Juni. Die Kopfwande sieht frisch aus, die Unterbindungsstelle der Jugularis fast verheilt. Die Wunde am Arm verkleinert sich regelmäßig durch Überbäntung. Ziemliche Steifigkeit im rechten Ellenbogengelenl. Methodische aktive und passive Bewegungen.

10. Juli. Armwunde verheilt.

18. Juli. Aus dem Aditus ad antrum werden noch mehrere kleine nekrotische Knochenplättchen entfernt.

Später rollkommen geheilt.

Epikritische Bemerkung. Daß sich an eine Nasentamponade eine akute Mittelohreiterung anschließt, ist nichts außergewöhnliches. Daß es dabei zu einem Übergreifen der Eiterung: auf die Nebenhöhlen der Paukenhöhle kommt, ja daß eine Sinusthrombose sich hinzugesellt, gehört schon zu den selteneren Beobachtungen. Bezüglich der Diagnose Sinusthrombose bot der Fall keine Schwierigkeiten. Daß das Fieber nach der Sinusoperation, anstatt zurückzugehen, sich noch weiter steigerte, es hielt allerdings nur noch 4 Tage an -. bängt zweifellos mit der Entwicklung der von der Ätherinjektionsstelle am rechten Unterarm ausgehenden Gasphlegmone zusammen. Es bedarf keiner besonderen Versicherung, daß die Injektion mit allen Kautelen vorgenommen ist, und es ist daher nicht angängig, die Entwicklung der Gasphlegmone auf eine bei der Injektion zustande gekommene Infektion zu beziehen. Wir müssen daher an- 
nehmen, daß die Injektion nur das Trauma gewesen ist, welches die Infektion des bei einer Sinusthrombose an und für sich vulnerabeleren Gewebes durch im Blute kreisende Mikroorganismen begünstigt hat. Eine derartige Beobachtung steht übrigens nicht vereinzelt $\mathrm{da}$.

5. Fall. Chronische Fiterung beiderseits mit Cholesteatom, links compliciert mit Sinusthrombose. Beiderseits Totalanfmeibelung; Jugularisunterbindang, Sinusoperation, Heilung.

Franz schulze, 7 Jahre alt, aus Helbra. Aufgenommen am 20. Aug. 1904. Entlassen am 7. Dezember 1904.

Das Kind wurde der Klinik wegen fötider doppelseitiger Mittelohreiterung zugeführt.

Status praesens: Mittelkraftiges, wenig intelligentes Kind in leidlich gutem Ernäbrungszustand. Brust- und Bauchorgane gesund. Urin obne Zucker und Eiweib. Temperatur normal.

Umgebung beider Ohren ohne Besonderbeiten.

Gehörgang-und Trommelfellbefund: Rechts: Totaldefekt des Trommelfelles, Paukenhöhle epidermisiert. Von Ossiculis nur der in Granulationen eingebettete Hammerkopf zu fühlen. Granulationen im Kappelraum und Aditus ad antrum. Links: Totaldefekt des Trommelfelles. Von Ossiculis nichts zu sehen. Krater vorn oben mit Cholesteatom darin.

$\mathrm{H}$ ö $\mathrm{pr}$ r ü $\mathrm{fu} \mathrm{n}$ wegen mangelhafter Intelligenz des Knaben nicht ausführbar.

20. August. T otala ufmeibelung rechts: Der ganze Warzenfortsatz mit zerfallenem Cbolesteatom erfüllt. Aus der Spitze des Proc. mast. quillt dünnflüssiger, fötider Eiter hervor. Resektion der Spitze. Aditus und Antrum durch das Cholesteatom stark erweitert. Eine tiefe Bucht geht bis an den Sinus sigmoideus, Sinus transversus und an die Dura der mittleren Schädelgrube heran. Sinus mit einer dicken Membran bedeckt. Ein anderer Receß fübrt zwischen horizontalen und hinteren senkrechten Bogengang. Keine Bogengangfistel. Von Ossiculis nur ein Hammerrudiment vorhanden. Steigbügel fehlt, das ovale Fenster durch Granulationen verschlossen.

21. August Temperatur $36,8-37,3^{\circ}$.

22. August. Temperatur $36,7-39,3^{\circ}$. Patient ist unrubig, schreit öfters auf. Nahrungsaufnahme reichlich. Obstipation.

23. August. Temperatur $37,6-40,8^{\circ}$. Patient wirft sich unruhig im Bett umber; er klagt uber Schmerzen in der Gegend des linken Emissarium, keine Schwellung. Obrbefund links unverändert. Nacken nicht druckempfindlich. Augenuntersuchungsbefund normal. Puls 120, weich, regelmäBig. Atmung ohne Beschwerden. Patient vermag über alles Auskunft zu geben.

24. Angust. Zustand unverăndert. Totala ufmeibelung links: Weichteile normal Kuppelraum, Aditus und Antrum mit schmierigen Cholesteatommassen ausgefüllt, mit Matrix ausgekleidet und bedeutend erweitert. Tiefer keceb zwischen horizontalem und vertikalem Bogengang. Vom Hammer nur der Kopf vorbanden, Amboß feblt. Freilegung des Sinus sigmoideus in einer Länge von ca. $21 / 2 \mathrm{~cm}$, seine Wandung gelhlich verfärbt. Die Panktion desselben ergibt das Vorhandensein einer obturierenden Thrombose. Jugularisunterbindung oberhalb der Einmündungsstelle der Vena facialis. Sinusoperation. Nach breiter Spaltung des Sinus werden zentralwärts mit dem scharfen Löffel größere Thrombenmassen entfernt. Vom peripheren Sinusende ber ein starker Blutstrom, der durch Jodoformgazetam. ponade gestillt wird. Spaltung nsw.

Vom 25. August an vốllig normaler Temperaturverlauf.

25. August. Wiederholt Erbrechen. Stärkere Unruhe; gegen Mittag plötzlicher Collaps, Puls kaum noch fühlbar, starke Anämie. Kochsalzinfusion. Campher. Nach etwa einer halben Stunde besserte sich der Puls, blieb jedoch weich, 130 , regelmäßig, nur zeitweise dikrot. Auftallender Lufthunger, tiefe Atmung mit Anstrengung aller Hilfsmuskeln. Gegen Abend Aufhören des Erbrechens. Von Seiten der Augen keine Besonderheiten. 
26. August. Patient etwas ruhiger, schreit jedoch noch offter plötzlich auf. Atmung weniger angestrengt, Puls leidlich kräftig, etwa 100, regelmäßig. Verbandwechsel reehts: Gutes Aussehen der Wunde. Links: Nur die obersten Schichten des Verbandes entfernt. Unterbindungsstelle der Jugularis reaktionslos.

30. August. Patient in den letzten Tagen ruhig. Puls stets beschleunigt, meist 130 . Atmung regelmäßig. meist 20 .

2. September. Puls 126. Allgemeinbefinden besser. Die beiderseitigen Operationswunden zeigen reichliche Granulationsbildung.

10. September. Rechts beginnende Epidermisierung.

20. September. Wundhöhlen beiderseits in bester Heilung begriffen, ebenso die Wunde am Halse. Allgemeinbefinden gut. Temperatur stets normal.

20. Oktober. Das linke Ohr ist gut epidermisiert, während die stark granulierende Paukenschleimhaut im rechten. Ohre immer noch zu festex Tamponade zwingt. Ekzem hinter dem rechten Ohre.

2. November. Ekzem hinter dem rechten Ohre abgeheilt. Ausspulungen dieses Ohres mit folgender Eintrăufelung von Tetraborsäure.

1. Dezember. Auch das rechte Ohr ist vollständig epidermisiert. Monat.

7 . Dezember. Geheilt entlassen. Gesamtdauer der Behandlung $31 / 2$

Epikitisehe Bemerkungen. Während der Nachbehandlung nach der Totalaufmeißlung des rechten Ohres stellten sich bei dem vorber völlig fieberfreien Kranken plötzlich Erseheinungen ein - insbesondere hohes Fieber, - welehe den Verdacht des Hinzutritts einer intracraniellen Komplication der Otitis nahelegten. Da die Druckempfindlichkeit der Emissarium mastoideum-Gegend des linken noch nicht operierten Ohres trotz fehlender äußerer retroauriculärer Entzündungserscheinungen in erster Linie auf dieses $\mathrm{Ohr}$ als Ausgangsort der neu hinzugetretenen bedrohlichen Erscheinungen hindeutete, wurde linkerseits sofort die Totalaufmeißlung ausgeführt. Dieselbe legte ein großes Cholesteatom frei und brachte uns eine sichere Unterlage für die Diagnose einer infektiösen Sinusthrombose. Der freigelegte Sinus zeigte sich nämlich gelblich verfärbt, und das Ergebnis der sofort vorgenommenen Probepunetion des Blutleiters - es floß dabei kein Tropfen Blut ab - gab unserer Annahme des Vorhandenseins einer Thrombose und zwar einer obturierenden eine feste Stütze. Diese Annahme wurde dann auch bestätigt bei der weiten Spaltung des Sinus, der wir, wie wir dies grundsätzlich tun, die Unterbindung der vena jugularis interna voransgesehickt hatten.

Der Verlauf nach der Operation war insofern ein überaus günstiger, als das hohe Fieber mit der Operation wie abgesehnitten war und in der Folgezeit der Temperaturverlauf ein völlig normaler blieb. Subjektiv zeigte der Kranke noch längere Zeit mannigfaltige Beschwerden. Ja, am Tage nach der Ope- 
ration, die der Kranke gut überstanden hatte, trat ganz plötzlioh ein schwerer Collaps ein, aus dem sich der Kranke nur Dank der sofortigen Anwendung von Exeitantien und einer schleunigen Kochsalzinfusion wieder erholte. Wir haben derartige Zustände eines schweren Collaps wiederholt ganz unerwartet im Verlaufe der Nachbehandlung nach Sinusoperationen eintreten sehen, und in vielen Fällen war die Sitnation eine so ernste, daß sicher der Tod eingetreten wäre, wäre nicht sofort sachgemäße ärztliche Hülfe zur Stelle gewesen. Solche Fälle machen es uns zur Pflicht, eine derartige schwere Operation wie die Sinusoperation nur dann vorzunehmen, wenn der Kranke: in der Klinik liegt und dadurch die Möglichkeit einer beständigen ärztlichen Überwachung und des sofortigen therapentischen Einschreitens, sowie sich solche bedrohliche Zustände ankündigen, gegeben ist.

Wir gehen jetzt zur Beschreibung der im Berichtsjahre vorgekommenen Todesfälle über:

Fritz Stelzer; $32 \mathrm{~J}$. alt, Krankenwärter Halle a. S. rec. am 3 . Nov. 1903, gestorben am 20. April 1904.

Anamnese: Im 5. Lebensjabre Masern. Ohren damals gesund. Seit dem 7. Lebensjabre beiderseits Otorrhoe mit zeitweisen, selbst Monate langen Intermissionen und zeitweiligem Foetor. Im 11. Lebensjahre Typbns ohne folgende Verschlimmerung des Obrenleidens. 18822 Monate lang in unserer Klinik ambulatorisch rechterseits behandelt (Paracentese). $1885 \mathrm{im}$ Herbst beiderseits ein Viertejjahr lang mit Ausspülungen behandelt. 1886 das rechte Ohr trocken. 1858 wiederbolt Schmerzen im linken Ohre.

30. Juli 1888. 1. A u fnahme in die Klinik wegen der linksseitigen chronischen Eiterung mit Entzündung des Warzenfortsatzes. Das rechte Obr damals trocken. Am 31 . Juli 88 Paracentese links. 7. August. AufmeiBelung links, im Antrum dabei kein Eiter, sondern nur fadenziebenden Schleim gefunden. 21. Angust Paracentese der vorgewölbten membr. Shrapnelli links. 27. August geheilt entlassen.

4. Oktober 1888 2. Aufnabme in die Klinik. Schwindel und taumelnder Gang $\mathrm{n}$ ach, nicht wăhrend des Ausspritzens, beim Aufstehen. bei Lageveränderung. Taumeln und Fallen nach rechts hinten beim stehen mit geschlossenen Augen. Doppelsehen, Trochlearislähmung (?) links; Kopfschmerz in der Stirn, manchmal auch in der linken Schläfe.

28.- 30. Oktober sind diese Erscheinungen nicht mehr vorhanden, um in der Zeit bis zum 18. Januar 1889 wieder aufzutreten. Intermission von neuem bis zum 26. Januar 1889, seitdem Rückkehr derselben. Am 29. Dezember 1888 abends einmalige Temperatursteigerung auf $38,8^{\circ}$. Seit 22 . Januar 1889 unregelmäBiges Fieber; Abendtemperaturen $z$ wischen $38,0-40,3^{\circ}$ Mäliger Stirnkopfsehmerz, geringer Schwindel. Puls in Rucksicht auf die Temperatur von auffallend geringer Frequenz (i0-80.) Keine Stauungspapille, keine Obstipation; keine Herdsymptome, abgesehen von der geringen und nicht näher zu bestimmenden Augenmuskelparese. Am 8. Oktober 88 folgendes Hörprüfungsresultat: Flüstersprache rechts $5 \mathrm{~m}$. , links $1 \mathrm{~m} . \mathrm{C}_{1}$ vom Scheitel nach links lateralisiert. Hohe Töne links nur bei stärkerem Anschlag.

Es wurde die Wahrscheinlichkeitsdiagnose ,linksseitiger KleinhimabszeB" gestellt und am 4. Februar 1889 auch das linkseitige Kleinbirn trepaniert. Weder mittels Aspiration noch breitem Einstechen mit dem Skalpell wurde Eiter gefunden. 
10 Minuten nach der Operation Collaps, künstliche Atmung. Nach dem Erwachen aus der Narkose vermehrter Kopfschmerz, Ubelkeit, im Laufe des Tages sechsmaliges Erbrechen. 5. Februar 1889. In der Nacht siebenmaliges Erbrechen. Am Tage vermehrter Stỉnkopfschmerz, beständige Übelkeit mit häufigem Erbrechen. 6. Februar. Kein Erbrechen, Stirnkopfschmerz geringer; beim Aufrichten kein Schwindel. 17. Februar. In Ambulanz entlassen. 18. März 1889. Wieder reichlichere Eiterung aus dem linken Ohre. Beim Ausspritzen, selbst bei geringem Wasserdruck, eigentümliche Zuckungen des Kopfes nach links und hinten. Beim Aufstehen vom Stuhl and beim Stehen mit geschlossenen Augen fällt Patient, nach links und hinten tanmelnd. 17. April 1859. Plötzlich heftiger schwindel beim Fruhsttick. 2. Mai 1889. Das linke Obr fast trocken. Beim Ausspülen Schwindel. Spontan Schwindel und Kopfschmerz mit Ubelkeit verbunden, aber nicht täglich. Die Anfälle dauern etwa $1 / 4$ Stunde. Flüstersprache damals links $10 \mathrm{~cm}$. In den nächsten zwei Jahren hin nnd wieder Schwindelanfälle; immer noch Doppelsehen, besonders beim Liegen im Bett. Der Patient arbeitete wăhrend dieser Zeit.

21. Juni 1891. 3. A ufnahme in die Klinik wegen Verdachtes auf HimabszeB. 4 Tage vor der Aufnahme hatte Pat. plötzlich starke Schwindel anfälle bekommen, besonders beim Bücken, beftige Kopfschmerzen in der linken Kopfhälfte, einige Male Stechen im Ohr. Druckschmerz auf der Spitze des linken Warzenfortsatzes, die nach dem Occiput zu verlaufende Narbe (von der erfolglosen Kleinhirntrepanation herrührend) auf Drack sehr empfindlich. Im linken $\mathrm{Ohr}$ nicht foetider Eiter, keine Gehörgangsstenose, hinten und unten große Perforation. Im rechten $\mathrm{Ohr}$ jetzt auch weniger Fiter, das eingezogene Trommelfell tellweise mit eingetrocknetem Sekret bedeckt. Perforation hinten unten. Flüsterzahlen links $13 \mathrm{~cm}$, rechts $3 \mathrm{~m}$. $\mathrm{C}$ vom Scheitel nach links lateralisiert. $G_{4}$ beiderseits deutlich. Temperatur $38,3^{\circ}$. 22. Juni. Kopfschmerzen nur bei Eisblase erträglich. 27. Juni. Heftige Kopfschmerzen, Puls 62 , 30. Juni. Puls $55-70.2$ Juli. In der linken Schläfengegend vorn oben an der Ohrmuschel ziemlich cirkumskripte Stelle, die auf Druck sehr empfindlich ist. 3. Juli früh Puls 43. 4. Juli. Links über dem Proc, brevis Fistel. $\%$. Juli. Hammer-Ambolexcision. Hammer gesund, vom Amboß fehlt der kurze Schenkel. Trepanation auf den linken Schläfenlappen, ohne daß auf Eiter gestoßen wurde. Abends Puls 80 . 8. Juli. In den nächsten Tagen die Klage über Kopfschmerzen unverändert. 12. Juli. Vermag die Zunge nicht herauszustrecken. Beim Versuche dies za tun, fibrillâre Zuckungen der Zunge. 13. Juli. Viel Kopfschmerzen. Scheint sich auf einige Worte nicht besinnen zu können. 14. Juli. Kopfschmerz fast verschwunden 15. Juli. Schmerzfrei. 18. Juli. Aufgestanden. Kein Schwindel; Kopf bisweilen leichter. 20. Juli. Leichte Fiebersteigerung. Klagen über Schmerzen in der linken Kopfhälfte. 21. Juli. Fieber- und schmerzfrei. Am 13. August entlassen.

27. Oktober 1892. 4. Aufnahme in die Klinik. Links: Trommelfell fleischig verdickt, große zentrale Perforation. Atticwand zum Teil zerstört. Hinten oben gelangt man direkt in das Antrum, aus dem reichlich Eiter hervorkommt. Von Ossiculis nichts zu sehen. Rechts: Trommelfell eingezogen, fleischig verdickt. Hammercontur deutlich. Vorn unten große Perforation, an deren hinterem Rande eine kleine Granulation sichtbar. Flüsterspraehe rechts $1 \mathrm{~m}, \mathrm{C} 1$ vom ganzen Schädel nach links. Fis 4 rechts gut, links nur bei stärkerem Anschlag. 28. Oktober 1892. TotalaufmeiBelung links, wobei Caries im Antrum und am Tegmen festgestellt wurde. Bei Tamponade der Wunde Taumeln nach links. 17. November. Klage über ein dem Puls synchronisches, linksseitiges Ohrgeräusch, teils zischend, teils sausend, welches häufig die Nachtruhe stört. 20 . November. Solange man die Carotis comprimiert, sistiert das quälende Geräusch. 2. Dezember. In den letzten Tagen enorme Zunahme des pulsierenden Geräusches. Selbstmordgedanken. Unterbindung der Carotis an der typischen Stelle Iinks. Nach der Unterbindung keine wesentliche Anderung in Puls und Atmung, insbesondere keine Lähmnngs- und Reizerscheinungen. 3. Dezember. Gleich nach der Unterbindung war das Ge- 
räusch verschwunden, um gegen ahend, wenn auch in gexingerem Grade, wiederzukehren. 6. Dezember. Wesentliche Abnanme der Ohrgeräusche. Allgemeinbefinden und Gemütszustand wesentlich geboben.

29. Januar 1894. 5. A ufnahme in die Klinik wegen Icterus. Patient hatte seit dem letzten Aufenthalte in der Klinik wieder arbeiten können, der Schwindel war in der letzten Zeit niemals erheblich gewesen. 8 Tage vor der Aufnahme war plötzlich Übelkeit, Erbrechen nnd allgemeine Mattigkeit aufgetreten, wenige Tage später Schwindel. In jeder Nacbt Erbrechen.

1895. Totala fmeiBelung rechts in der Obrenklinik zn Berlin.

Mitte Oktober 1903 fiel Patient bei der Arbeit von einer Leiter herab und schlug mit dem Hinterkopf gegen eine Schrankecke. lm Anschlub daran wieder heftiges Obrensausen, das so unerträglich warde, daß der Kranke sich nach 3 Tagen in die linke Brust schoh. Aufnahme in die chirurgische Klinik, von wo Patient am 3. November 1903 in die Ohrenklinik verlegt wurde wegen Verdachtes auf eine intracranielle Komplikation der Otitis und wegen pulsierender linksseitiger Ohrgeräusche.

Status praesens yom 3. Norember 1903 . Temperatur $37,8^{\circ}$. Sehr blasser, elender Mensch. Über dem Oberlappen der linken Lunge pleuritiscbes Reiben. Herzdănpptung nicht vergrößert, Herztöne rein, Pals regelmäßig, kräftig, 70. Starke Gleichgewichtsstörungen, keine Sensibilitätsstörungen, rohe Kraft erhalten, Patellar- und Bauchdeckenreflexe erhalten. Augenhintergrund normal. Keine Augenmuskellähmungen, kein Nystagmus, Urin ohne Zucker und Eiweib.

Umgebung des Ohres: Hinter dem rechten Ohr eine 5-Pfennigstück große persistente Offnung, hinter dem linken Ohr Operationsnarbe.

Gehörgang-undTrommel fell be f a d. Links: Totalaufmeißelungshöhle, spärliche Eitersekretion. Caries der Labyrinthwand. Rechts: Entsprechender Befund. Hier eine kleine cariöse stelle hinten unten im Antrum die Quelle der noch bestehenden spärlichen eitrigen Sekretion.

Hörprü fu ng: Flüstersprache beiderseits nicht gehört. $C_{1}$ vom Scheitel

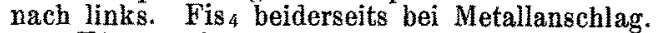

Th e rapie: Ausspulen beider Ohren, Eintrăuflung von Tetraborsäurelösung. Eisblase auf den Kopf.

Die Temperaturen waren in den ganzen folgenden Wochen hochnormal and leicht- and mittelfebril. Hin und wieder wurde auch $39^{\circ}$ aberschritten, mehrmals warden Temperatursteigerungen bis $39,6^{\circ}$ beobachtet.

4. November. Sehr unruhige Nacht. 0,01 Morphium ohne Wirkung.

7. November. Jeden Abend 0,01 Morphium ohne Wirkung auf den Unruhezustand. Die Eiterung in beiden Ohren hat fast vollkommen aufgehört.

8. November. Jeden Abend heftige Excitation. 0,01 Morphium subkutan. Nachts 2 Uhr Wiederbolung der Morphiuminjection, worauf sich Patient erst etwas beruhigt.

9. November. Puls zwischen 60 und 72 . Jodkall innerlich $\{5,0: 200,0$ 3 mal täglich ein EBlöffel). In den nächsten Tagen führten auch stärkere Jodkalidosen keine Änderung in dem Befinden des Patienten herbei.

19. November. Nach 2,0 Amylenhydrat mehrere Stunden Schlaf. Ohrgeräusche links bestehen unverändert fort.

20. November. Abends heftige Excitation.

In den nächsten Tagen trotz Bromkali keine Änderung im Befinden des Kranken. Die Excitation wird immer heftiger, er singt und schreit laut auf.

12. Dezember. Beide Ohren trocken.

14. Dezember. Patient versucht einige Zeit im Lehnstuble zuzubringen, muß aber das Bett sofort wieder aufsuchen, da heftige Schwindelanfälle auftreten und das Geräusch beim Sitzen zunimimt.

4. Januar 1904. Während des ganzen Tages ist Patient sehr aufgeregt, des Abends so sebr, daB er von mehreren Patienten im Bett festgehalton werden mul.

12. Jauuar. Abends heftiger Tobsuchtsanfall. Patient schlägt um sich, tritt mit den FủBen und schreit laut auf wegen unerträglicher Geräusche in der linken Kopfseite. Gegen $12 \mathrm{Uhr}$ nachts schläft Patient vollkommen erschöpft ein. 
13. Januar. 3 mal täglich 24 Tropfen Tct. opii simpl. Wenig Schlaf.

15. Janur. Patient wird zur Beobachtung seines Zustandes in die Kgl. Nervenklinilk verlegt.

19. Januar. Wiederaufnahme in die Kgl. Obrenklinilk. Der Berieht der Kgl. Nervenklinik lautete: "Links extradurale Eiteransammlung (Augenmuskellăhmung durch Doppelbilder nachweisbar, Nystagmus, gehäuftes Erbrechen, spontane und Perkussionsschmerzen, intermittierende Brachykardie). Psychogene Symptome: Monokuläre Doppelbilder, leicht elementare Visionen, schwere Affekterregungen (auch heiterer Natur mit Coupletsingen) und hysterische Druckpunkte. ${ }^{\text {. }}$

20. Jannar. Nacht sebr rubig, täglich 3 mal 24 Tropfen Tinet, opii simpl.

23. Januar. Zustand unverändert. Nächte ruhig. Kein Erbrechen seit der Wiederaufnahme am 19. Januar.

5. Februar. Puls stets regelmäßig. Temperatur mäßig erhöht. Am Vormittag ruhiger, schläft bisweilen, nachmittags unruhig, Schlaf nur nach Einnahme von Schlafmitteln (abwechselnd Cbloralhydrat $1-2 \frac{1}{2} \mathrm{~g}$, Sulfonal 1-2 g., Tinct. opii simpl. 3 mal täglich 20 Tropfen). Appetit leidlich. Stuhl nur nach Klysma.

Allmählich nahm die Reizbarkeit wieder zu, der Schlaf wurde schlechter, die Dosen der Schlafmittel mußten vergrößert werden. Tägliche Bitte des Patienten, ihn durch Operation vou seinem Leiden zu befreien.

Am 10. Mărz Klage über Doppelseben; der Wunsch des Patienten, operiert zu werden, immer dringender.

12. März. Auf Vorschlag der Nervenklinik Trepanation in der Gegend der oberen Windang des linken Schläfenlappens und des angrenzenden Parietallappens. Keine extradurale Eiteransammlung. Beim Einschneiden der Dura Liquorabflub, Pus non inventum beim Eingehen in den Schläfenlappen.

13. März. Temperatur $38,4-38,6^{\circ}$. Puls 88. Klage über Pochen im Kopfe, welches mit dem Herzstoß synchron sein soll.

18. März. Temperatur $3 \pi, 9^{\circ}$ wie vor der Operation. 1. Verbandwechsel. Geringer Prolaps der Hirnsubstanz. Beginnende sensorische Aphasie. Gutes Aussehen der Wunde.

22. März. Patient bat sich am Abend vorher den Verband heruntergerissen und war dabei ertappt worden, wie er in selbstmörderischer $A b$ sicht mit dem Finger in der Operationswunde herumwühlte. Verbandwechsel: Prolaps etwas vergrößert, Wundränder schmutzig verfärbt, blutiger Eiter. Zunahme der sensorischen Aphasie.

25. März. Temperatur $37,9-38,2^{\circ}$. Krampfartige Zuckungen sämtlicher Extremitäten, später nur rechtsseitige Zuckungen mit rechtsseitigen Facialisspasmen. Speichelfuß. Aphasie.

27. März. Temperatur $38-38,4^{\circ}$. Puls 72. Die Zuckungen haben aufgehört. Anästhesie der Haut uber den ganzen Körper verbreitet. Patellarreflexe erhalten, Cremasterreflexe erloschen.

28. März. Temperatur $39-39,7^{\circ}$. Puls 66. Verbandwechsel; Wunde sieht gut aus.

29. März. Temperatur 39,8-40 ${ }^{\circ}$. Puls 74. Große Unruhe, Aphasie. In selbstmörderischer Absicht Verweigerung der Nahrungsaufnahme. Verband wieder abgerissen, Wunde schmierig.

4. April, Temperatur 37,3. Puls 53. Verweigert fast jede Nahrung. Nächtliches Áufschreien. Aphasie besteht fort.

6. April. Temperatur $37,6-37,5^{\circ}$. Puls 64 . Patient beginnt wieder etwas feste Nahrung za sich za nebmen.

10. April. Nachdem Patient 3 Tage lang mit Heißhunger gegessen, verweigert er wieder jede Nahrung, auch Milch. Große Unruhe. Verband nachts abgerissen, obwohl derselbe durch Stärkebinden fixiert war. Das Bett mit Blut und Eiter besudelt (neuer Selbstmordversuch).

15. April. Temperatur $37,3-37,7^{\circ}$. Puls 52 . Schlaf gut. Patient nimmt nur Milch zu sich. Hirnprolaps hat etwa Wallnufgröße. Aphasie.

18. April. Temperatur $37,3-38,0^{\circ}$. Puls 62 . Patient liegt vollkommen apathisch da, verweigert jetzt auch Milchnabrung, läft Stuhl und Urin 
unter sich. Prolaps etwas vergrößert, mit schmutzig grauen Granulationen bedeckt.

19. April. Temperatur $40^{\circ}$. Puls 106, aussetzend, Sensorium benommen, Pupillen maximal erweitert, reagieren nicht. Schnarchende Atmung. Läßt Urin unter sich. Nährklystier.

20. April. exitus letalis.

A uszug aus dem Sektionsbefund: Männliche Leiche in gatem Ernährungszustand. Totenstarre, Totenflecke vorhanden. Oberhalb der linken Ohrmuschel befindet sich eine Trepanationsöffnung, etwa $4,5 \mathrm{~cm}$ lang and $3,0 \mathrm{~cm}$ breit, in welcher sich außer einem Tampon vorgestülpte Gehirnmasse von mibfarbenem Aussehen befindet. $7 \mathrm{~cm}$ oberbalb der linken Brustwarze findet sich eine pigmentierte, unregelmäßige, leicht eingezogene Narbe. Zwerchfellstand rechts 4. Interkostalraum, links 4. Rippe. Beide Lungen sinken zurück, linke hinten und unten fest mit der Brustwand verwachsen. Kein Inhalt der Pleurahöhlen.

Herzbeutel liegt in mittlerer Ausdehnung frei, im Cavum 1 Teelöffel klaren Serums. Innenfläche glatt und glänzend, etwas hyperämisch. Herz entsprechend groß, mäßjg kontrahiert. Epikardiales Fett gering. Trikuspidalis für 3 , Mitralis für 2 Finger durchgängig. Arterielle Klappen schlußfăhig. An Mitralis ist die eine knötchenförmig hervortretende Verdiekung etwa stecknadelkopfgroß und hyperămisch. Klappen des rechten Herzens zart. Elastizităt der Aorta herabgesetzt. Intima zeigt gelblichweife Verdickungen. Coronararterien o. B. Herzmuskel von dunkelroter Farbe, mäßig konsistent.

Rückenmark. Am Wirbelkanal keine Besonderheiten. Dura etwas injiziert. Innenfäche der Dura im wesentlichen glatt und glänzend; auch die Pia etwas injiciert. Konsistenz des Rückenmarkes gut, Zeichnung ebenfalls, Gewebe etwas blaß.

Schädeld a ch entsprechend dick. Dura von erhöhtem Blutgehalt und etwas vermehrter Spanxung. Im Sinus Iongitudinalis eine reichliche Menge dunklen, geronnenen Blutes. Innenfläche der Dura von etwas mattem Glanze, links finden sich membranöse Blutgerinnungen. Bei dem Versuche, das eingezogen erscheinende Gehirn herauszunehmen, quillt grünlichgelber, übelriechender Eiter aus der Wunde hervor, Weiche Gehirnhăute zart, nur im Umkreis der Trepanationswunde mibfarben. Sinus transversi frei glattwandig, nur rechterseits zeigt sich am Übergange in den Sinus sigmoideus ein festes, graurotes Gerimnsel. Das Gehirn wird in toto in Formol gehărtet. Im gehärteten Zustande der linke Scbläfenlappen, das linke Kleinhirn und die Ventrikel eröffnet. Im linken Kleinhirn nichts. Eine Narbe, von der frühen lncision herrührend, daselbst makroskopisch nicht zu erkennen. Im linken Parietallappen fand sich, in unmittelbarer Năhe des Schläfenlappens, ein oberfiächlich gelegener, sehr flacher, glattwandiger Herd in der Hirnsubstanz, der mit Eiter und Hirndetritus erfüllt war. Ein zweiter entsprechender, vielleicht kirschgroßer Herd im hinteren Teil der oberen Windung des linken Schläfenlappens. Beide Herde communizierten nicht. Die Hirnventrikel von normaler Beschaffenheit.

L. Lunge von geringem Volumen und Gewicht. Aus dem Bronchus entleert sich auf Druck nichts. Schleimhaut injiziert. Lunge überall nachgiebig, aus drei Lappen bestehend. Pleura glatt und glänzend mit Ausnahme der adhärenten Stellen; besonders fest sind die Adhaesionen an der, der Schußlinie entsprechenden Stelle. Oberlappen zeigt gleich dem Mittelund Unterlappen erhöbten Blut-und Saftgebalt. Letzterer zeigt im oberen Teile eine breite, strangförmige, bindegewebige, nicht deutlich abgegrenzte Induration; an der Pleura eine geringe narbige Einziehung.

R. Lunge von vermebrtem Volumen und Gewicht, besonders im Bereich des Unterlappens Ober- und Mittellappen gleichen dem Oberlappen der anderen Seite, nur Blutgehalt etwas stärker. Unterlappen in ganzer Ausdehnung luftleex. Seine Pleura etwas matt. Farbedunkelrot mit fleckigen, grau verwaschenen Partieen. Schnittiäche etwas granuliert.

Die übrigen Organe ohne erwähnenswerte Besonderheiten. 
Die linke A.carotis, die im Jahre 1892 unterbunden wurde, herausprăpariert. Unterhalb der Teilungsstelle in die Interna und Externa erscheint sie an Umfang sebr reduziert und mehr vom Charakter eines Bindegewebstranges; sie erweist sich bindegewebig obliteriert.

Epikritische Bemerkungen. Seit dem Jahre 1882 war dieser an Mannigfaltigkeit der Krankheitserscheinungen einzigartige Fall, wenn auch mit jabrelangen Unterbrechungen, in Beobachtung der Ohrenklinik; 6 mal ist er hier in stationärer Behandlung gewesen, und bis zuletzt, kann man sagen, bot er eine Anzahl von Symptomen dar, deren diagnostisehe Deutung: die größten, wenn nicht unüberwindliche Schwierigkeiten verursachte. So wurde er denn im Laufe der Jahre bei der Vieldeutigkeit der von ihm geklagten Symptome zu einem Objekt vielfacher diagnostischer Irrtïmer und damit zusammenhängend, und weil dabei die Intensität der Beschwerden coûte que coûte auf operative Abhilfe zu drängen schienen, zum Objekt vielfacher Operationsversuche.

Fuhren wir uns die Hauptetappen seiner langen und sehweren Leidenszeit noch einmal vor Augen.

Bei der1. Aufnahme in die Klinik am 30. Juli 1888 standen die linksseitigen Ohrsymptome bezw. Entzündungserscheinungen am Warzenfortsatz im Vordergrunde. Damals wurde der linke Warzenfortsatz, in dessen Hohlyäumen sich fadenziehender Schleim fand, aufgemeißelt. Nach kurzer Zeit Heilung des Ohres. Die 2. Aufnahme erfolgte bereits nach wenigen Wochen (4. Oktober 1888) und zwar wegen starken Schwindels, Doppelsehens und Kopfschmerzes. Es gesellte sich schließlich ein fieberhafter Zustand hinzu, der Puls zeigte eine der Höhe der Fiebertemperatur nicht entsprechende, auffällig geringe Frequenz, der Kranke bot schließlich ein Bild dar, welches an die Möglichkeit des Bestehens eines linksseitigen Kleinhirnabszesses denken lassen mußte. Indessen ward bei der probatorischen Incision des linken Kleinhirns ein Eiterherd, wie man ihn vermutete, nicht gefunden. Noch längere Zeit nach der Operation blieben die Schwindelanfälle fortbestehen, um allmählich immer mebr abzuklingen. Das Doppelsehen aber dauerte in den nächsten zwei Jahren, in denen der Kranke wicder arbeitete, fort. Am 21. Juni 1891 erfolgte die 3. Aufnahme in die Klinik wegen Symptomen, die auf einen linksseitigen Schläfenlappenabszeß hindeuteten (ef. Anamnese). Auch im linken Sohläfenlappen wurde bei dem probatorischen operativen Eingriff ein Eiterherd 
nicht gefunden. Zugleich wurde, weil sich allmählich eine Kuppelraumeiterung: linkerseits herausgebildet hatte, vom Gehörgange aus der gesunde Hammer und erkrankte Amboß entfernt. Bereits 21/3 Monat nach seiner Entlassung ans der Klinik mußte er von Neuem aufgenommen werden. Es galt jetzt zunächst, der immer weiter um sich greifenden Paukennebenhöhleneiterung des linken Ohres durch die Totalaufmeißelung Merr zu werden; die Operation stellte Caries im Antrum mastoideum und am Tegmen fest. Wäbrend der Nachbehandlung, gut einen halben Monat nach der Totalaufmeibelung, stellte sich auf dem linken Ohre ein dem Puls synchronisches Geräusch ein, welches wegen seiner Heftigkeit und Unerträglickeit die Psyche des Kranken so alterierte, daß er sich Selbstmordgedanken hingab. Weil das Geräusch jedesmal durch Kompression der Carotis zu kupieren war, unterbanden wir die Carotis. Das Geräusch sistierte nur bis zum Abend des Unterbindungstages, dann kehrte es wieder, allerdings so wesentlich vermindert, dab sich der krankhafte Gemütszustand des Kranken sichtbar von Tag zu Tag hob. Die 5. Aufnahme des Kranken in die Klinik am 29. Januar 1894 erfolgte insofern irrtümlich, als der von ihm dargebotene Symptomenkomplex, Übelkeit, Erbrechen, allgemeine Mattigkeit, Schwindel, für einen otogenen gehalten wurde. Das Auftreten von Ieterus zeigte aber bald, daß es sich um eine katarrhalische Dünndarmaffektion handelte, die mit dem Ohre nichts zu tun batte. Interkurrent war weiterhin in der Berliner Ohrenklinik im Jahre 1895 auf dem rechten Ohre die TotalaufmeiBelung vorgenommen worden.

In den nächsten Jahren war der Kranke bei leidlichem Befinden arbeitsfähig, bis im Jahre 1903 im Anschluß an einen Fall auf den Hinterkopf im linken Obre wieder ein so unerträgliches Ohrensausen auftrat, daß er schon 3 Tage nach Beginn des Sausens einen Versuch machte, sich zu erschießen. Er kam in die Kgl. chirurgische Klinik, von wo er zu uns verlegt wurde sowohl wegen der qualvollen, pulsierenden, linksseitigen Obrgeräusche, als auch wegen Verdachtes des Bestehens intrakranieller Komplikationen der Otitis.

Während der 51/2 monatlichen Aufenthaltszeit standen die Erscheinungen einer Psychose im Vordergrunde des Krankheitsbildes: Verstimmung, Angstzustände, Erregungszustände, die sich zeitweise zu Tobsuchtæanfällen steigerten. Auch die mebrfachen Selbstmordversuche, das Losreiben des Verbandes und Eindringen 
mit dem Finger in die durch die Operation gesehaffene Hirnwunde, das hartnäekige zeitweilige Verweigern jeder Nahrungsaufnahme in selbtmörderischer Absicht sind hierher zu rechnen. Inwieweit diese psychische Alteration anf die meist unerträglich linksseitigen Ohr- und Kopfgeräusehe zu beziehen ist, muß dahin gestellt bleiben.

Mit der Möglichkeit, daß ein intracranieller Folgezustand der Otitis vorliegen könne, mußte man auf Grund folgender Momente immerhin rechnen: Die Ohreiterung beiderseits bestand bei der Aufnahme des Kranken, wenn auch in spärlicher Menge, noch fort. Als Ausgangspunkt derselben waren circumskripte, cariöse Stellen der Mittelohrwandungen nachzuweisen. Der Kranke zeigte einen fieberhaften Zustand, für welchen die Untersuchung des ganzen übrigen Körpers keine Erklärung gab. Außerdem bestand heftiger Kopfsehmerz, Schwindel, Doppelsehen und Pulsverlangsamung.

Zu einemerneuten probatorise he n operativen Eingriff entschlossen wir uns erst nach langem Zögern, nicht auf das dringende Verlangen des Kranken nach einer Operation hin, sondern erst dann, als die Beobachtung seines Zustandes in der Kgl. Nervenklinik dort die Wahrscheinlichkeitsdiagnose einer extraduralen Eiteransammlung in der Gegend der oberen linksseitigen Schläfenlappenmündung und des angrenzenden Teiles des Parietallappens hatte stellen lassen. Die operative Freilegung der genannten Partie lieb ebensowenig einen Eiterherd anfdecken, wie das probatorische Eingehen in den Sehläfenlappen.

Die unmittelbare Todesursache ist schlieblich der Hinzutritt einer Pneumonie (rechter Unterlappen) geworden. Die beiden bei der Autopsie gefundenen cerebralen Eiterherde sind nicht spontan entstanden, sondern als Folge des operativen Eingriffes in Verbindung mit einer Infection der Hirnwunde aufzufassen, die der Kranke selbst durch das in selbstmörderischer Absicht vorgenommene Herumwählen mit dem Finger in der Hirnwunde sich zugezogen hatte. Die erst nach der Operation aufgetretenen cerebralen Symptome (sensorisohe Aphasie, Spasmen des entgegengesetzten Facialis etc.) erklären sich ungekünstelt aus dem Sektionsbefunde.

2. Johannes Bins, 9 Jahre alt, Arbeitersohn aus Greppin. Aufgenommen am 4. Januar 1905, gestorben am 8. Januar 1905.

A namnese: Schon seit frühester Kindheit Ausfluß aus dem rechten Ohre. Über die Ursache können die Eltern nichts angeben. Seit mehreren 
Jahren hört Patient schwer. Vor 5 Tagen traten Stirnkopfschmerzen und Schwindel auf.

Stat us praesens: Sehr schwächliches anämisches Kind, welches den Eindruck eines Schwerkranken macht. Abdomen leicht eingezogen. Lungen und Herz obne Besonderheiten. Puls 9t, regelmäßig. Temperatur 37,90. Reflexe normal. Pupillen gleichweit, reagieren prompt. Rotierender Nystagmus beim Blick nach der Seite. Angenhintergrund normal. Beim stehen mit geschlossenen Augen schwankt Patient nach rechts. Keine Nackensteifigkeit, keine Druckempfindlichkeit der Halswirbelsäule. Urin frei von Zucker und Eiweiß.

Umgebung des Ohres: Ekzem hinter dem rechten Ohre. In der Gegend des Emissarium mast. eine kleine Hautfistel.

Gebörgang und Trommelfellbefund. Rechts: Mäßige Senkung der oberen Gebörgangswand. Im Hintergrunde, von hinten oben kommend, polypöse Granulation. Beim Sondieren kommt man dort in einen tiefen Krater. Mäßige Mengen sehr fötiden Eiters im Gehörgange. Links: Trommelfell diffus getrübt.

Hörprü fung: Flüstersprache rechts direkt nicht gehört, links in $3 \mathrm{~m}$ Entfernung. $C_{1}$ vom Scheitel nach links lateralisiert. Fis 4 rechts bei starkem Kuppenanschlag, links normal gehört. Rinne rechts negativ, links positiv. $-37,4^{0}$.

Therapie und Krankheitsverlauf: Temperatur $38,2-37,5-37,7$

5. Januar. Totalaufmeißelung. Weichteile ohne Besonderheiten bis auf eine kleine Fistel unterhalb der Gegend des Emissarium. Die obere knöcherne Gebörgangswand ist durchbrochen. Durch diesen Durchbruch fließt Eiter vermischt mit stinkenden Cholesteatommassen. Entsprechend der Weichteilfistel ist auch die Corticalis durchbrochen und kommt daselbst etwas hellgelber Eiter heraus. Kuppelraum und Aditus mit dicken Cholesteatommassen ausgefültt. Tegmen tympani und Aditus wird in Bohnengröße freigelegt. Ausgedehnte Caries im Antrum. Im horizontalen Bogengang eine stecknadelkopfgroße Fistel, aus der kein Eiter quillt. Freilegung des Sinus. Hierbei quillt aus der Umgebung desselben Eiter hervor. Der Sinus ist entsprechend der Knochen-Weichteilfistel mit einem dicken Granulationspolster bedeckt und tritt stark hervor. Resection der Spitze, in der sich mehrere cariöse Zellen finden. Excision der Hautfistel, Plastik, Tamponade, Verband. Nach der Operation Allgemeinbefinden bedeutend besser; Kopfschmerzen gănzlich verschwunden, nur noch geringes Schwindelgefühl.

Temperatur: $36,9-37,1-37,2-37,3-37,1-36,9^{\circ}$.

6. Januar. Befinden vorzüglich. Nahrungsaufnahme sehr gut.

Temperatur: $36,8-36,9-36,8-36,6-36,5^{\circ}$.

7 . Januar. Schwindelgefühl vollständig verscbwunden; Patient kann sich im Bett gut aufrichten.

Temperatur: $36,5-37,4-36,8-36,7-36,4^{\circ}$.

๖. Januar. Gegen Morgen einmal vor dem Kaffeetrinken und einmal nach demselben Erbrechen.

Klage über Schmerzen in der Stirngegend. Mäßiger Opistbotonus. Nystagmus beim Blick nach rechts. Pupillen gleichweit, reagieren prompt. Sehnenund Hautreflexe normal. Beweglickeit des Kopfes gut, keine Nackenstarre. Sensorium frei. Puls 72, regelmäßig. Keine Temperatursteigerung. Verbandwechsel. Die Wunde sieht gut aus. In der Bogengangfistel kein Eiter. Der Sinus beginnt sich mit frischen Granulationen zu bedecken.

Im Laufe des Vormittags verschwindet der Opisthotonus wieder. Patient ißt mit Appetit sein Mittagbrod.

Gegen $23 / 4$ Uhr p. m. bohrt Patient plötzlich, nachdem er sich noch kurz vorher mit seinen Nachbarn unterhalten hat, den Kopf nach hinten in die Kissen und schreit laut auf; darauf sofortiger Exitus letalis.

Sektionsprotokoll.

Kindliche männliche Leiche in mäßigem Ernährungszustand, zartem Knochenbau. Leichenstarre und Flecke vorhanden. Haut blaß. An den Oberschenkeln, seitlichen Gesäßpartien und in der Unterbauchgegend kleinste bis markstückgroße teils schuppende, teils mit gelben und dunkelroten flachen Borken be- 
deckte Stellen. Umgebung etwas gerötet, nicht geschwollen. Hinter dem rechten Ohre eine bogenförmige $6 \mathrm{~cm}$ lange auf $3 \mathrm{~cm}$ klaffende tamponierte Wunde, die bis in die Cellulae mastoid, reicht.

Schädeldach zart, ohne Besonderheiten. Dura zart, mäßig blutreich, mäßig gespannt. Innenfläche glatt, weiß. Weiche Häute zart, māßìg blutreich. Subarachnoideale Flüssigkeit nicht vermehrt, klar. Gyri deutlich abgeplattet. Im Sinus longitudinalis und dem Sinus der Schädelbasis Blut- und Speckgerinnsel. Bei Durchschneidung des Tentoriumansatzes am rechten Bchlafenbein wird das Klein hirn verletzt, wobei dickrahmiger, graugrüner, stinkender Eiter aus demselben sich entleert. Gefäße der Basis zart, ohne Besonderheiten. Seitenventrikel etwas erweitert durch klare Flüssigkeit. Ependym glatt, glänzend. Tela und Plexus zart, blutarm. Rautengrube ohne Besonderheiten.

In der rechten Kleinhirnhemisphärewirdeingut haselnuBgroßer, mit etwa $1 \mathrm{~mm}$ dicker schmierigbelegter Membran ausgekleideter Abszeß eröffnet. Umgebnng nicht besonders injiziert. Zeichnung der Rinde, Grenze gegen Mark, das sehr saftreich ist, sehr feucht. Ganglien des Hirnstammes, Brücke, Medulla oblongata, Großhirn deutlich gezeichnet, blutarm, sehr saftreich.

Dura und weiche Häute des Rückenmarks zart, blutarm, obne Besonderheiten.

Fettpolster und Muskulatur der Brust und des Bauches gering entwickelt. Was fettarme Netz bedeckt die collabierten Dünndärme. Serosa glatt und glănzend. Leber überragt den Rippenbogen. Wurmfortsatz frei. Kein fremder Inhalt in der Bauchhöhle. Zwerchfellstand rechts 4, links 5 . Rippe. Thymus reicht bis zur 3 . Rippe, blaßrosa. Lungen sind zurücligesunken. Pleuraböhle leer. Herzbeutel liegt in Fünfmarkstüclegröße vor, enthălt $10 \mathrm{ccm}$ klare seröse Flüssigkeit. Innenfläche glatt, ohne Besonderheiten.

Herz schlaff, größer als die Faust der Leiche, enthält wenig Blut- und Speckgerinnsel. Tricuspidalis und Mitralis für 2 Finger durchgängig. Endocard zart. Arterielle Klappen schluffāhig. Klappenapparat zart. Aorta, Kranzgefäße ohne Besonderheiten. Linker Ventrikel mäßig erweitert. Myocard blaß, gelbbraun.

Linke Lunge: Aus dem Bronchus entleert sich auf Druck reichlich schaumige Flussigkeit. Schleimbaut imbibiert und injiziert. Pulmonalis frei. Peribronchiale Lymphknoten vergrößert, markig geschwollen, nicht verkăst. Pleura glatt, glanzend. Lunge überall lufthaltig und nachgiebig, entsprechend groß, sehr blut- und saftreich. Schnittfiäche glatt, bellrot; im Unterlappen dunkelrot.

Rechte Lunge: Bronchus, Pulmonalis, Pleura und Lange wie links.

Milz: Kapsel dünn, leicht gerunzelt. Milz vergrößert. Follikel deutlich, Trabekel zart. Pulpa weicb, dunkelrot.

Linke Nie re etwas vergrößert. Fettkapsel mäßig, fibröse zart, leicht löslich. Oberfiäche glatt, dunkelviolett. Rinde quillt etwas vor, etwas verbreitert, gegen die ebenfalls sehr blutreichen dunkelblauroten Markkegel scharf abgegrenzt.

Nierenbecken und Ureter ohne Besonderheiten. Nebenniere erweicht.

Rechte Niere wie links. Nierenbecken etwas erweitert, Schleimhant injiziert. Pyramiden leicht abgeplattet. Aus dem etwas erweiterten, zarten Ureter entleert sich trüber Harn in geringer Menge. Hindernis des Abflusses konnte nicht gefunden werden.

L e ber etwas vergröBert. Oberfäche glatt. Parenchym gelbbraun, blutreich, dentlich gezeicbnet, weich.

Gallen blase ohne Besonderheiten.

Magen erweitert. Schleimhaut dünn, blaß, wenige Petechien.

Pancreas ohne Besonderheiten.

Dünndarmschleimhaut wenig geschwollen, blaß.

Dickdarmschleim hau dünn, blaß, zeigtdeutliche Follikelschwellung.

L ymphknoten des fettreichen Mesenterium markig geschwollen.

Große GefäBe, Genitalien ohne Besonderheiten.

Diagnosis post mortem: Nassendes, scbuppendes Ekzem der Beine und des Rumpfes. Anämie und Oedem des Gehirns. 
Kleinhirnabszeß. Dilatation des linken Ventrikels. Anämie des Herzmuskels. Hyperämie und Oedem der Lungen. Lymphome am Hals und Lungenhilus. Thymus persistens. Stauungsmilz. Stauungnieren. Hydronephrose rechts. Stauungleber. Gastritischronica atrophicans. Colitis follicularis chronica. Lymphadenitis nodulorum lymphat. mesenterii.

Sektion des Schläfenbeins.

Dura der hinteren Schädelgrube an der dem Kleinhirnabszeb einerseits und dem Sacculus endolymphaticus andererseits entsprechenden Stelle in $1 / 2 \mathrm{~cm}$ Länge und $3 \mathrm{~mm}$ Breite schwarz verfärbt. Sacculus endolymphaticus schwielig verdickt, mißfarben, jedoch keinen freien Eiter enthaltend. In den Bogengängen mibfarbene Granulationen, in Vorbof und Sehneckedicker gragräner Eiter. Steigbügel intaktimovalen Fenster. Porus acusticus internus und Nerven desselben obne Besonderheiten. Sämtliche Sinus frei.

Epikrise: Bei der am Tage nach der Aufnahme ausgefubrten Totalaufmeißlung stellten wir ein großes Cholesteatom sämtlicher Mittelobrräume verbunden mit Antrumcaries fest. Das Cholesteatom hatte durch seinen Druck zu einer Usur des horizontalen Bogenganges geführt, der eine Fistel von Stecknadelkopfgröße anfwies. Durch diesen Befund waren vollständig die Elscheinungen von Kopfschmerzen, Nystagmus und Schwindel, welche der Knabe bei seiner Aufnahme hatte, erklärt. Da diese Fistel vollständig frei lag und in derselben weder Granulationen noch freier Eiter zu sehen waren, nahmen wir von einer Exploration des Labyrinths Abstand. Wir stehen auf dem Standpunkt, daß derartige trockene Fisteln, welehe bei großen Mittelohrcholesteatomen ein garnicht seltener und relativ harmloser Befund sind, ein noli me tangere sind und vermeiden es bei der Operation sorgfältig, durch starkes Tupfen oder gar Sondieren einen eventuell vorhandenen Verschlub des Labyrinths nach der infizierten Wundhöhle zu lösen oder bei offenen Fisteln eine Infektion des Labyrinths herbeizuführen.

Wir konnten anch mit dem Erfolge unserer Operation vollständig zufrieden sein, denn die Kopfschmerzen waren sofort nach der Operation gänzlich verschwunden, und das Schwindelgeftuhl bestand nur noch in geringem Maße. Der Zustand des Kranken besserte sich in den nächsten Tagen sichtlich; am zweiten Tage konnte er sich schon im Bett aufrichten, ohne daß eine Spur von Schwindel auftrat. Plötzlich am Morgen des dritten Tages erbrach er zweimal und klagte über Schmerzen in der Stirn; hierzu gesellte sich leiehter Opisthotonus. Die Temperatur war normal und am Pulse lieb sich nichts besorgniserregendes feststellen. Bei dem sofort vorgenommenen Verbandwechsel konnten wir keinen Anhaltspunkt für obige Er- 
scheinungen finden, die Wunde sah sehr gut aus. Im Laufe des Vormittags besserte sich der Zustand des Patienten wieder derartig, daB er mit großem Appetit sein Mittagessen verzehrte und sich lebhaft mit seiner Umgebung unterhielt. Der Tod trat am Nachmittage ganz plötzlich auf, ohne daß irgend eine bedrohliche Erscheinung vorangegangen wäre.

Bei der Sektion fanden wir einen haselnußgroßen Kleinhirnabszeß, der noch keine Spur von eitriger Leptomeningitis verursacht hatte. Es wäre dies ein prognostisoh selten günstiger Fall für die Operation gewesen. Hätten wir hier eine Labyrintheröffnung vorgenommen, so wäre uns sicher der Abszeß nicht entgangen, da der Weg; den die Infektion vom Vittelohr aus genommen hatte, dann deutlich vor uns gelegen hätte. Die durch das Cholesteatom via Fistel im horizontalen Bogengang verursachte Labyrintheiterung hatte zu einer Infektion des Sacenlus endolymphatieus gefubrt, von dem aus der Kleinhirnabszeß per contiguitatem induziert worden war.

Der plötzliche Tod des Patienten läßt sich auf eine dnrch das starke Hirnoedem hervorgerufene Lähmung des Atmungszentrums zurückfübren.

3. Karl K e r n, 52 Jahre alt, Arbeiter ans Bitterfeld. Aufgenommen am 2. Februar 1905, gestorben am 3. Februar 1905.

A n a $\mathbf{m}$ e se: Die Begleiter des Patienten, welcher am spăten Abend in die Klinik eingeliefert wird, geben an, daß bei dem Patienten früher niemals ein Ohrenleiden bestanden haben soll. Im November 1904 babe er sich eine Verbrennung des Gesichtes und der Hände in einer chemischen Habrik zugezogen. Wahrend des Abheilens des Brandschorfes sei Gesichtsrose hinzugekommen und hierbei sei Ausflub aus dem rechten Ohre aufgetreten.

Am 28. Januar 1905 haben sich plötzlich heftige Schmerzen im rechten Obre und in der rechten Kopfhälfte eingestellt. Gegen abend sei Patient stark benommen gewesen. Erbrechen sei nicht aufgetreten, sondern nur Aufstoßen. Patient habe die Annahme jeder Nahrung verweigert. Dieser Zustand habe unverändert bestanden. Heute morgen sei die Körpertemperatur uber $40,0^{\circ}$ gewesen.

Status praesens: Sehr blaß aussehender, schlecht genăhrter Mann. Lunge und Herz ohne Besonderheiten. Puls gespannt, regelmäßig, 116. Temperatur $39,2^{\circ}$.

patient ist stark soporös, antwortet jedoch anf lautes Anrufen. Er gibt seinen Namen richtig an, erkennt auch ihm vorgehaltene Gegenstände und bezeichnet sie richtig. Sprache etwas undeutlich. Nackensteifigkeit und Druckempfindlichkeit der Halswirbelsăule nicht vorbanden. Passive Beweglichkeit des Kopfes gut und schmerzlos. Patellar- und Cremasterreflexe stark herabgesetzt, Bauchdeckenreflexe erloschen. Sensibilität erhalten. Pupillen mittelweit, reagieren prompt; kein Nystagmus. Augenbintergrund normal.

Umgebung des Ohres ohne Besonderheiten.

Gehörgang- und Trommelfell befund. Rechts: Gehörgang mäßig weit, gerötet; Senkung der hinteren oberen Gehörgangswand. Im Gehörgange mäßige Mengen dicken Fiters mit mazerierter Epidermis vermischt. Trommelfell blaurot, vorgewölbt. Stecknadelkopfgroße Perforation im vorderen 
unteren Quadranten. Über dem Proc. brevis etwas nach vorn fistelverdächtige Stelle. Links: Trommelfell indifferent.

Hörprüfung: Wegen des soporösen Zustandes des Patienten nicht ausführbar.

Therapie und Krankheitsverlauf: Paracentese. Verband. Patient wird nach Mitternacht sehr unruhig, will mehrmals das Bett verlassen. Morphiuminjection. Gegen Morgen läßt er Urin unter sich. Temperaturen während der Nacht $39,8-39,9-40,0^{\circ}$.

3. Februar. Morgentemperatur 40,6 ${ }^{\circ}$. Puls sehr klein, kaum fühlbar, unregelmäßig, 150. Atmung tracheal, 38. Cyanose. Patient liegt im tiefen Coma. Pupillen mittelweit, starr; keine Zwangsstellang der Bulbi. Reflexe und Sensibilităt erloschen. Aus dem rechten Obr mäRige blutig-seröse Sekretion. Exitus 5 Uhr p. m. Temperatur kurz vor dem Tode 410.

Sektionsprotokoll.

Große männliche Leiche von kräftigem Knochenbau und mittlerem Ernäbrungszustande. Haut trocken, Leichenstarre und Flecke vorhanden. Die rechte Ohrmuschel und der äuhere Gehörgang mit frischen, schwarzroten Blutkrusten bedeckt.

S c bädelda c h unverletzt, symmetrisch, von mittlerer Dicke. Diploë sehr gering. Innenfläche glatt, Gefäbfurchen mäBig tief. AuBenfläche der Dura raub, vor allem am Sin. longitudinalis superior. Gefäße mäßig injiziert. Im sinus longitudinalis superior nur Speckgerinnsel. Innenfläche der Dura glatt, einige frische Blutunterlaufungen. Weiche Häute zart, in den unteren Yartien gelb getrübt. Pia im allgemeinen blutreich, an der oben bezeichneten Stelle unter der Arachnoidea das Gewebe eitrig infltriert. Im übrigen die Subarachnoidealfiussigkeit leicht getrübt. Weiche Häute der Basis, vor allem um das Chiasma herum, am Kleinhirn und der linken Art. cerebri media eitrig infiltriert, im übrigen stark injiziert. Arterien der Basis zart. Hemispbären symmetrisch, Gyri abgeplattet, Sulei seicht. In den Seitenventrikeln wenig leicht geträbte seröse Flüssigkeit, Ependym sehr feucht, glatt. Rautengrube ebenfal is von leicht getrübter Flüssigkeit bedeckt. Kleinhirn sehr feucht, blutarm, gut gezeichnet. Marklager des Großhirns, besonders rechts ziemlich blutreich, sehr weich. Rinde blab. Ganglien des Stammes gut gezeichnet, sehr feucht, măßig biutreich. Die rechten Sinus der Basis werden nicht eröfinet; in den linksseitigen Cruorgerinnsel. Sinus cavernosus frei. Dura der Basis sonst glatt. In beiden Keilbeinhöblen und in der Nase stinkender dicker Eiter. In den Keilbein- und Stirnhöhlen Scbleimhaut geschwollen. Die Schleimhaut der Highmorshöhle zart.

Fettpolster der Brust- und Bauchhaut mäßig. Muskulatur blaß. Das mäßig fettreiche Netz herabgeschlagen. Darmserosa glatt und glänzend. Wurmfortsatz frei, nach innen und oben geschlagen. Kleines Becken leer. Zwerchfellstand rechts 4., links 5. Rippe. Lungen berühren si ch bis zur 3 . Rippe, nirgends verwachsen. Herzbeatel in Größe eines Fünfmarkstückes freiliegend. Herzbeutel zart, enthält einige Tropfen klaren Serums. Innenflächen glatt.

Herz größer als die Faust der Leiche, sehr schlaff. Arterielle Klappen schließen; Tricuspidalis für 3, Mitralis für 2 Finger durchgängig. Rechter Ventrikel etwas weit, Wand etwas hypertrophisch. Klappenapparate zart. Auch der linke Ventrikel etwas dilatiert. Endocard zart; Aorta elastisch. KranzgefäBe weit. Intima zart. Myocard blaß, deutlich gelb gefleckt, auch in den Papillarmuskeln.

Linke Lunge: Aus dem Bronchus entleert sich reichlich Schaum. Pulmonalis frei. Peribronchiale Lymphknoten frei Pleura glatt. Oberlappen mäBig blut,, sehr saftreich, stark gebläbt. Unterlappen erheblich blutreicher, uberall lufthaltig. Schnittliache glatt.

Rechte Lunge: Bronchus, Pulmonalis, Pleura wie links; Lunge wie links.

Rachen und Halsorgane: Tonsillen sehr klein, blaß, mit Schleim bedeckt; in der linken ein ganz kleiner Pfropf, O es op bag u s blaß, Kehlk o p feingang frei; im Keblkopf reichlich Schleim; Schleimhant blaß. Schilddrüse ohne Besonderheiten. Lymphdrüsen des Halses klein, weich. Gefäße des Halses ohne Besonderheiten. 
Milz: $12: 6: 2^{1 / 2} \mathrm{~cm}$. Kapsel glatt, Follikel undeutlich, Trabekel deutlich, Pulpa dunkelblaurot, mäfig weich.

Linke Niere: Fettkapsel mäBig, fibröse zart, leicht abziehbar. Oberfiäche glatt, violett. Rinde etwas getrubt, quillt etwas vor. Pyramiden mäßig blutreich. Nierenbecken blaß, etwas erweitert.

Rechte Niere wie die linke.

Nebenuiere erweicht.

Leber entsprechend groß. Kapsel im allgemeinen glatt. Über dem rechten Lappen mehrere derbe, weiße, über die Oberfläche prominierende Knötchen. Leber sehr deutlich gezeichnet, ziemlich derb.

Gallenblase ohne Besonderheiten.

Magen entsprechend groß. Wandungen zart. Schleimhaut blanschwärzlich pigmentiert. In der Schleimhaut, besonders nach dem Pylorus zu, frischere feine Ekchymosen. Schleimhaut glatt.

Pancreas ziemlich weich, grauviolett.

Mesenterium fettreich; Drusen klein und weich.

Blase durch $1 / 21$ trüben Urin ansgedehnt. Schleimhaut blaß, ganz wenig injiziert. Trabekel zart.

Prostata klein, weich.

Große GefäBe ohne Besonderheiten.

Diagnosis post mortem: Leptomeningitis cerebralis puru * lenta. Katarrh der Stirnbein- und Keilbeinhöhlen. Emphysem beider Lungen. Herzparalyse. Fettige Entartung des Herzmuskels. Trübe Sehwellung der Nieren.

Sektion des Schlafenbeins.

Thochen elfenbeinhart. Trommelfell stark verdickt; im hinteren oberen und unteren Quadranten klaffender Spalt und aber dem Proc.brevis eine punktformige Perforation. Pankenhöhle und Aditus ad antrum angefüllt von Eiter und eitrig infiltrierter. stark geschwollener Schleimbaut. Hammer gesund, vom AmboB fehlt derganze lange Schenkel. Großes Antrumem pyem mit einem plat menkerngroben Sequester. TegmenAntri in Bohnengrobezerstort. An dieser Stelle ein Extraduralabszeß, welcher ungefahr einenhalben Teeloffel Eiter enthält. Entsprechend diesem AbszeB ist die Dura der mittleren Schädelgrube mit dicken festausitzenden Granulationen bedeckt. Vonder Spitze ausgehend ein Senkungsabszel nach dem Bul: bus venaejugularis. Derden Bulbus umgebende Knochen eitrig infiltriert. AuBere Waud der Vene graurot verfärbt. Innenwand vollstandig intakt. Ebensosamtlicbe übrigen Sinus frei. Labyrinth vollstandig intakt, ebenso Sacculus endolymphaticas. Steigbagel in Granulation eingebettet.

Epikrise: Bei der Aufnahme des Patienten konnten wir nur leichte Symptome einer intereraniellen Komplikation feststellen. Wir waren zu Anfang zweifelhaft, ob es sich um eine diffuse eitrige Leptomeningitis oder um eine Blutleiterthrombose handelte. Wenn man beachtet, daß neben den hohen Temperaturen - am Morgen des Einlieferungstages soll die Körpertemperatur über $40^{\circ}$ betragen haben - nur noch Sopor bestand, der leicht auf die Einwirkung des Fiebers zurückgeführt werden konnte, während Naekensteifigkeit und Druekempfindlichkeit der Halswirbelsäule nicht vorhanden waren und außerdem die Beweglichkeit des Kopfes frei war, so hätte man geneigt sein können, sich für eine Sinusthrombose zu entscheiden. Im Laufe der Nacht und gegen Morgen häuften sich jedoch die Symptome 
einer eitrigen Leptomeningitis in so rapider Weise, daB wir an der Natur des Leidens nicht mehr zweifeln konnten. Der Patient bekam starke Unruhe, so daß er mehrmals aus dem Bett zu steigen versuchte, das Sensorium war vollständig getrübt, gegen Morgen ließ er Urin unter sich, die Pupillen waren mittelweit und starr, sämtliche Reflexe und die Sensibilität waren erloschen. Wir konnten deshalb von der Sicherstellung unserer Diagnose durch eine Lumbalpunktion Abstand nebmen. Am Vormittag trat dann tiefes Coma auf, der Puls wurde sehr klein und Trachealrasseln trat ein, so daß der Patient vollständig moribund ersehien. Der Tod trat bereits am Nachmittag desselben Tages ein.

Die Sektion ergab eine diffuse eitrige Leptomeningitis. Wenn wir auch nicht in der Lage waren, eine direkte Wegleitung vom $\mathrm{Ohr}$ zu den Meningen festzustellen, so ist doeh mit ziemlicher Sicherheit anzunehmen, daß die Meningitis von dem Extraduralabszeß ausgegangen ist. Neben der Ohrerkrankung: wurde noch ein akuter eitriger Katarrh der Stimbein- und Keilbeinhöhle gefunden. Da jedoch an dieser Stelle der Knochen vollständig intakt war, brauchen wir wohl nicht hier die $\mathrm{Ur}$ sache für die Meningitis zu suchen.

Was nun das Ohrenleiden selbst anbetrifft, so ist es vollkommen ausgeschlossen, daß dasselbe als eine Folge der im November erlittenen Verbrennung und des im Anschlub daran aufgetretenen Erysipels anzusehen ist. Vielmehr handelte es sich um ein Leiden, das der Patient sicher schon Jahre lang mit sich herumgetragen hat. Allerdings dürfen wir nicht auBer Acht lassen, daß der im November erlittene Unfall eine Exacerbation des Leidens und somit eine Beschleunigung des letalen Ausgangs herbeigeführt hat.

4. Carl Fickenscher, 47 Jahre alt, Graveur aus Selb bei Hof. Aufgenommen am 12. November 1904, gestorben am 16. November 1904.

Anamnese: Patient bemerkte im 11. Lebensjahr, daß er auf dem linken Obre taub war. Ursache ist ihm unbekannt.

Im 9. Lebensjahre überstand er eine schwere Gehirnerschütterung (sechswöchentliche Bewustlosigkeit) durch Fall auf den Hinterkopf. Im 11. Jahre begann rechts Sausen und starke Schwerhörigkeit. 1896 wurde links angeblich ein Cerumenpropf entfernt, worauf das Ohr einige Wochen geeitert haben soll. Am 2. Oktober 1904 wurde ein Polyp der linken Nasenbälfte gebrannt und zu gleicher Zeit wurde wieder aus dem linken Ohre ein "Obrenschmalzpfropf* entfernt. Nach Entfernung des Propfes trat starkes Sausen und stinkende Eiterung auf. Gegen Ende Oktober gesellte sich Schwindel hinzu. Patient begab sich zu einem Arzt nach Planen, welcher einen Polypen aus dem linken $\mathrm{Ohr}$ entfernte. $\mathrm{Da}$ das Leiden sich nicht besserte, und vor 3 Tagen Erbrechen und leichtes Frösteln binzutrat, suchte Patient die Klinik auf. Augenblicklich klagt Patient über leichte Schmerzen 
in und hinter dem linken Obre, sowie in der ganzen linken Kopfhälfte. AuBerdem besteht beiderseits sehr starke Schwerhörigkeit und Schwindelgefühl. Auf dem linken Ohre besteht spärlicher stinkender Ausfiuß.

Status praesens: Sehr kräftig gebauter, gesund aussehender Mann, mit stark entwickeltem Fettpolster. Diastase der Recti. Herz und Lunge ohne Besonderheiten. Puls kräftig, regelmäBig, 82. Temperatur $38,4^{\circ}$. Pupillen gleichweit, reagieren prompt auf Lichteinfall; geringer Nystagmus beim Blick nach rechts. Augenhintergrund normal. Sebnenreflexe normal. Urin frei von Eiweib und Zucker.

Umgebung des Ohres: Leichtes Oedem über dem linken Proc. mastoideus. Druckempfindlichkeit über der Spitze und in der Gegend des Emissariums.

Gehörgang-und Trommelfellbefund. Recbts: Trübung. Links Obere Gehörgangswand mäßig inflitriert und gesenkt. Trommelfell diffus gerötet, glanzlos. Hammergriff nicht differenzierbar.

Hörprüfung: Erhobene Konversationssprache rechts nur durch den Hörschlauch. Flüstersprache links in $5 \mathrm{~cm}$ Entfernung. $\mathrm{C}_{1}$ vom Scheitel nach links lateralisiert. Fis * rechts bei starkem Nagelanschlag, links bei starkem Fingerkuppenanschlag.

Nase und Nasenrachenranm: Rechte untere Muschel hyperplastisch. Linke Nasenbălfte durch stark vorspringende Spina verengt.

Ergebnis bei Catheterismus tubae: Rechts Blasegerăusch. Links Catheterismus wegen Unwegsamkeit der Nase nicht ausführbar.

Theraphie und Krankheitsverlauf: Paracentese links. Es entleert sich eine geringe Menge schleimig eitrigen Sekretes. Eisblase hinter das Obr. Bettruhe. Calomel 0,3 .

13. November. Temperatur $38,2-38,4-38,7^{\circ}$, Puls 84 . Atmung 20, ohne Resonderheiten

Druckempfindlichkeit und Oedem sind bedeutend zurückgegangen. Senkung der oberen Gehörgangswand geringer. Man bemerkt jetzt hinten oben zwei kleine Granulationen. Beim Sondieren gelangt man nach hinten oben in einen weiten Krater mit rauhem Knochen

14. November. Morgens $6 \mathrm{Uhr}$ Temperatur $39,0^{\circ}$.

Totala ufmeiblung links. Weichteile normal. Oberhalb der Spina eine kleine Fistel, durch die man ungefähr $1 \mathrm{~cm}$ in die Tiefe sondieren kann. Nach Wegnahme der hinteren Gehorgangswand quillt Eiter aus der Gegend der Spitze und des Sinus berror. In Antrum, Aditus und Kuppelraum großes zerfallents Cholesteatom. Nach Entfernnng desselben liegt die Dura uber dem Kuppelraum in Linsengröfe frei; auf derselben Cholesteatomtapete. Im borizontalen logengange längliche Fistel mit mißfarbigen Rändern. Facialis liegt in großer Ausdehnung frei. Bei Freilegung des Sinus quillt dicker stinkender Eiter aus dem Suleus sigmoideus hervor. Der Sinus ist collabiert und füllt den Sulcus nicht aus.

Jugularisunterbindang. Reseltion der eitrig durchsetzten Spitze, weite Freilegung des Sinus, dessen Wand stark verdickt und grünlich verfärbt ist. Spaltung des Sinus und Entfernung von eitrig zerfallenen Thrombenmassen mit dem scharfen Löffel möglichst weit pexipher- und zentralwärts, ohne daß von beiden Seiten. Blutung erreicht wird. Tamponade. Verband.

Temperatur $38,8-39,4-38,8-38,8-37,9-38,8^{\circ}$.

15. November. Patient hat in der Nacht wenig geschlafen. Nach Mitternacht ziemlich heftige Stirnkopfschmerzen. Die rechte Pupille ist etwas weiter als die linke. Reaktion der Pupillen gut. Augenhintergrund normal. Leichtes Erbrechen beim Husten; geringe Bronchitis. Sensorium frei. Puls 128, dikrot.

Temperatur $37,8-38,4-38,8-38,9-38,2-37,7^{\circ}$.

16. November. Morgentemperatur $37,5^{\circ}$.

Patient ist in der Nacht sehr unrubig gewesen; er hat mehrmals versucht, das Bett zu verlassen. Leichte Delirien.

Morgens starke Benommenbeit. Patellarreflexe fast erloschen. Pupillendifferenz stärker als gestern, Reaktion fast vollständig aufgehoben. 
Beiderseits starke Chemosis, besonders links. Mäßige Protrusio bulbi links. Puls kaum fühlbar, unzählbar, häufig aussetzend. Atmung tracheal.

12 Uhr mittags Exitus im tiefen Coma.

\section{Sektionsprotokoll.}

Männliche, kräftige Leiche. Totenstarre und Flecke vorhanden. Hinter dem linken $\mathrm{Obr}$ eine tamponierte Trepanationswunde, an der linken Halsseite nach unten und median verlaufende, $6^{1 / 2} \mathrm{~cm}$ lange, ebenfalls tamponierte Operationswunde, aus dèr Fäden herausschauen.

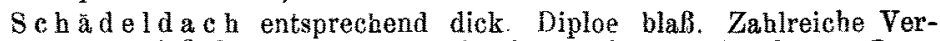
wachsungen, so daß das Dach nur mit der Dura gelöst werden kann. Dura zeigt erhöhten Blutgehalt, Innenflăche glatt und glänzend. Im Sinus longitudinalis superior ein lockeres speckgerinnsel, in der Wand zahlreiche Pacchioni'sche Granulationen. Arachnoidea kaum getrabt. Sabarachnoideale Flüssigkeit besonders in den hinteren Partien vermehrt. Gyri ohne Besonderheiten. Pia zeigt eine mäßige Gefäßfüllung. Bei Herausnahme des Hirns zeigt sich die Dura-Innenfläche an der Sella turcica und am Clivus Blumenbachii gelblich verfarbt, von sulaigen membranartigen Auflagerungen bedeckt und stellenweise stark injiziert. Die gelbliche Verfärbung setzt sich auch auf die linke Felsenbeinpyramide fort. Beim Lösen der linken Kleinhirnhemisphäre ans der hinteren Schädelgrube zeigt sich die Pia des Kleinhirns von dickem gelblich gränen Eiter am Sulcus transversus bedeckt. Das darunter liegende Kleinhirngewebe ist im Bereiche der Rinde von zahlreichen Hämorrhagien durchsetzt. Sonst nirgends in der Kleinhirnsubstanz Eiter. Ventrikel nicht erweitert, Ependym zart. Zentralganglien ohne Besonderheiten, desgleichen Brücke und Medulla. Consistenz des Gehirns gut, Blutgehalt mäßig. Tela und Plexus nicht injiziert. Rinde ohne Besonderheiten. Gefäße der Basis zart. Beide Sinus cavernosi, sowie der beide verbindende Sinus intercavernosus ant. sind von graurötlichen, derben der Wandung anhaftenden Thrombusmassen ausgefüllt. Der rechte Sinu. transversus und sigmoideus ist frei.

Fettpolster reichlich, besonders am Abdomen. Muskulatur wenigers Netz sehr fettreich, herabgeschlagen. Kein fremder Inhalt im Abdomen. Serosa der Därme glatt und glänzend. Zwerchfellstand rechts 4 ., links 5 . Rippe. Rippenknorpel teilweise verknöchert. Herzbeutel liegt in großer Ausdehnung frei. Linke Lunge sinkt zuräck, nirgends mit der Brustwand verwachsen. Rechte Lunge in ganzex Ausdehnung durch leichte Verwachsungen der Brustwand adhaerent. Innenflache des Herzbeutels glatt und glänzend. Herzbentel enthält 3 Teelöffel klarer Flussigkeit.

Herz: Ventrikel, größte Länge 11, größte Breite 12, größte Dicke $7 \mathrm{~cm}$. Auch beide Vorböfe dilatiert. Epicardiales Fett mäßïg, Contraktionszustand ziemlich schlecht. Tricuspidalis für knapp 4, Mitralis knapp für 2 Finger durchgängig. Im Herzen reichlich flüssiges Blut und Speckgerinnsel. Arterielle Klappen schluffähig. Gesamtes Endocard leicht gelblich, vereinzelte Blutaustritte in demselben. Klappen des rechten Herzens zart, die des linken fibrös verdickt aber glatt. In einem der Trabekel des linken Ventrikels findet sich ein kleiner knapp stecknadelkopfgroßer weißlich gelber Herd. Elastizităt der Aorta herabgesetzt. Coronararterien zeigen reichliche gelblich weilße Verdickungen der Intima. Dicke des Herzmuskels etwa $18 \mathrm{~mm}$, Consistenz gut, Farbe rotbraun mit zahlreichen gelben diffusen Flecken.

Linke Lunge von vermehrtem Volumen und Gewicht. Aus dem Bronchus quillt auf Druck reichlich schaumig-seröse Flüssigkeit. Bronchialschleimhaut ist injiziert. Pulmonalis frei. Pleura glatt und glänzend. Unterlappen weniger nachgiebig als Oberlappen. Im Oberlappen Blut und Saftgehalt erhöht, Luftgehalt überall vorhanden. Unterlappen dunkelrot, Schnittfläche teilweise etwas trocken, doch Luftgehalt uberall vorhanden. Saftgehalt nicht erhöht.

Rechte Lunge von stärkerem Volumen als die linke, sonst aber dieser völlig gleich

Racheneingang etwas injiziert, desgleichen Trachea und Kehlkopf. 
Schilddrüse beträchtlich in beiden Lappen vergrößert, Schnittfläche gekörnt, gelblich braun, einige Colloidcysten enthaltend.

Milz: $16: 9: 3 \mathrm{~cm}$. Kapsel glatt, zart, nur in der vorderen oberen Fläche eine pfennigstäckgrobe, bindegewige flache Auflagerung. Gewebe sehr weich, kirschrot. Zeichnung verwaschen. Follikel und Trabekel undentlich.

Linke Niere etwas groß. Fettkapsel enorm dick. Fibröse Kapsel im allgemeinen ohne Substanzverlust abziehbar, etwas derb. Oberfüche glatt, zeigt einige Substanzverluste und zahlreiche kirschkerngrobe, gelbe, teils flüssige, teils breiige Herde, die etwas über die Oberfläche hervorragen. In Rinde und Mark zahlreiche ebensolche Herde. Rinde verbreitert. Grenze zwischen Rinde und Mark undeutlich. Zeichnung verwaschen. Nierenbecken leer, mäßig injiziert. Linke Nebenniere im Zentrum erweicbt.

Bechte Niore, Nierenbecken and Nebenniere wie links. Rechte Niere etwas kleiner.

Leber entsprechend groß. Oberflăche glatt und glänzend. Schnittflăche graugelb. Zeichnung ziemlich deutlich. Zentralvenen etwas erweitert. Gallenblas e klein, von zarter Wand, entbält wenig dünne gelbe Galle. Pancreas entsprechend groß, graurötlich.

M a gen sehr groß, Wand dünn. Schleimhaut grau, ziemlich glatt, von wenig Schleim bedeckt, zeigt besonders am Fundus zahlreiche, kaum linsengrobe teils schwarze, teils hellrote Blutungen.

Dundarm, Wurmfortsatz, Diekdarm ohne Besonderheiten.

Mesenterium, Netz enorm fettreich. Lymphknoten nicht vergrößert. ve größert.

Harnbla se entsprechend gro $B$, Schleimbaut blaß, zart. Prostata nicht

Hoden und Nebenhoden obne Besonderheiten. Linke Tunica propria enthālt einen Kaff̈eelöffel klarer, seröser Flüssigkeit.

Große GefäBe ohne Besonderheiten.

Diagnosis post mortem: Meningitis purulenta circumscriptacerebelli sin. Pachymeningitis interna basal. Pachymeningitis externa. Hyperaemia pulmonum. Septischer Milztumor. Pyaemische Abszesse in beiden Nieren. Nephritis parenchymatosa acuta et chronica. Fettleber. Hydrocele sin. Adipositas intestinorum et omenti majoris.

Sektion des Schlatenbeins.

Unterbindung der Vena jugularis interna. Unterhalb der Unterbindung ein ca. $1 / 2$ cm langes dunkelrotes weiches Cruorgerinnsel. Innenwand der Vene siehtgut aus. Nach oben soi ider grauschwarzer Thrombas. Im Bulbus venae jugularis, welcher abnorm grof ist, ein eitrig zerfallener lihrombus, Peribulbarer AbszeB; der umgebende Knochen ist eitrig infiltriert. An der Einmundungsstelle des Sinus sigmoideas in den bulbus fester bindegewebiger AbschluB. Im Sinus sigmoideus and im sinus transversus bis zum Toreular Herophili grane schmierige Massen. Eitrig zerfallene Thromben im Sinus petrosus superior in beiden sinus cavernosi und im sinus petrosus inferior. Samtliche Sinuswande sind eitrig infiltriert. Die Mittelohrräume sind freigelegt. Eine Fistel im horizontalen Bogengang ist gegen das hatige Labyrinth abgeschlossen. Labyrinthwasser klar.

Epikrise: Das gerötete Trommelfell des linken Ohres und die leichte Senkung und Infiltration der oberen Gehörgangswand täuschte uns bei der Anfnabme des Patienten eine einfache akute Mittelohrentzündung vor. Auch der Befund des Paukenhöhlenexsudates, schleimig-eitriges Sekret entsprach unserer Diagnose. Wir verordneten deshalb dem Patienten Bettruhe und applizierten eine Eisblase hinter das Ohr. 
Am nächsten Tage war die Schwellung der oberen Gehörgangswand so weit zurỉekgegangen, daß wir vor dem Trommelfell einige kleine Granulationen entdecken konnten, die von hinten oben kamen. Mit der Sonde gelangten wir an dieser Stelle in einen tiefen Krater. Nach diesem die Chronizität des Obrenleidens bekundenden Befunde konnte nun selbstverständlich nur noeh die Totalaufmeißlung in Frage kommen. Bei derselben fanden wir ein grofes zerfallenes Cholesteatom sämtlicher Mittelohrräume, welches durch seinen Druek zu einer Fistelbildung im horizontalen Bogengang geführt und den Nerv. facialis in großer Ausdehnung freigelegt hatte. Im weiteren Verlauf der Operation stießen wir auf eine Eiterung aus dem Suleus sigmoideus. Nach Freilegung des Sinus sigmoideus fanden wir diesen vollständig collabiert, sodaß wir an die Totalaufmeißlung sofort die Jngularisunterbindung und Sinusoperation ansehlossen. Wir erzielten bei der Sinusausräumung mit dem Löffel weder nach oben noch nach unten einen frischen Blutstrom und brachen zunächst die Operation $a b$, um den weiteren Temperaturverlauf abzuwarten. Der Temperaturabfall am nächsten Morgen bis auf 37,8 war zunächst ein erfreulicher. Im Laufe des Tages stieg die Temperatur jedoch wieder bis zu einer Abendtemperatur von $38,9^{\circ}$, so dali wir für den nächsten Tag eine weitere Ausräumung des Sinus nach dem Sinus transversus und nach dem Bulbus venae jugularis zu planten. In der folgenden Nacht trat aber eine rapide Verschlechterung im Zustande des Patienten ein, und am Morgen konnten wir uns iberzeugen, daß unsere operativen Maßnahmen aussichtslos sein würden. Die starke Chemosis beider Augen und die Protrusio des linken Bulbus zeigten uns, daß die Thrombose sich nicht mehr auf den Sinus sigmoideus besehränkt hatte, sondern schon bis in den Sinus cavernosus vorgedrungen war. Der Patient machte schon einen vollständig moribunden Eindruck, er war stark benommen, hatte Trachealrasseln, die Pupillen reagierten kaum noch auf Lichteinfall, der Puls war kaum füblbar und setzte häufig aus. Der Tod trat schon gegen Mittag ein.

Das Sektionsergebnis war eine ausgedehnte eitrige Thrombophlebitis sämtlicher Sinus im Bereich des rechten Schläfenbeins bis zum Toreular Herophili, den Sinus cavernosi und der Vena jugularis interna. Dab diese ausgedehnte Thrombose nicht erst in den letzten Tagen aufgetreten ist, sondern daB dieselbe sicher schon äber eine Woche bestanden hatte, wird 
wohl jedem einleuchten. Hierfür spricht neben dem eitrigen Zerfall im ganzen Bereich des Sinus auch der vollständige bindegewebige Abschluß des Sinus sigmoidens gegen den Bulbus venae jugularis. Aus diesem Befunde können wir uns vielleicht den Weg rekonstruieren, den die fortschreitende Thrombose genommen hat. Der primäre Erkrankungsherd der Blutleiter ist im Sinus sigmoideus zu suchen. Von hier aus ist die Thrombose nach oben und unten weitergegangen, hat unten vor dem Bulbus venae jugularis Halt gemacht und hier zu einem festen Abschlub geführt. Nach oben ist sie durch den Sinus transversus einerseits bis zum Torenlar Herophili und andererseits durch den Sinus petrosus superior tiber beide Sinus cavernosi und den Sinus petrosus inferior nach dem Bulbus venae jugularis und weiter in die Vena jugularis selbst gegangen.

Außerdem hatte die Thrombopllebitis zu einer circumscripten eitrigen Meningitis am Kleinhirn per contiguitatem und zu septischen Veränderungen an Herz, Milz und Nieren geführt.

5. Heinrich Hoppe, 64 Jahre alt, Maurer aus Wolmirsleben. Aufgenommen am 9. August 1904, gestorben am 14. August 1904.

Anamnese: Im 10. Lebensjahre will Pat. eine Ohrfeige auf das linke Ohr erhalten haben. Seit dieser Zeit Schwerhörigkeit, eitriger Ausfiuß mit geringen Unterbrechungen und zeitweise Schmerzen. Seit 3 Monaten, infolge von Erkältung, stärkerer Ausfluß, Schwindelgefühl und reißende Schmerzen in Schläfen- und Stirngegend.

Status praesens: Kräftig gebauter Mann, in gutem Ernährungszustand. Arteriosklerose und Emphysem in geringem Grade. Herz und Lunge sonst $0 . B$. Pupillen gleichweit, reagieren prompt; deutlicher, horizontaler Nystagmus beim Blick nach links. Pat. muB gefübrt werden, da er wegen starken Schwindelgefühls sich nicht aufrecht erhalten kann. Kein Fieber.

Urin frei von Eiweil und Zucker.

Umgebung des Ohres: o. B.

Gehörgang und Trommelfellbefund: Rechts: Trubung, Einziehung. Links: Gehörgang weit; in ihm sehr foediter Eiter. Beim Ausspritzen werden zahlreiche Cholesteatomschüppchen entfernt. Totaldefekt des Trommelfells. Hinten oben großer Krater im Knochen. Mittelohrschleimhaut gerötet. An der medialen Atticwand Cholesteatomtapete.

Hörprüfung: Flästersprache rechts in $4 \mathrm{~m}$ Entfernung, linkes Ohr sprachtaub. $\mathrm{C}_{1}$ vom Scheitel nach rechts lateralisiert. Fis 4 rechts gut gehört, links nicht gebört. Rinne rechts + , links -.

Therapie und Krankheitsverlauf: 10. August. In der Gegend des horizontalen Bogenganges eine circumscripte Eiterstelle. Schwindelgefühl besteht auch bei Bettruhe. Leichte Facialisparese in der Gegend der linken Mundseite. Wiederholtes Erbrechen. Augenhintergrund normal. Haut und Sehnenreflexe erhalten. Temperatur $36,3^{\circ}-36,6^{\circ}$.

11. August. Totala u fmei $B$ el ung. Hochgradige Osteosclerose. Ossicula fehlen. Im Antrum dicke, mit Epidermis bedeckte Schleimhaut. Auf dem horizontalen Bogengang kleine circumscripte Granulation; dementsprechend Fistel. Die Sonde dringt tief in das Labyrinth, Eitex quillt neben der Sonde hervor. Eröffnung des Labyrinths von der binteren Pyramidenfläche her, dabei tiefer extraduraler Abszeh in der Gegend des Aquaeductus vestibuli. 'Fistelverdächtige Stelle an der Kleinhirndura, aber keine Fistel gefunden. Spaltung, Tamporade, Verband. Temperatur $36,5^{\circ}-36,6^{\circ}$. Puls 78 . 
12. August. Patient hat in der Nacht leidlich geschlafen, fühlt sich im allgemeinen besser als bisher. Er nimmt reichlich Nahrung zu sich. Schwindelgefühl bei Bettruhe fast geschwunden. Keine Kopfschmerzen mehr. Pupillen gleichweit, gute Reaction; Kein Nystagmus. Kein Fieber. Die Facialisparese ist fast völlig geschwunden.

13. August, Allgemeines Woblbefinden. Verbandwechsel: Wunde sieht gut aus; keine Eiterverhaltung. Puls etwas klein, regelmäßig, 80 Schläge in der Minute. Atmung regelmäßig. Keine Nackensteifigkeit; keine Druckempfindlichkeit der Halswirbelsäule. Augenhintergrund normal. Kein Fieber.

14. August. Unruhiger Schlaf während der Nacht Seit heute Morgen liegt Patient benommen da reagiert nicht auf Anrufen. Pupillen eng, reagieren nicht. Augenhintergrund normal, Kein Nystagmus. Puls 110, regelmäBiy, sebr klein. Atmung 20. Patellarreflexe verstärkt, Cremaster- und Bauchdeckenreflexe nicht vorhanden. Gegen Mittag wird Patient plötalich unrubig, so dah er kaum im Bett gehalten werden kann. Nach einer balben Stunde ist Patient wieder ruhig. Atmung oberflächlich. Tiefe Benommenheit hălt an. Bei Druck auf den Nacken kein Zeichen von Schmerz. Kein Trachealrasseln. Am Nachmittage Exitus, Keine Temperatursteigerungen.

Sektionsprotok oll

Männliche Leiche in mäßjgem Ernäbrungszustande. Totenstarre und Flecke vorhanden. Einter dem linken Ohr eine $5-6 \mathrm{~cm}$ lange durch Gaze tamponierte Operationswunde.

Am Ruckenmarkskanal keine Veränderungen. Im oberen Tell ist die Hinterfläche des Duralsackes mit dem Knochen verklebt. Bei Eröffnung des Duralsackes die Dura glatt. Die Innenfäche der Dura etwas verdickt und rauh. Auf den weichen Häuten teils freiliegende, teils festsitzende fibröse, stellenweis verkalkte Plättchen, besonders im Bereich des Lendenmarks. $\ddot{A u ß e r l i c h ~ b i e t e t ~ d a s ~ R u ̈ c k e n m a r k ~ k e i n e ~ V e r a ̈ n d e r u n g e n ~ d a r . ~}$

Schädeldach in seinem vorderen Teil mit der Dura oberflächlich verwachsen. Diploe deutlich. Blutgehalt des Knochens erhöht. Dura von starkem Blutgehalt, etwas erböhtem Saftgehalt. Im Sinus longitudinalis dunkles fast fiüssiges Blut. Die Innenfläche der Dura beiderseits trocken. Weiche Hirnhäute nur ganz leicht in den hinteren Partien getrubt. Hier anch die subarachnoideale Flüssigkeit etwas vermehrt. GefäBe der Pia stärker gefullt.

Bei Heransnahme des Gehirns zeigt sich das Kleinhirn leicht dem Knochen adhaerent und beim Lösen von Verklebungen quillt dicker heller Eiter hervor. Nach Herausnahme des Gehirns wird festgestellt, daß der Eiter der linken Kleinhirnhemisphäre entstammt. Bei einem horizontalen Schnitt durch die linke Hemisphäre zeigt sỉch diese zur Hälfte eingenommen von einem Abszeß, der mit grünlichgelbem Eiter gefüllt ist, und dessen Wandungen an mehreren Stellen kapselartige Verdickungen zeigen. In der Ungebung des Abszesses finden sich multiple berdförmige Blutaustritte. Das rechte Kleinhirn ist frei. Brücke und Medulla ohne Befund.

Pia der Basis zeigt nirgends Trübungen oder Eiterungen. Ventrikel sind erweitert durch klare seröse Flüssigkeit. Ependym zart.

Großhirnganglien ohne Veränderungen. Consistenz in der Gegend der Ventrikel schlecht, sonst ziemlich gut. Blutgehalt etwas erhöht.

Fettpolster und Muskulatur mäBig entwickelt. Das fettreiche Netz ist herabgeschlagen. Serosa der Därme glatt und glänzend. Zwerchfellstand bdsts. 5. Rippe. Kein fremder Inhalt im Abdomen. Herzbeutel liegt in mäßiger Ausdehnung frei. Seine Innenflăche glatt und glänzend. Fr entbält ungefähr $1 / 2$ EBßlöflel klarer Flüssigkeit. Lungen sind nicht mit der Brustwand verwachsen. Kein fremder Inhalt in der Pleuraböhle.

Herz etwa entsprechend grob, ziemlich schlaff. Mäliges epikardiales Fett. Tricuspidalis für 3, Mitralis für 2 Finger durchgängig. Arterielle Klappen schlubfähig. Klappen des rechten Herzens sind zart. Die Mitralis $z$ war verdickt, aber glatt. Die Aortenklappen teilweise gefurcht, ebenfalls leicht verdickt. Elastizităt der Aorta ist ziemlich reduziert. Coronararterien ohne Befund. Herzmuskel von braunroter Farbe, mäßige Consistenz. 
Linke Lunge von vermehrtem Volumen nnd Gawicht. Aus dem Bronchus entleert sich reichlich Schaum. Schleimhaut leicht injiziert. Pulmonalis frei. Pleura glatt und glänzend, zeigt aber zahlreiche weiße Fleckchen. Lunge überall nachgiebig. Im Oberlappen Blutgehalt und besonders der Saftgehalt stark erhöht. Im Unterlappen Luftgehalt im ganzen herabgesetzt. Kleine Lungenstückchen sinken unter.

Rechte Lunge: Volumen nicht so stark vermebrt wie links. Im Unterlappen der Blutgehalt ebenso stark vermehrt, Luftgehalt nicht in dem Mafe aufgehoben wie links.

ohne Befund.

To nsillen zerklüftet, enthalten Eiterpfröpfe. Im übrigen Halsorgane

Milz entsprechend groß. Parenchym blaß, graurot, Consistenz schlecht.

Linke Niere etwas klein. Fettkapsel gering, fibröse Kapsel leicht löslich. Oberfläche glatt. Rinde etwas schmal, wenig deutlich getrennt von den Pyramiden. Blutgehalt im ganzen erhöht. Consistenz gut. Nierenbecken obne Befund.

Rechte Niere im wesentlichen wie die linke.

Leber entsprechend groh. Kapsel glatt. Parenchym ohne Befund. Farbe ziemlich gut, ebenso Zeichnung und Consistenz.

Gallenblase enthălt außer ziemlich brauner Galle ein etwa erbsengroßes Concrement und mehrere kleine.

Blasenschleimhaut blaß.

Darmschleimhant ohne Befund. Etwa $1 \mathrm{~m}$ über der Bauhin'schen Klappe ein Meckel'sches Divertikel.

Hoden ohne Befund.

Magen ohne Befund.

Große Gefäße ohne Befund.

Diagnosis post mortem: KleinhirnabszeB links, Hyperaemie der Hirnhäute. Hydrocephalus externus et internus. Chron. Leptomeningits spinal (circumscripta fibr.). Hochgradiges Lungenoedem. Beginnende hypostatiscbe Pneumonie beider Unterlappen. Diverticulum Meckelil. Cbolelithias is. Sektion des Schlarenbeins.

Vertikaler Bogengang vollständig dureh Nekrose zerstört. Am Promontorium stecknadelkopfgroße Fistel, aus der Eiter quillt. Im Labyrinth, vor allem in den Bogengängen dïnner Eiter. Sacculus endolymphaticus erweitert, Wandungen desselben verdickt. Beim sondieren desselben ge langt man durch eine Fistel, die von Granulationen umwuchert ist, in den extraduralen Raum. Wine Fistel nach dem Kleinbirnabszef konnte nicht nachgewiesen werden

Epikrise. In diesem Falle waren wir in der Lage, schon im otoscopischen Bilde eine Bogengangfistel mit Eiterung aus dem Bogengang festzustellen. Durch cariöse Zerstörung der lateralen Atticwand war der horizontale Bogengang direkt sichtbar gemacht worden. Auch die Symptome, welche der Patient bei der Aufnahme darbot, Kopfschmerzen, Nystagmus, hochgradiger Schwindel und das Ergebnis der: Hörprüfung - völlige Taubheit - entsprachen diesem Befund einer Labyrintheiterung. Wir schlossen deshalb an die Totalaufmeißelung sofort die weite Eröfnung des Labyrintbs von der hinteren Sebläfenbeinpyramide aus an, welehes wir vollständig vereitert fanden. Hierbei stießen wir noch auf einen tiefliegenden Extraduralabszeß nach der Spitze 
der Sehläfenbeinpyramide. In der an dieser Stelle verfärbten Dura konnten wir trotz eifrigsten Suchens keine Fistel nach dem Kleinhirn entdecken.

Nach der Operation trat sogleich eine erhebliche Besserung: im subjektiven wie im objektiven Befinden des Patienten ein. Die Kopfschmerzen waren vollständig gesehwunden, ebenso der Nystagmus, und das Schwindelgefübl hatte sich erheblich gebessert. Am 3. Tage nach der Operation trat plötzlich eine Wendung zum schlechteren ein. Patient wurde schwer benommen, die Papillenreaction hörte auf, der Puls wurde klein, unregelmäBig und sehr beschleunigt. Dieses Stadium schwerer Benommenheit wurde gegen Mittag durch eine Excitation von halbstündiger Dauer unterbrochen. Der Exitus trat bereits am Nachmittage desselben Tages ein.

Wir fanden bei der Sektion einen Abszeb, welcher fast die Hälfte des linken Kleinhirns einnahm. Derselbe war nicht direkt ausgegangen von einem Empyem des Sacculus endolymphaticus, sondern auf dem Umwege eines tiefgelegenen Extraduralabszesses der hinteren Schläfenbeinpyramide entstanden. Der erkrankte Sacculus endolymphaticus zeigte eine Fistel, welche zu dem extraduralen AbszeB führte. Von hier aus war eine Infektion des Kleinhirns per contiguitatem erfolgt, denn auch bei der Sektion war eine Fistel nach dem Kleinhirn nicht nachweisbar. Der Tod erfolgte infolge des Hirndruckes, welcher durch den starken Hydrocephalus internus und externus verursacht war.

6. Bruno Zerner, 10 Jahre alt, Arbeitersohn aus Döhlau. Aufgenommen am 22. Juni, gestorben am 13. Juli 1904.

A namnese: Seit 3 Jabren mit kurzen Unterbrechungen eitriger Ausfluß aus dem linken Ohr. Vor 3 Wochen Masern, daran anschließend stärkerer AusfluB und Schwellung binter dem linken Ohre. Zeitweise soll anch seit dieser Zeit beim Bücken und schnellen Gehen Schwindel aufgetreten sein. Patient sucht die Klinik wegen der Schwellung hinter dem Ohre auf.

Status praesens: Mittelkräftig gebauter Junge in gutem Ernährungszustande. Brust- und Baucheingeweide ohne Besonderheiten. Puls regelmäßig, kräftig, 76 . Temperatur $36,7^{\circ}$.

Pupillen gleichweit, reagieren gut auf Lichteinfall. Kein Nystagmus. Schwindel objektiv nicht nachweisbar.

Umgebung des Ohres: Hinter dem linken Ohre starke ödematöse Schwellung bis zur Spitze des Proc. mastoid. herabreichend. Fluktuation deutlich fühlbar.

Gehörgang- und Trommelfellbefund: Rechts: Ohne Besonderheiten. Links: Gehörgang weit, jn ihm mäßjige Mengen tubelriechenden Eiters. Trommelfell trübe, Hammergriff stark retrahiert. Im vorderen unteren Quadranten große Perforation. Paukenhöhlenschleimhaut blaß.

Hörprüfung: Flüstersprache rechts in $5 \mathrm{~m}$, links in $30 \mathrm{~cm}$ Entfernung gehört. Stimmgabeln: Wegen der ungenauen Angaben des Patienten nicht zu ermitteln. Rinne rechts +, links - 
Ergebnis bei Catheterismus tubae: Perforationsgeräusch.

Therapie und Krankheitsverlauf. Typische AufmeiBelung. Weichteile speckig infiltriert. Spaltung eines subperiostalen Abszesses. Corticalis mit zablreichen Blutpunkten. Eröffnung des Antrum; in ihm selbst kein Eiter, dagegen in den umgebenden Zellen. Die sehr tief stebende Dura der mittleren Schädelgrube wird an einer Stelle freigelegt. Bei Entfernung einiger vereiterter Zellen quillt plötzlich aus der Sinusgegend Eiter hervor. Resektion der Spitze und Entfernung der Sulcuswand Im Sulcus wenig freier Eiter. Sinus mit grauroten Granulationen bedeckt. Freilegung des Sinus in großer Ausdehnung bis zum Sinus transversus. Excision der $\mathbf{A b}$ szeßmembran. Tamponade, Verband.

Fieberfreier Heilungsverlauf.

26. Juni. Verbandwechsel: Die Wande sieht gut ans. Frische Granulationsbildung. Im Gehörgang noch Eiter.

30. Juni. Im Gehörgange Eiter. Aditus durch Granulationen verlegt. Ätzung derselben mit Arg. nitricum. Kein Fieber.

2. Juli. Aditus wieder verschlossen. Einlegung eines $\mathrm{Schw}$ ar tze'schen Bleinagels.

6. Jnli. Patient klagt uber Übelkeit, hatte gestern und heute einmal Erbrechen. Die Wunde sieht gut aus. Beim Beklopfen des Kopfes keine Schmerzen. Pupillen normal, reagieren prompt. Puls regelmäßig, 74. Kein Nystagmns; kein Schwindel. Auffallend ist die langsame Sprache. Sensorium vollständig frei. Temperatur $36,7-37,0-37,2^{\circ}$. $-39,1^{\circ}$.

7. Juli. Befinden unverändert. Temperatur $37,0-38,4-39,3-39,1-39,2$

8. Juli. Patient hat in der Nacht sehr unruhig geschlafen und wiederholt laut aufgeschrieen. Auf Fragen antwortet er stets mit "Ja". Gegenstände, die ihm gezeigt werden, wie Uhr, Schlüssel erkennt er nicht. Bei Aufforderung, die Zunge zu zeigen oder den Mund zu offnen, tut Patient es erst, nachdem ihm dasselbe vorgemacht ist, und dann auch nur langsam und nur zeitweise. Stahl ist seit gestern angehaiten. Urin hat er in der Nacht unter sich gehen lassen. Kein Verlangen nach Nahrung. Wenn Milch ihm gereicht wird, nimmt er nur einige Schlucke zu sich. Kanm eine Minute liegt ex ruhig da. Keine auffallende Nackensteifigkeit, auch keine Druckempfindlichkeit der Halswirbelsäule. Fupillen gleichweit, gute Reaktion; kein Nystagmus. Augenhintergrund normal. Sensibilität an den oberen GliedmaBen und am Thorax fast aufgehoben, an den unteren Gliedmaßen stark herabgesetzt. Patellarreflexe aufgehoben. Cremaster- und Bauchdeckenrefiexe normal. Kein FuBclonus. Puls sehr beschleunigt, gespannt, regelmäßig, 110 .

Lu mbalpunktion: 35 ccm milchig getrübter Cerebrospinalfussigkeit, die unter hohem Druck steht, wird abgelassen. Im Ausstrich keine Bakterien. Freilegung sämtlicher Mittelohrräume. Von Ossiculis nur Hammer mit fehlendem Griffende vorhanden. Granulationen in den Mittelohrräumen. Wände der Räume zum Teil cariös. Hintere Fläche der Schläfenbeinpyramide freigelegt. Von hier aus das Labyrinth eröfnet, ohne dal Eiter zu sehen war. Mittlere und hintere Schädelgrube weit freigelegt. Zwischen Tegmen antri und Dura der mittleren Schädelgrube wenig freier Eiter und Granulationen (Pachymeningitis externa). In der Dura eine weiße, käsig aussehende, mißfarbene Stelle. Diese Stelle entspricht einer Fistel in der Dura, durch welche man in einen Schläfenlappenabszeß gelangt. Freilegung des Schläfenlappens und Entleerung des, viel fötiden Eiters, enthaltenden $\mathrm{Ab}$ szesses. Drainage und Tamponade der Abszeßhöhle. Spaltung des Gehörganges ohne Naht. Tamponade. Temperatur $39,3-39,5-38,9-39,3-39,2-$ $38,9-38,8-38,1-37,4^{\circ}$.

9. Juli. Patient war in der Nacht sehr unruhig, bohrt mit dem Hinterkopf in die Kissen. Wiederholtes Zähneknirschen und lautes Aufschreien, wobei Patient dann oft nach der Stirngegend greift. Sehr starker Opisthotonus; Druckempfindlichkeit im Nacken. Augenbefund unverändert normal. Puls sehr beschleunigt $(100-130)$, regelmäßig, wenig gespannt. Sehr geringe Nahrungsaufnahme; Patient trinkt nur wenig Milch. Keine Lähmun- 
gen des Gesichtes und der Extremitäten. Urin läßt er unter sich. Stuhl bis jetzt noch nicht erfolgt. Vollige Benommenheit. Atmung regelmäßig. Reflexe unverändert. Im Liquor sind Meningokokken nachgewiesen (hygienisches Institut).

Lumbalpunktion, wobei $18 \mathrm{ccm}$ sehr trüber Flüssigkeit, welche unter geringerem Druck steht als gestern, entleert werden. Verbandwechsel. Deutliche Fistel in der Hirnabszeßhöhle nach dem Ventrikel. In der Fistel pulsierende Flüssigkeit. Injektion von 2,5 ccm Streptokokkenserum Menzer.

Temperatur $37,8-38,3-38,7-34,0-38,9-38,5-38,5-38,4-38,8-38,0^{0}$.

10. Juli. Zustand unverändert. Lumbalpunktion: $10 \mathrm{ccm}$ trüber Flüssigkeit entleert. Injektion von $5 \mathrm{ccm}$ Streptokokkenserum.

Temperatur $39,3-38,4-39,2-39,2-39,0-39,1-38,9-38,8-38,7^{\circ}$.

11. Juli. Verbandwechsel. |Hirnabszeßhöhle ungefähr $4 \mathrm{~cm}$ Durchmesser; Fistel nicht mehr deutlich zu erkennen, keine Pulsation. Wunde sonst unverändert. Puls 120, zeitweise aussetzend. Atmung sehr oberflächlich, 30 . Starke Benommenheit. Keine Nabrungsaufnahme. Strabismus convergens. Pupillen weiter als bisher, träge Reaktion. Patellarreflexe aufgehoben. Sensibilität stark herabgesetzt.

Temperatur $39,4-38,4-38,4-38,0-38,4-37,9-38,3-38,0-38,2-38,1^{\circ}$. $-38,1^{\circ}$.

12. Juli. Temperatur $38,1-38,4-38,5-38,4-38,7-38,3-38,7-38,9$

13. Juli. Keine Änderung im Zustande. Patient ist vollstāndig benom. men, schreit oft anf. Da er keine Nahrung per os aufnimmt, in den letzten Tagen Nährklystiere. Atmung ganz oberfǟchlich, 52 . Temperatur 38,1$38,7--39,9^{\circ}$.

Gegen Abend Exitus im tiefen Coma.

Sektionsprotokoll.

Kindliche männliche Leiche von etwas reduziertem Ernährungszustande. Totenstarre und Flecko vorbanden. Serosa der Därme glatt und glänzend, etwas injiziert. Kein fremder Inbalt im Abdomen. Netz herabgeschlagen. Zwerchfellstand rechts 4 . Rippe, links anterer Rand der 4 Rippe. Beide Lungen an der Spitze verwachsen. Kein fremder Inhalt in den Pleurahöblen.

Schädeldach entsprechend dick. Dura etwas injiziert. Spannung leicht erböht. Im Sinus longitudinalis zartes Speckgerinnsel. Innentäche der Dura matt und trocken. Ebenso Arachnoidea, aber nicht getrubt. Jedoch sieht man am linken Scheitellappen unter der Arachnoidea kleine Eiterherde. Hinter dem linken Ohre eine ausgedehnte tamponierte Trepanationswunde. Blutgehalt der Pia kaum erhöht. Bei Herausnahme des Gehirns entleert sich von der Basis her reichlich grünlich-gelber Eiter. Pia an den Fossae Sylvii stark verklebt. Windungen stark abgeflacht. Der linke Schlăfenlappen unten seitlich zeigt eine etwa Zehnpfennigstückgroße mit Gaze tamponierte Offinung, in deren Umgebung sich wobl kleinere Blatungen, jedoch keine Spur von Eiter findet. Besonders reichlich ist die Eiteransammlung am Kleinhirn und in der Gegend des Chiasma. Die Ventrikel sind etwas erweitert und mit dünnem Eiter gefüllt. Hirnsubstanz um die Ventrikel erweicht. Kleinhirn ödematös, ohne Besonderheiten. Der oben erwähnte tamponierte Schläfenlappenabszeß, in dem sich kaum Eiter findet, dessen Wände mißfarben hämorrhagisch sind, läßt sich bis zum linken Unterhorn verfolgen, ohne daß eine jetzt deutlich sichtbare Kommunikation sich nachweisen läbt. Zentralganglien odematös, von mäßig deuticher Zeichnung. Hirnsubstanz feucht, von schlechter Consistenz. Rinde ödematös. Der Sinus sigmoideus rechts mit Cruorgerinnsel gefüllt.

Herzbentel in mäßiger Ausdebnung freiliegend. Innenfläche glatt und glänzend. Inbalt ca. $20 \mathrm{ccm}$ klaren Serums.

Herz entsprechend groß, mäßig contrabiert. Wenig epicardiales Fett. Tricuspidalis knapp für drei, Mitralis für zwei Finger durchgängig. Aortenklappen schließen. Gesamter Klappenapparat zart, intakt. Herzmuskel blaßjrot, mit zahlreichen gelben Flecken. Aorta und Coronararterien obne Besonderheiten.

Linke Lunge von entsprechendem Volumen und Gewicht. Aus dem 
Bronchus entleert sich auf Druck etwas trüber Schleim. Schleimbaut etwas injiziert. Pulmonalis frei. Pleura, glatt und glänzend, zeigt Reste von Verwachsungen mit geringen Hämorrhagien. Lunge äberall nachgiebig. Blutund Saftgehalt kaum erhöht. Luftgehalt überall vorhanden.

Rechte Lunge gleicht in bezug auf Bronchas, Pulmonalis und Pleura der linken. Im oberen Teile des Oberlappens finden sich mehrere dunkelrote, prominierende, luftleere Herde, teilweise confluierend. Mittellappen lufthaltig. Unterlappen zeigt sehr lileine luftleere, dunkelrote Herde. Blutgehalt etwas erhöht. Bronchiale Lymphdrüsen etwas vergrölert, pigmentiert. Halsorgane ohne Besonderheiten. Tonsillen etwas vergröbert.

Milz: 10:5:21/2 cm, guter Consistenz, grauroter Farbe, ziemlich dunkler Zeichnung.

Linke Niere entsprechend groß. Fettkapsel sehr gering. Oberflache glatt. Fibröse Kapsel leicht löslich. Parenchym blaß. Rinde etwas verbreitert, deutlich abgegrenzt von den etwas dunkleren Pyramiden. Nierenbecken ohne Besonderheiten.

Rechte Niere wie die linke.

L eber entsprechend grob. Kapsel glatt. Parenehym von dunkelbraunroter Farbe. Zeichnung mäBig deutlich. Consistenz gut. Gallenblase ohne Besonderheiten. mosen.

Magen entsprechend groß. Schleimhant gefaltet, mit kleinen Ekchy-

Darm ohne Besonderheiten, desgleichen Pankreas, Mesenterium, Aorta.

Blasenschleimhaut blaß.

Diagnosis post mortem: Schlafenlappenabszeb links. Eitrige Meningitis. Pyocephalus internus. Hirnodem. Bronchitis catarihalis. Kleine bronchopneumonische Herde der rechten Lunge. Plenritis chronica adhaesiva beiderseits. Verbreiterung der Nierenrinde. Verfettung des Herzmuskels.

Sektion des Schläfenbeins wurde nicht ausgeführt, da schon bei der Operation Intaktheit des Labyrinth festgestellt war.

Epikrise: Wir operierten den Knaben wegen eines retroauriculären Abszesses, von dem wir noch zweifelhaft waren, ob er iberhaupt vom Ohre ansging oder nur von einer vereiterten Lymphdrïse. Nach Spaltung des Abszesses fanden wir auf der Corticalis des Planum mastoideum zahlreiche Blutpunkte, so daß wir die typische Aufmeißelung anschlossen, bei der wir außer einem Empyem der Warzenzellen einen perisinuösen Abszeb fanden. Obwohl wir wußten, daß wir es mit einer chronischen Eiterung zu tun hatten, besehränkten wir uns trotzdem nur auf die einfache Mastoidoperation nach S chwartze, da nach dem otoskopischen Befunde wie auch nach dem Befunde im Warzenfortsatz die Bedingungen für ein gutes Ausheilen des Prozesses gegeben waren (vgl. Grunert und Schulze, Jahresbericht der Halleschen Ohrenklinik 1901/1902. Dieses Archiv, Bd. LVII).

Der Heilungsverlauf war auch, abgesehen von einer üppigen Granulationsbildung im Aditus, welehe wir mit Hilfe des $\mathrm{Schw}$ artzeschen Bleinagel 5 zurückhalten mußten, ein zufriedenstellender. Der Patient konnte nach 6 Tagen das Bett wieder verlassen. 
Am 6. Juli, also 14 Tage nach der Operation, klagte der Patient über Übelkeit und Erbrechen. Da wir beim Verbandwechsel und ebenso nach einer sorgfältigen Körperuntersuchung keine Erklärung für diese Erscheinungen finden konnten, glaubten wir sie auf eine Verdauungsstörung zurückführen zu können. Zwei Tage später zeigte Patient abel so bedenkliche cerebrale Symptome, daß wir eine intracranielle Komplikation annehmen mubten. Diese Symptome bestanden in starker Unruhe, Monophasie, sensorischer Aphasie, Herabminderung der Sensibilität, Incontinentia urinae; Symptome, welche für Hirnabszeß, vielleicht schon kompliziert mit diffuser eitriger Meningitis sprachen. Die Lumbalpunktion ergab milchig getrübte Cerebrospinalfüssigkeit. Da wir einerseits im Ausstrichpräparat keine Bakterien nachweisen konnten, andererseits aber auch nieht warten konnten, bis wir von den angelegten Kulturen Aufschlub über das Vorhandensein oder Nichtvorhandensein von Bakterien in der Cerebrospinalflüssigkeit erhielten, so entseblossen wir uns zur sofortigen Operation.

Nach Eröffnung des Labyrinths, welches wir gesund fanden, stieben wir auf einen tiefen ExtraduralabszeB der mittleren Schädelgrube, welcher vom cariösen Tegmen antri ausgegangen war. Von diesem Abszeß führte eine Fistel durch die Dura in einen Schläfenlappenabszeß. Nach breiter Freilegung wurde der Abszeß entleert.

Trotz dieses Eingriffes verschlechterte sich der Zustand des Patienten zusehends; bald trat völlige Benommenheit ein. A m näehsten Tage konnten wir beim Verbandwechsel in der Hirnabszeßhöhle eine Fistel nach dem Ventrikel entdecken, in der pulsierende Flüssigkeit stand. Der Zustand des Patienten dawerte unverändert noch 6 Tage fort, an welchem er dann in tiefem Coma starb.

Wir haben es also hier mit einem großen Schläfenlappenabszeb zu tun, der bis zu seinem Durchbruch in den Ventrikel absolut kein Symptom gemacht hatte. Erst als er in den Ventrikel durchgebrochen war und von hier aus die Meningen infiziert hatte, konnten wir eine intracranielle Komplikation feststellen.

7. Angust Wissel, 59 Jahre alt, Schiffer aus Rosslau. Aufgenommen am 22. März 1905, gestorben am 23. März 1905.

Anamn ese: Patient soll früher nie ohrenkrank gewesen sein. Gegen Ende Januar traten Schmerzen im rechten Ohre auf, zu denen sich nach einigen Tagen Ansfluß aus dem Obre gesellte. Zu gleicher Zeit soll Patient 
auch über Schmerzen in der rechten Kopfseite geklagt haben. Patient bat aber immer seine Arbeit verrichtet. Am Morgen des 21. März traten plötzlich Schüttelfrost und Schmerzen im Genick auf. Gegen Abend war Patient benommen und abwechselnd sebr unruhig, mit Delirien. Erbrochen hatte Patient nicht.

Status praesens: Kräftig gebauter, gesund aussehender Mann. Innere Organe ohne Besonderheiten. Puls sehr klein, unregelmäßig, 120. Temperatur 39,8 o. Sensorium vollständig getrübt. Flockenlesen der rechten Hand. Patient murmelt undeutliche Worte vor sich hin. Starke Unruhe; Patient deckt sich bloß und wälzt sich im Bett umber. Pupillen mittelweit, reaktionslos. Augenhintergrund ohne Besonderheiten. Kein Opisthotonus, doch scheinen passive Bewegungen des Kopfes mit geringer Schmerzhaftigkeit verbunden zn sein. Reflexe und Sensibilität erloschen.

Urin frei von Eiweiß und Zucker.

Umgebung des Ohres: Mäßige Druckempfindlicbkeit des ganzen Warzenfortsatzes.

Gehörgang- und Trommelfellbefund. Rechts: Im Gehörgang seröse Flüssigkeit und viel macerierte Epidermis. Senkung der oberen Gehörgangswand. Trommelfell blaurot. Fistelverdächtige Stelle nach hinten oben.

Hörprüfung wurde nicht ausgeführt.

Therapie und Krankheitsverlanf: Morphiuminjektion. Eisblase auf dem Kopf. Gegen Morgen wieder starke Unruhe. Temperaturen während der Nacht $39,5-38,6-39,8^{\circ}$.

23. März. Morgentemperatur $38,4^{\circ}$. Starke Unruhe. Patient läßjt Stuhl und Urin unter sich. Pupillen mittelweit, starr. Cyanose. Déviation conjugée nach rechts. 'Irachealrasseln. Puls kanm tühlbar, unzählbar, häufig aussetzend.

Exitus 11 Uhr a. m.

Sektionsprotokoll.

Große männliche Leiche von krä́ftigem Körperban. Starre und Flecke vorhanden. Haut blal, trocken. Abdomen leieht aufgetrieben.

Schädeldach: Quadratschädel leicht angedeutet, mäßig dick. Diploe vorhanden. Gefäßfurchen deutlich. Pacchionische Granulationen seicht.

Dura: Außenfläche glatt, sehr blutreich, kaum durchscheinend. Innenflüche matt, trocken, mit feinen blutigen Fibrinbelägen bedeckt. Im Längsblutleiter wenig Speckgerinnsel.

Weiche $\mathrm{Häu}$ te getrübt, sehr stark injiziert. Subarachnoidealfiùssigkeit nicht vermehrt, in eine dicke grüngelbe Eitermasse verwandelt; besonders die weichen Hănte der Hirnbasis um Pons und Chiasma herum dick eitrig inflitriert. Ebenso die linke Kleinhirnhemisphäre. Die Gyri der Grobhirnhemisphäre stark abgeplattet. Seitenventrikel leicht erweitert durch klare seröse Flüssigkeit. Ependym glatt, glänzend, blaß.

Tela chorioidea injiziert, ebenfalls eitrig infiltriert. Plexus chorioideus blutreich. Rautengrube ohne Besonderheiten. lich feucht.

Kleinhirn von guter Konsistenz, sehr blutreich, gut gezeichnet, ziem-

Ganglien des Stammes gut gezeichnet, mäBig blutreich, von guter Konsistenz; ebenso Pons und Medulla.

Großhirnhemisphären von guter Konsistenz, sebr blutreich, besonders die Marklager. Rinde nicht verschmälert. Die Dura des Rückenmarkes glatt. Die weichen Hãute ebenfalls eitrig infiltriert. Im Brustteil stecknadelkoptgroße bis fast linsengroße zarte weiche Kalkplatten.

Fettpolster der Brust- und Bauchhant stark entwickelt, feucht; ebenso die Muskulatur. Das fettreiche Netz ist nach oben gerollt. Serosa der mäßig geblähten Dărme glatt, glänzend, blaß. Wurmfortsatz frei. In der Bauchhöhle elnige Tropfen leicht getrübte, seröse Flüssigkeit. Zwerchfellstand rechts 4. Rippe, links oberer Rand der 5 Rippe. Lunge nicht zurückgesunken, leicht mit der Brustwand verwachsen. Beide Pleurahöhlen leer.

Herzbeutel liegt in Handtellergröße freí, ron reichlichem Fettgewebe überlagert, wenige $\mathrm{ccm}$ klarer, seröser Flüssigkeit enthaltend. Innenfläche glatt, spiegelnd. 
He rz sehr schlaff, entsprechend groß, enthält reichlich flüssiges, wenig geronnenes Blut.

Tricuspidalis und Mitralis für je 3 Finger durchgängig. Epicard sehr fettreich, glatt. leicht getrübt, besonders über dem rechten Ventrikel einige blasse Sehnenflecke. Klappenapparate zart, intakt, nur die Ansatzlinie der Aortenklappe leicht fibrös verdickt

Linker Ventrikel leicht erweitert, ebenso der linke Vorhof. Aorta elastisch, Kranzgefäbe ohne Besonderheiten. Myocard sehr weich, feucht, deutlich gelb gefleckt.

Linke Lunge: Aus dem Bronchus entleert sich auf Druck mäßig viel schaumiger Schleim. Schleimhant etwas injiziert und imbibiert. Pulmonalis frei. Peribronchiale Lymphknoten klein, weich. Pleura abgesehen von den flächenhaften Verwachsungen, glatt und durchsichtig. Oberlappen voluminös, überall lufthaltig. nachgiebig; sehr blut-, mäßig saftreich. Unterlappen blut- und saftreicher, doch überall lufthaltig.

Rechte Lunge: Bronchus, Pulmonalis wie links. Oberlappen und Mittellappen wie linker Oberlappen. Unterlappen voluminös, schwer, sehr blut- und saftreich. Schnittläche zäh, leicht gekörnt. Luftgehalt fast vollkommen aufgehoben.

Tonsillen und Zäpfchen geschwollen, gerötet. Schleimhaut. intalkt. Oe s ophagus: Schleimhaut blaßrosa.

Keblk opf: Eingang frei. Schleimbaut blaß. Die etwas verdickten Stimmbänder blafo.

Schilddrüse, besonders der linke Lappen $(\$ 1 / 2 \mathrm{~cm})$ erheblich vergröbert Auf der Schnittfläche mehrere kleine Cysten, neben blaßgelbem colloid entartetem Gewebe.

Milz: 12:9:21/2 cm. Kapsel gerunzelt, trüb. Pulpa dunkelrot, sebr weich Follikel undeutlich. T'rabekel etwas vermehrt.

Linke Niere entsprechend groB, etwas derb. Fettkapsel sehr stark entwickelt, tibröse zart, leicht abziehbar. Rinde quillt leicht uber, leicht getrübt, blutreich. Markkegel ebenfalls trüb, leicht gestreift, nicht besonders deutlich gegen die Rinde abgesetzt. Die Spitzen der Markkegel leicht injiziert. Nierenbecken leer. Schleimhant blaß, ohne Besonderheiten; ebenso Urether. Linke Nebenniere erweicht, klein.

Rechte Niere wie die linke, etwas blutarmer.

Leber entsprechend groß, weich. Kapsel glatt, durchsichtig. Parenchym ziemlich undeutlich gezeichnet, mäßig blutreich.

Gallen bla se durch reichliche dünnflüssige Galle ausgedehnt. Wan. dung zart. Schleimhaut intakt.

Magen ziemlich groß. Wandungen zart. Schleimhaut zum Teil verdaut, die erbaltene, schiefrig verfärbte, glatt. Im Fundus einige ältere und frische Fkehymosen.

Dünndarm: Schleimhaut blaß, von wenig Schleim bedeckt. Peyersche Haufen pigmentiert, besonders in dem unteren Drittel, neben den zahlreichen, blassen, zum Teil ebenfalls pigmentierten Follikeln.

Dickdarm: Schleimbaut etwas injiziert, schiefrig verfärbt. Auch hier die Follikel pigmentiert.

Pankreas sebr weich, glatt, rötlich gelb.

Mesenterium sehr fettreich. Lymphknoten sehr klein, weich, blaß.

Aorta abdominis ohne Besonderbeiten.

Diagnosis post mortem: Leptomeningitis cerebrospinalis purulenta acuta. Hy perämie des Gehirns. Herzparalys e. Fettige Degeneration des Herzmuskels. Dilatation des linken Ventrikels. Hyperämie und 0edem der Lungen. Hypostatische lobulare Pneumonie des rechten Unterlappens. Struma colloides Trübe Schwellung der Nieren. Abgeheilte Enteritis chron. Gastritis chronica.

\section{Sektion des Schläfenbeins.}

Inder Pakenböhleviel Eiter und eitrig infiltrierte Schleim haut; ebenso im Aditus. Ossicula makroskopisch gesund. GroBes Antrumempyem mitbildung eines perisinuỏsen Abszes- 
ses ron Zehnpfennigstückgröße am Sinus sigmoideus und an schlieBend daran nach binten eines extraduralen Abszesses. der hinteren Sebajdelgrabe in Bobnengröe. Sinus an der Stelle des Abszesses mit roten, derben Granulationen bedeckt. Dura der hinteren Sebädelgrube an Innen- und Außenfläche grau verfärbt. Innenwand des Sinus sigmoideus sieht gut aus. Sämtliche übrigen Sinus gesund. Labyrinth intakt.

Epikrise: Der Patient wurde uns sehon moribund in die Klinik eingeliefert. Die Symptome die er darbot, waren so ausgesprochen, daß kein Zweifel an einer diffusen eitrigen Leptomeningitis aufkommen konnte. Wir beschränkten uns deshalb selbstverständlich nur auf eine palliative Bebandlung. Der Tod trat schon am nächsten Vormittag ein.

Bei der Sektion fanden wir eine ausgedehnte diffuse eitrige Leptomeningitis. Dieselbe war ausgegangen von einem Empyem des Warzenfortsatzes und zwar hatte sie folgenden Weg genommen: Das Empyem des Antrum hatte zu einem Abszeß um den Sinus sigmoideus geführt. Von bier aus war die Eiterung in der hinteren Schädelgrube weiter nach hinten gedrungen, hatte hier die Dura durehsetzt und die Meningen infiziert. Neben dieser Meningitis fanden wir auch noch schwere septiscbe Veränderungen am Herzen.

8. Carl Wackes, 67 Jahre alt, Weber aus Kloster Zinna bei Jüterbogk. Aufgenommen am 4. August 1904. gestorben am 13. August 1904. A n a mese: Im 7. Lebensjabre Ausfluß aus beiden Ohren. Ursache unbelzannt. Der Ausflu? bestand einige Jahre. Seitdem nie wieder etwas an den Ohren bemerkt. For einem Monat ohne bekannte Ursache Schmerzen und Austuf am rechten Ohr. Seit dieser Zeit auch Schwerhorigkeit und bisweilen schwindel.

Status praesens: Kräftig gebauter Mann in gutem Ernährungszustande. Lungen und Herz gesund. Puls kräftig, voll, regelmäßig. Temperatur 36,6 . Schwindel objektiv nicht nachweisbar, kein Schwindelgefühl. Pupillen gleichweit, reagieren prompt; kein Nystagmus. Augenhintergrund normal. Haut- und Sebnenreflexe etwas herabgesetzt. Keine Percussionsemptindlichkeit des Kopfes. Urin frei von Eiweil und Zucker.

Umgebung des Ohres: obne Befand

Gehörgang- und Trommelfellbefund: Recbts: Gebörgang stark gerötet und geschwollen. so daß man nichts vom Hintergrunde sehen kann. Măßige Mengen Eiter. Beim Ausspülen zahlreicbe weiße Schüppchen. Links: obne Befund.

Hörprü fung: Flüsterprache rechts direkt nicht gehört, links in $3 \mathrm{~m}$ Entfernung. $C_{1}$ rom Scheitel nach rechts lateralisiert. Fis 4 rechts nur bei starkem Nagelanschlag.

Ergebnis bei Catbeterismus tubae: Perforationsgeräusch.

Therapie und Krankheitsver lauf: Behandlung der Otitis externa mit A usspulungen nnd Eintränfelungen von Borsänrealkohol.

7. August. Gehörgang weit, abgeblaßt. Keine stechenden Schmerzen im Obre mehr. Sebr geringe Sekretion. Totaldefekt des Trommelfells. Defekt der lateralen Attícwand. An dieser Stelle mehrere Granulationen; unter diesen mit der sonde rauher Koochen fühlbar. Allgemeinbefinden vorzüglich. Wubrend in den Wochen vor seiner Aufnabme Appetit und Schlaf sebr schlecht waren, haben sich dieselben sebr gebessert. Kein Fieber.

11. August. Seit gestern Nachmittag stärikere Eiterung im rechten Ohr. 
Angeblich sind auch wieder Schmerzen aufgetreten. Geringe Druckempfind lichkeit der spitze des Warzenfortsatzes und dicht hinter der Obrmuschel. Der äußere Gehörgang wieder stärker geschwollen. Die Granulationen im Hintergund sind gewachsen, so da $\beta$ sie Eiterretention bedingen. Entfernung derselben mit der Schlinge. Kein Schwindel. Augen obne Befund. Appetit geringer. Temperatur $37,2^{\circ}-37,4^{\circ}$.

12. August. Patient hat in der Nacht wenig geschlafen, da die Schmerzen im Ohre wieder sehr beftig waren. Ohrbefund unverändert. Geringe Druckempfindlichkeit der Spitze. Beim Beklopfen des Schädels keine Schmerzen. Pupillen gleichweit, reagieren prompt; kein Nystagmus. Kein Erbrechen. Keine Druckempfindlichkeit der Halswirbelsäule.

Totalaufmei Belung: Osteoselerose. Knöcherner Gehörgang und Paukenhöhle sehr eng. In Aditus und Antrum Cholesteatomtapete. Ausgedehnte Caries sămtlicher Mittelohrräume, welche zu weiter Freilegung der Dura der mittleren und hinteren Schädelgrube zwingen. Sinus in großer Ausdebnung freigelegt. Dura der mittleren Scbädelgrube mit dicken, derben Membranen belegt, welche mit der Vitrea sehr fest verklebt waren. Resection der Spitze. Ein tiefes Uleus geht bis unter die untere Gebörgangswand. Ein anderes Uleus am Boden der Paukenhöhle zwingt zur Entfernung eines Teiles der unteren und vorderen Gehörgangswand. Der Facialis wird hierbei an einer Stelle freigelegt; mehrere Spasmen. Von Ossiculis nur Hammergriff gefunden. Spaltung; keine Nabt Tamponade, Verband. Am Nachmittage Facialisparese. Temperatur $36,5^{\circ}-36,5^{\circ}-36,6^{\circ}-37,4^{\circ}$.

13. August. Patient hat in der Nacht sehr unruhig geschlafen. Wiederholtes Erbrechen. Temperatur heute Morgen gegen 6 Thr 39,4 ${ }^{\circ}$. Starke Benommenheit. Zwangsstellung der Augen nach rechts oben. Pupillen gleichund mittelweit, reagieren gut. Geringer oscillatorischer Nystagmus beim Blick nach rechts. Patellarreflexe normal, Cremaster- und Bauchdeckenreflexe fast aufgehoben. Pals klein, i30. Atmung oberfächlich, sehr beschleunigt; geringes 'Trachealrasseln, das allmählich stärker wird.

Lumbalpunktion: Stark getrübte Cerebro-Spinalflüssigkeit, unter sehr hohem Druck stehend, mit Diplococeengehalt. Es werden $30 \mathrm{ccm}$ entleert.

An die Lumbalpunktion anschließend Injektion von $15 \mathrm{ccm}$ Streptococcenserum Menzer.

Am Nachmittag starker Nystagmus. Pupillen reaktionslos. Stertoröses Atmen. Puls 150, kaum füblbar. Vollständige Benommenheit. Temperatur $39,4^{0}-39,6^{\circ}-39,8^{0}$. $6^{\text {b }}$ p. m. Exitus.

\section{Sektionsprotokoll.}

Männliche Leiche von gutem Ernäbrungszustande. Totenstarre und Flecke vorhanden. Hinter dem Ohr eine ca. $8 \mathrm{~cm}$ lange Wunde.

Dura mit der Schädelinnenfläche fest verwachsen. Arachnoidea diffus getrubt, stellenweise matt, sulzig getrabt. Blutgehalt der Pia gering. Bei Herausnahme des Gehirns entleert sich reichlich trübe eitrige Flüssigkeit. An der Unterfläche des Kleinhirns findet sich besonders an beiden seitlichen Partien eine eitrige Infiltration der weichen Hirnhäute. Die Gefäbe der Basis sind zart. Beim Abzieben der weichen Hirnhăute zeigen sich diese sehr stark verdickt Ventrikel erweitert durch trube, Eiterflocken enthaltende Flüssigkeit. Ependym glatt. Tela und Plexus ohne Besonderheit. Beide Kleinhirnhemisphären ohne Besonderheit. Centralganglien ohne Besonderheit, von guter Zeichnung; desgl. Brücke und Medulla. Consistenz des Hirns mangelhaft. Schnittfäche feucht, Blutgehalt gering. Im Sinus longitudinalis superior finden sich lockere Blutgerinnsel. Blutgehalt der Dupa gering, menfläche der Dura zeigt etwas berabgesetzten Glanz. Schädehach entepechend dick. Diploe nicht vorhanden. Über der rechten Scapafenbeinpyranade zeigt die Dura einen hämorrhagischen Belag. Beim Elascaneiđerran dieser Stelle kommt man auf einen Tampon. Von der Untetfache distontoriums läßt sich ein eitriger Belag abstreifen. Die Oberfäcne.sulzig vardickt, abe甘t glatt und glänzend.

Die Sektion der Brust- und Bauchhöhle wurde den A reateriged verweigert. 
Diagnosis post mortem: Pachymeningitis externa. Chronische Arachnitis. Eitrige Meningitis.

Sektion des Schläfenbeins in situ.

In der Schnecke und dem Vorhof dickes eitriges Sekret, in den Bogengängen leicht geträbte Flüssigkeit. Die Nerven des Porus acusticus internus eitrig infiltriert. Eine Fistel nach dem Mittelobr war nicht nachzuweisen.

Epikrise. Als der Patient die Klinik aufsuchte, bestand neben seiner chronischen Eiterung noch eine heftige Otitis externa, welche es uns wegen der dadurch erschwerten Untersuchung der tieferen Teile des Ohres unmöglich machte, über die Natur der ersteren Klarheit zu bekommen. Mit Hülfe von Einträufelungen von Boralkohol gelang es uns, die Otitis externa zu beseitigen, zugleich war aber anch die andere alte Erkrankung derartig günstig hierdurch beeinflubt worden, daß unserer Ansicht nach augenblicklich keine dringende Indication zu einem operativen Eingriffe vorlag. Vier Tage später trat jedoch wieder stärkerer Ausflub auf, und außerdem klagte Patient wieder über Schmerzen im Ohre. Wir glaubten diese Erscheinungen auf eine Eiterretention, welche durch inzwisehen eingetretene Vergrößerung der Granulationen im Ohre verursacht werde, zurückführen zu können, und suchten dieselbe durch Entfernung der Granulationen zu beseitigen. Als jedoch bis zum nächsten Morgen keine Besserung eingetreten war, die Sehmerzen vielmehr noch erheblicher geworden waren, schritten wir zur Totalaufmeißelung. Hierbei fiel uns außer einer Pachymeningitis externa chronica, die durch die ausgedehnte Caries der Mittelohrräume verursacht war, nichts besonderes auf. Am Nachmittage des Operationstages stellten wir eine Facialisparese fest; bei der Operation mußte der Facialis an einer Stelle freigelegt werden. Im Laufe der Nacht trat eine derartige Verschlimmerung im Zustande des Patienten ein, er erbrach öfter, war stark benommen, hatte Déviation conjugée, Nystagmus, seine Körpertemperatur war am Morgen $39,4^{\circ}$, so dab wir mit einer diffusen eitrigen Leptomeningitis rechnen mußten. Das Ergebnis der Lumbalpunktion, - stark getrübte Cerebro-Spinalflüssigkeit, welche unter sehr hohem Druck stand und Diplococeen enthielt, - bestätigte unsere Annahme. Die Meningitis nahm einen derartig rapiden Verlanf, daß der Tod des Patienten sehon am Nachmittag ein trat; die Ersoheinungen der Meningitis hatten also ungefäbr 18 Stunden bestanden.

Wegen der Sektion machten die Angehörigen Schwierigkeiten, so daf wir uns anf die Sektion der Schädelhöhle und Er- 
öffnung des Sebläfenbeins von innen besehränken mußten. Wir fanden eine diffuse eitrige Meningitis am Kleinhirn und im $\mathrm{Ohr}$ eine Labyrintheiterung mit eitriger Infiltration der Nerven des Porus acusticus internus. Eine Fistel nach dem Mittelohr konnten wir nicht entdecken. Die Meningitis war höchstwahrseheinlich von der Labyrintheiterung aus auf dem Wege der Nerven des Porus acusticus internus herbeigefibrt worden.

Zweifellos ist es, daß die Meningitis bei dem Patienten sehon längere Zeit latent bestanden hat; möglich ist es, daß dieselbe durch die Meißelerschütterung bei der Operation aus dem Stadium der Latenz in das, man kann wohl sagen apoplektiforme Stadium übergeführt worden ist. Möglicherweise hätte der Patient obne Operation noch einige Tage, vielleicht sogar noch einige Wochen gelebt, sein Schicksal war aber sehon vor der Operation besiegelt.

9. Anna Mö vi us, 11/4 Jahre alt, Tischlerskind aus Dederstedt bei Eisleben. Aufgenommen am 16. Dezember 1904, gestorben am 1. Jannar 1905.

A namnese: Das Kind hat in der vergangenen Woche an Husten und Schnupfen gelitten. Seit zwei Tagen Ausfluß aus dem rechten Ohre und Rötung hinter demselben. Patientin ist in den letzten beiden Tagen sebr unruhig gewesen und hat wenig geschlafen.

Status praesens: Mäßig entwickeltes, anämisches Kind. Innere Organe ohne Besonderbeiten.

Umgebung des Ohres: Hinter dem rechten Ohre flache Schwellung welche blaurot verfärbt ist. Die geschwollene Stelle ist stark druckempfindlich. In der Tiefe dicht am Ansatz der Ohrmuschel Fluktuation füblbar.

Gebörgang-und Trommelfellbefund: Rechts: Gehörgang weit, in ihm reichliche Mengen dünnflüssigen Eiters. Trommelfell diffus gerötet; steeknadelkopfgroße Perforation im vorderen unteren Quadranten, aus der Eiter pulsiert. Lin $\mathrm{z}$ \&: Ohne Besonderheiten.

Nase und Nasenrachenraum: Starke Sekretion aus der Nase.

Therapie und Krankheitsverlauf: 17. Dezember. Typische Aufmeißelung. Weichteile stark ödematös durchtränkt; kein subperiostaler Abszeß . Corticalis sehr blutreich. Im Antrum und in den dasselbe umgebenden Zellen reichliche Mengen dünnflüssigen gelben Eiters. Spitze frei. Sinus sigmoideus wird in Linsengröße freigelegt, sieht gut aus. Drain, Tamponade, Verband. Temperatur $38,1-38,7-39,8-39,3-38,8^{\circ}$.

21. Dezember. In den vorhergebenden Tagen immer noch erhöhte Temperaturen, zwischen 37,7 und $39,4^{\circ}$ schwankend. Nabrungsaufnahme mäßig. Das Kind ist ziemlich unruhig. Verbandwechsel. Die Wunde sieht gut aus. Nur ganz geringes Sekret im Gehörgange.

22. Dezember. Bronchitis; feuchtes Rasseln über der ganzen linken Lunge. Feuchte Einpackung. Abendtemperatur $40,1^{\circ}$.

23. Dezember. Verbandwechsel. Gehörgang trocken.

26. Dezember. Bronchitis auf beiden Seiten. Ununterbrochen erböhte Temperaturen. Die Operationswunde am $0 \mathrm{hr}$ sieht gut aus.

29. Dezember. Staxke Atemnot. Cyanose. Im Rachen nichts nachweisbar. Tracheotomie. Temperatur $37,2-38,2-38,4-38,5-38,7^{\circ}$.

31. Dezember. Starke Schwäche. Naurung wird verweigert. Tod an Entkräftung.

Sektionsprotokoll.

Kindliche weibliche Leiche in mäßigem Ernährungszustande, mit sehr blasser Haut. Totenstarre und Flecke vorhanden. Abdomen etwas meteoristisch aufgetrieben. In der Mittellinie des Halses befindet sich eine nicht mehr ganz 
frische Tracheotomiewunde von ca. $3 \mathrm{~cm}$ Länge, deren unterer Teil durch eine Nabt geschlossen ist und deren Wundränder etwas trocken und nicht eitrig belegt sind. Hinter dem linken $0 \mathrm{hr}$ erstreckt sich eine etwa $5-6 \mathrm{~cm}$ lange mit Jodoformgaze tamponierte Operationswunde.

Gehirn: Schädeldach entsprechend dünn, Diploe reichlich vorhanden. Dura mit dem Schädeldach verwachsen. Im Sinus longitudinalis sind reichlich Cruorgerinnsel. Innenfläche der Dura glatt und glänzend, der Blutgehalt ist gering. Die weichen Häute sind nicht getrübt, die subarachnoideale Flüssigkeit kaum vermehrt. Die Piagefă ${ }^{3 e}$, auch an der Basis und in den Fossae Sylvii zart und sehr reichlich gefült. Ventrikellitssigkeit ebenfalls ganz wenig vermehrt; Ependym glatt. Kleinbirn von mittlerem Blutgehalt. Die Hemisphären zeigen capilläre Hyperämie, die Rinde ist rosig grau. Die Zentralganglien sind blasser. Die Schnittfäche ist mäfig feucht, das Gehirn von sehr guter Consistenz und ohne Besonderheiten.

Das Netz ist sebr kurz und fettarm. Die Darmschlingen sind gebläht und außerordentlich blaß, das Peritoneum spiegelnd. Die Leber überragt den Rippenbogen $u m$ drei Fingerbreiten. Zwerchfellstand rechts 4., links 5. Rippe Die Lungen sinken zurück, rom Herzbentel eine mäßige Fläche frei. Die Pleuraböhlen entbalten einige Tropfen klares Serum.

H e rz. Der Herzbentel, dessen Innenfläche glatt und glänzend, enthäit etwa einen ERIöffel voll klare Flüssigkeit. Das Herz ist entsprechend groß, der linke Ventrikel gut contrahiert. Das rechte Herz ist durch reichlich Cruor und wenig flässiges Blut mähig stark ausgedehnt. Die Klappen sind schluffähig und zart. Aorta ohne Besonderheiten. Die Muskulatur blaß, von gleichmäßig braunroter Farbe.

Linke Luage: Volumen etwas, Gewicht beträchtlich vermehrt, besonders im Unterlappen. Die Pleura ist überall glatt und glänzend. Aus dem Bronchus entleert sich auf Druck reichlich schaumige Flüssigkeit; die Schleimbaut ist blaß. Pulmonalis frei. Gewebo des Oberlappens blab granrot, von etwas vermehrtem Saftgehalt; Luftgehalt aberall vorhanden. Der Unterlappen befindet sich im Zustande pneumonischer Infiltration, die Schnittfläche ist glatt, von grauer Farbe.

Rechte Lunge: Volumen und Gewicht vermehrt. Bronchus, Pulmonalis und Pleura wie links. In gleicher Weise sind pneumonisch infiltriert der Mittellappen, der untere Teil des Oberlappens und Teile des Unterlappens; die äbrigen Teile der Lunge sind etwas gebläht und sehr blaß.

Thymus noch erhalten, das sie umgebende Gewebe sehr ödematös. Die Gaumenbögen sind etwas gerötet, die Tonsillen ziemlich stark zerklüftet, etwas geschwollen, gerötet, jedoch sonst kaum verändert. Erheblicher ist die Schleimhaut am Kehlkopfeingang geschwollen und injiziert; der Eingang selbst ist völlig verschlossen. Der Kehldeckel ziemlich derb entzündlich infiltriert. $\mathrm{Zu}$ beiden Seiten desselben und an der Hinterwand des Rachens bis einen Finger breit unterhalb des Kehlkopfes, nach oben etwa bis an den unteren Rand der Tonsillen sich erstreckend, finden sich ziemlich scharfrandige, bis über bohnengrole Geschwüre in der Schleimhaut, deren Grund mit bröckligen weißen Zerfallsmassen belegt ist, die sich nur sehr schwer vollständig beseitigen lassen. Links finden sich deren drei, rechts ein noch größeres. Die Schleimhant des Kehlkopfes selbst und der Trachea ist mit einer weißen Membran bedeckt, die ím Kehlkopf bröcklig ist, in der Trachea dagegen sich leicht von der scheinbar unversehrten und blassen schleimhaut abheben läbt und den Eindruck einer röhrenförmigen croupösen Membran macht. Aus einem Broncbus gewinnt man einen baumartig verzweigten fibrinösen Ausguß von im ganzen über Fingerlänge.

Die ubrigen Organe ohne Besonderheiten.

Diagnosis post mortem: Tracheotomiew unde. Aufmeißelung des linken Warzenfortsatzes. Allgemeine Anämie. Capilläre Hyperämie des Gehirns. Lobuläre Pneumonie. Diphtherie der Rachenschleimhaut; croupöse Membranen im Kehlikopf, der Trachea, Fibrinfäden in den Bronchien.

Sektiondes Schläfenbeins.

Narbeim Trommelfell. Paukenschleimbaut mäBigverdickt; 
in der Paukenhöhle wenig seröse Flüssigkeit. Aditus und Antirum voll frischer Granulationen. Labyrinth intakt.

Epikrise. Der Fall bietet nichts besonders Bemerkenswertes. Es handelte sich um eine gewöhnliche typische Aufmeibelung wegen eines Antrumempyems, deren Heilungsverlauf ein zufriedenstellender war. Die andauernd hohen Temperaturen waren auf eine ausgedehnte Bronchitis zurückzuführen. Das Kind starb schließlich an einer lobulären Pneumonie and einer Diphtherie der tieferen Luftwege.

10. Moritz Böhme, 39 Jahre alt, Musiker aus Kemberg. Aufgenommen am 6. September, gestorben am 19. September 1904 .

A namnese: Patient hat seit seinem 10. Lebensjahre an Ausflub aus dem rechten Ohre und zeitweiligen Schmerzen mit kurzen Unterbrechungen gelitten. Das Ohr ist öfters ärztlich behandelt worden, aber ohne Erfolg. Seit 4 Monaten stärkerer Ausfluß und Schmerzen in der linken Schläfengegend, Schwerhörigkeit hat früher nie bestanden, erst seit 4 Monaten. Kein Schwindel.

Status praesens: Krăftig gebanter Mann in gutem Ernährungszustande. Brust- und Bauchorgane gesund. Augenhintergrund normal. Pupillen gleichweit, reagieren prompt. Kein Nystagmus. Schwindel objektiv nicht nachweisbar. Haut- und Sehnenreflexe normal. Puls kräftig, regelmäßig, 80. Kein Fieber.

Urin frei von Eiweiß und Zucker.

Umgebung des Ohres: Ohne Besonderheiten.

Gehörgang - und Trommelfellbefund: Rechts: Weiter Gehörgang, in der Tiefe etwas stinkender Eiter. An der unteren Gebörgangswand dicht vor dem Trommelfell eine traubenförmige harte Granulation, die zwei Drittel des Gehörgangslumens verschließt. Fom Trommelfell wegen der Granulation nur wenig $\mathbf{z n}$ sehen. Hinten oben Krater mit Eiterstraße. Im Krater rauher Knochen zu fuhlen. Links: Residuen.

Hörprüfung: Flüstersprache rechts direkt, links in $5 \mathrm{~m}$ Entfernung gehört. $C_{1}$ vom Scheitel nach links lateralisiert. Fis 4 rechts herabgesetzt. Rinne rechts -, links + .

Ergebnis bei Catheterismus tubae: Perforationsgeräusch rechts.

Therapie und Krankheisverlauf: 7 . September. Excision der Granulation und Uberweisung an das pathologische Institut wegen Verdacht aut Carcinom.

8. September. Im pathologischen Institut ist die Geschwulst als tuberkulöse Granulationsgeschwulst mit Cholesteatombilang festgestellt worden.

12. September. Totalaufmeibelung rechts. Weichteile und Corticalis normal. Linea temporalis etwas tief stehend. Nach Freilegung von Antrum, Aditus und Kuppelraum alles von schmierigen Granulationsmassen angefülit, kein freier Eiter. Tegmen antri cariös. Bei Freilegung der Dura der mittleren Schädelgrube scheinbare Verletzung der Dura. Es hängt ein ungefähr hirsekorngroßes Gewebsstück von der Dura herab. Dasselbe wird zur mikroskopischen Untersuchung mit der Schere abgetragen. Erweiteruug des jetzt sichtbaren Defektes in der Dura durch Kreuzschnitt mit dem Knopfmesser. Auf der Höhe des horizontalen Bogengangs eine Fistel, aus der kein Eiter quillt. Ossicula nicht vorhanden. Plastik, Bildung eines größeren unteren Lappens. Tamponade, Verband Nach der Operation Facialisparese.

13. September. Das von der Dura stammende Gewebsstück besteht aus tuberkulösem Granulationsgewebe.

21. September. Bisher normaler, fieberfreier Wundverlauf. Seit gestern geringe Schmerzen in der Wunde. Beim heutigen Verbandwechsel profuse Hiterung aus der Paukenhöhle. Schläfenlappenprolaps in der Wunde. Geringes Schwindelgefühl. Augenbefund normal. Puls 87 , regelmäBig, kräftig.
Kein Fieber.

22. September. Beim Verbandwechsel zeigt sich profuse Eiterung aus 
der Tiefe der Operationshöhle, zugleich Abfluß blutig seröser Flüssigkeit, dabei vermehrtes Schwindelgefühl. Foetor ex ore. Appetitlosigkeit. Puls 90 , Temperatur $36,8-37,3^{\circ}$.

23. September. Geringer Nystagmus beim Blick nach links. Schwindel hat nachgelassen. Profuse Eiterung aus dem Hintergrunde der Wunde. Temperatur $36,8-36,8-36,9^{\circ}$, Puls 92 .

26. September. Täglicher Verbandwechsel. Profuse Eiterung. Schläfenlappenprolaps vergrößert sich, so daß er die Fistel überlagert. Appetit gering. Foetor ex ore. Schlafsucht. Temperatur $36,6-36,9^{\circ}$, Puls 80 .

27. September. Auffallende Müdigkeit. Langsame Sprache. Fieberfrei. 28. September. Weite Pupillen, Reaktion derselben normal. Grobe Müdigkeit, geistige Trägheit, geringer Appetit. Puls 68. Temperatur 36,7 $-36,9^{\circ}$.

29. September. Sensorium etwas benommen. Patient macht unrichtige Angaben. Patellarreflexe normal, Cremaster- und Bauchdeckenreflexe etwas herabgesetzt. Augenhintergrund normal. Die Kraft der Hände gleichstark, Sensibilität der Haut der Extremitäten erbalten. Patient klagt jetzt über vorübergehende geringe Kopfschmerzen und Schwindel. Der Hirnprolaps hat sich vergrößert. Profuse Wundeiterung: Temperatur $36,9-36,6^{\circ}$, Puls $67-70-59$.

30. September. Patient macht einen morosen, aber vollständig klaren Eindruck. Keine Störungen in der Sensibilität und Motilität. Reflexe erhalten. Pupillen gleichweit, reagieren prompt; kein Nystagmus. Verband von Eiter durchtrănkt. Beim Aufheben des Hirnprolapses, der den ganzen Hintergrund verlegt, mit der dicken Silbersonde quillt kein Eiter von hinten vor. Temperatur $37,2-36,9$, Puls 62 .

2. Oktober. Am Nachmittage ist Patient leicht desorientiert. Nachdem er sein Bett verlassen hat, legt er sich in ein falsches. Pupillen etwas über mittelweit, reagieren etwas träge. Temperatur $36,3-36,5$, Puls $65-100$.

3. Oktober. Beim Aufheben des Prolapses quillt aus der Tiefe unter hohem Druck stehender Eiter hervor. Der Eiter steht unter so hohem Druck, daß es sich nicht feststellen läßt, ob er aus der Labyrinthfistel oder aus dem Hirnprolaps stammt. Patient verweigert seine Einwilligung zur Vornahme eines operativen Eingriffs. Er ist vollkommen klar. Temperatur $36,5-36,3^{\circ}$, Puls 120 . Wegen der profusen Eiterung täglich zweimaliger Verbandwechsel.

4. Oktober. Verbandswechsel. Der Verband ist ganz mit Eiter durchtränkt. Beim Lösen des Gazestreifens aus dem Gehörgange quillt sofort pulsierender Eiter nach. Nach Abtupfen und Anbeben des Hirnprolapses läßt sich in dem Prolaps eine Fistel feststellen, aus welcher der Eiter kommt. Man gelangt mit der Silbersonde bequem in eine Abszeßhöhle im Schläfenlappen. Wiederfreilegung der alten 0 perationshöhle, welche vollständig von einem kugelförmigen von oben kommenden Hirnprolaps ausgefült ist. An der unteren Fläche des Hirnprolapses eine Fistel, aus welcher sich vor der Operation Eiter entleert hatte and in welcher jetzt die Sonde $6 \mathbf{c m}$ tief eindringt. Die Abszeßhöhle gespalten, erweist sich als leer, wird mit Jod of ormgaze tamponiert.

Temperatur $36,9-36,6-37,1-36,9-36,8^{\circ}$. Puls 114.

5. Oktober. Befinden gut. Patient gibt ganz klare Antworten. Ausdruck der Augen bedentend lebhafter als in den letzten Tagen. Pupillen gleichweit, von guter Reaktion. Reflexe normal. Temperatur 36,6-37,2$37,2-37,1-37,3^{\circ}$. Puls 100 .

7. Oktober. Verbandwechsel. Tampon aus dem Schlăfenlappen vollständig mit Eiter durchtränkt. Es quillt sofort Eiter in großer Menge nach. Pankenhöhle und Bogengangfistel frei. Kein Fieber. Puls 120.

8. Oktober. Aus dem Abszeß kommen nur einige Tropfen Eiter. Der Prolaps ist nicht größer geworden. Mittelohr vollständig frei vom Eiter, gut übersichtlich.

9. Oktober. Keine Eiterung aus dem Mirnabszeß. Klage über geringe Stirnkopfschmerzen. Eisblase. Temperatur $37,9-38,0-37,9-37,7-37,4^{0}$. 
10. Oktober-16. Oktober. Bis auf geringe Stirnkopfschmerzen Befinden gut. Wunde sieht gut aus. Aus dem Hirnabszeß keine Eiterung. 17. Oktober Klagen über stärkere Kopfschmerzen. Pupillen über mittelweit, reagieren etwas träge. Patellarreflexe gesteigert, Fußklonus. Patient ist wieder stark moros. Er liest die Zeit von der Taschenuhr zuerst falsch ab, auf Zureden verbessert er sich. Am Abend behauptet er, es sei Vormittag. Er hat vergessen, daß or am Vormittag verbunden ist. Starker Foetor ex ore. Temperatur 36,7-39,0-39,0-39,4-39,1-39,5. Puls $96-84$.

18. Oktober. In der Nacht einmal Erbrechen, sonst ruhig. Klagen ñber sehr heftige Kopfschmerzen. Lumbalpunktion: Punctio sicca, trotzdem man zweifellos in den Spinalkanal gekommen war. Trepanation a $\mathrm{f}$ den Schläfenlappen von der Seite her und breite Eröffnung der Abszeßhöhle. Man kann 2 Glieder des kleinen Fingers einfübren. Höhle leer. Trepanation auf das Kleinhirn. Bei Eroffnung der Dura mit der Paracentesennadel quillt in kräftigem Strahle anscheinend getrübte Cerebrospinalflüssigkeit hervor. Spaltung der Dura und Eingehen mit dem Messer in das Kleinhirn. Pus non inventum.

Nach der Operation läßt Patient einmal Urin unter sich. Patient liegt. rubig da. Einige Male Zuckungen in beiden Armen. Auf Anrufen offnet er die Augen, antwortet aber nicht. Pupillen über mittelweit, reagieren träge. Kein Nystagmus. Patellarreflexe gesteigert, Cremasterreflexe erhalten, Bauchdeckenreflexe erJoschen. Kein Opisthotonus. Temperatur 39,5-38,1 $-39,0-38,4-38,3-38,4^{\circ}$.

19. Oktober. Temperatur $39,1-40,0-44,2^{\circ}$. Puls sehr klein, unregelmäßig, 136. Atmung oberfächlich, 36. In der Nacht zunehmende Onruhe, mehrmaliges Erbrechen. Pupillen über mittelweit, reaktionslos. Patient liegt. im tiefen Coma, läßt mehrmals Urin unter sich. Exitus $6 \mathrm{Uhr}$ p. m.

Sektionsprotokoll.

Männliche, mäßig kräftige Leiche. Totenstarre und Flecke vorhanden.

Am Wirbelkanal keine Veränderungen. Der untere Teil des Duralsackes ist etwas aufgetrieben. Nirgends abnorme Injektion. Die Innenfläche der Dura ist bla\}, aber im ganzen Verlauf des Rückenmarks durch zarte Auflagerungen getrübt. Die Arachnoidea ist ebenfalls in ganzer Ausdehnung von eitrig gallertigen Massen durchsetzt. Die Konsistenz des Rückenmarkes ist schlecht, besonders nach dem Brustmark zu zerfließt das Rückenmark fast. Die Zeichnung hierselbst und in der näheren Umgebung völlig verwaschen. Die graue Substanz ist etwas byperämisch.

$\mathrm{Sch}$ äd eld a c h entsprechend dick, von der Diploe nur wenig vorhanden. Dura hyperämisch, von erhöhter Spannung. Im Sinus longitudinalis superior reichlich Cruor, Speckgerinnsel und fiüssiges Blut. In der Wand des Sinus kleine Pacchioniscbe Granulationen. Innenfläche der Dura etwas matt, trocken, injiziert. Weiche Hirnbäute ebenfalls trocken und matt. Subarachnoidealräume fast verstrichen. Nirgends an der Konvexität Trübungen. Die Gyri sind stark abgeplattet, die Sulci sehr flach. An der Basis des Hirns, besonders am Kleinbirn links, finden sich zahlreiche eitrige Massen intrameningeal. Der rechte Schläfenlappen ist durch einen Gazestreifen tamponiert, der tief in das Gewebe hineingeht. Bei Eröffnung der Ventrikel zeigen sich diese durch trübe eitrige Flüssigkeit erweitert. Ependym ebenfalls getrübt. Außerdem finden sich subependymale punktförmige Blutaustritte. Die Umgebung der Ventrikel ist sehr weich, der oben erwähnte drainierte Schläfenlappenabszeß geht tief in das Gewebe hinein und ist nur durch eine geringe Menge erweichter Hirnsubstanz von den Großhirnkernen getrennt. Die Gefäße der Basis sind zart, insbesondere an denen der Art. Fossae Sy]vii nirgends Trübungsn oder Knötchen. Mit Ausnahme der Substanz um den AbszeB herum zeigt das Hirn eine gute Konsistenz, mittleren Blutgebalt Großhirnganglien ziemlich gut gezeichnet, desgleichen Kleinhirn etc. Medulla ist in den Wirbelkanal etwas hineingetrieben. Die Sinus der Basis sind frei.

Fettpolster des Abdomens $3 \mathrm{~cm}$. Das ziemlich fettreiche Netz im 
oberen Drittel des Abdomen. Darmserosa glatt und glänzend. Kein abnormer Inhalt in der Bauchböhle. Zwerchfellstand links 4, rechts 3. Rippe. Die linke Lunge collabiert mehr wie die rechte. Die linke Lunge nur hinten und oben, die rechte in größerer Ausdebnung mit der Brustwand verwachsen Kein fremder Inhalt in den Pleurahöhlen. Der Herzbeutel liegt in mäßiger Ausdehnung frei. Innenfläche glatt und glänzend. Inhalt ungefähr ein Teelöffel klaren gelblichen serums.

Horz entsprechend groß, ziemlich gut kontrahiert. Epicardiales Fett mäßig. Tricuspidalis für 3 , Mitralis für 2 Finger durchgängig. Im Herzen viel flüssiges dunkles Blut, wenig Speckgerinnsel. Gesamter Klappenapparat des Herzens intakt. Arterielle Klappen schlußfähig. Elastizität der Aorta etwas reduziert. Intima der Aorta sowie der Coronararterien zeigt geringe wulstige Verdickungen. Herzmuskel von blaß braunroter Farbe, etwas gefleckt.

Linke Lunge von etwas vermehrtem Volumen, stärker vermehrtem Gewicht. Aus dem Bronchus, dessen Schleimbaut intensiv violett injiziert ist, entleert sich auf Druck trübe, etwas schaumige Flüssigkeit. Pulmonalis frei. Pleura im großen und ganzen glatt und glänzend. Im Lungenparenchym, besonders im Oberlappen, fühlt man unnachgiebige Knoten. Oberlappen an seiner Spitze narbig eingezogen. Um eine schwielige Induration herum findet sich eine Aussaat von miliaren einzelstehenden Knötchen. Auch im ganzen Oberlappen verstreut finden sich Knötchen von derselben Beschaffenheit. Blut- und Saftgehalt im Oberlappen beträcbtlich erhönt. An einzelnen Stellen des Oberlappens sind die Knötchen zu größeren Herden konfluiert. Unterlappen zeigt erhöhten Blut- und Saftgehalt. Auch im Unterlappen vereinzelte Knötchen.

Rechte Lunge ist an der Spitze eingesunken Bronchus, Pulmonalis und Pleura wie links, doch sind die Verwachsungen der letzeren weitaus stärker. Oberlappen in seiner oberen Hälfte von einer mehrkammerigen Caverne eingenommen, deren Wandungen zerklüftet und stellenweis von einer eitrigen Membran bedeckt ist. Der übrige Teil gleicht, wie der Mittellappen, der anderen Seite. In beiden Unterlappen finden sich neben der Hyperämie und den Knötchen mehrere erbsengroße verkäste Herde. Bronchiale Lymphknoten vergrößert, pigmentiert, induriert.

Im unteren $D$ ä nu darm sind die follikel leicht geschwollen und oberhalb der Klappe findet sich ein kleines quergestelltes hämorrhagisches Geschwür. Dicht darüber eine leicht pigmentierte narbige Einziehung.

Die übrigen Organe ohne Besonderheiten.

Diagnosis post mortem: Meningitis purulenta spinalis. Myelitis transversa acuta. Meningitis purulenta basilaris. Pyocephalus. Schläfenlappenabsel. Altere und frischere Tuberkulose der Lungen. Tuberkulöses Darmgeschwür. Kadaveröse Magenerweiterung.

Sektion des Schläfenbeins.

Sämtliche Sinus frei. Fistel im horizontalen Logengang. Im Labyrinth mäßig getrübte Flüssigkeit. Steigbügeĺfest i m ovalen Fenster.

Epikrise: Wir hielten anfangs die Granulationsgesehwulst, welche wir im Gehörgange sahen, fïr einen carcinomatösen Tumor. Die mikroskopisehe Untersuchung ließ aber tuberkulöses Granulationsgewebe mit Cholesteatombildung feststellen. Bei der Totalaufmeißlung fanden wir eine ausgedehnte Caries sämtlicher Mittelohrräume, welche uns zwang, die Dura der mittleren Schädelgrube freizulegen. Hierbei hatte anseheinend der Operateur das Milogeschick, die Dura zu verletzen, denn wir bemerkten, daß von derselben ein Stüek Gewebe herabbing. Zur Sicherstellung, ob wir es tatsächlich mit einer Verletzung. 
der Dura zu tun hatten oder ob es sich auch um eine tuberkuIöse Granulation handelte, entfernten wir das betreffende Gewebsstilick und übergaben es dem pathologischen Institnt zur mikroskopisehen Untersuchung. - Nach einer Mitteilung aus dem pathologischen Institut bestand das nntersuchte Gewebsstïck ebenso wie der aus dem Gehörgange stammende Tumor aus tuberkulösem Granulationsgewebe. - Den jetzt in der Dura sichtbaren Substanzverlust vergröBerten wir zur Sicherheit durch einen Kreuzsehnitt mit dem geknöpftem Messer, wie wir es in allen Fällen von vermeintlicher Duraverletzung bei der Operation zu tun pflegen.

Der Wundverlauf war in der ersten Zeit ein vollständig zufriedenstellender, abgesehen von dem allmählich eintretenden Prolaps der Hirnsubstanz durch die Öffnung in der Dura, welcher sich aber in so bescheidenen Grenzen hielt, daß wir ihm zunächst keine ernstere Bedeutung beimaßen. 9 Tage nach der Operation klagte der Patient wieder uber Kopfsehmerzen und mäBigen Schwindel. Beim Verbandwechsel fanden wir eine profuse Eiterung ans der Operationshöble. Anfangs glaubten wir, daß wir es mit einer Eiterung im Labyrinth zu tun hatten und erst am 4. Oktober konnten wir mit Sicherheit feststellen, daß der Eiter aus dem Schläfenlappenprolaps stammte. Die Eiterung war so profus, daß der Verband morgens vom Eiter vollständig durchtränkt war und daß wir genötigt waren, denselben täglich zweimal zu wechseln.

In der zweiten Hälfte des September zeigte der Patient so unbestimmte Kopfsymptome, daß wir uns nicht berechtigt glaubten, einen weiteren operativen Eingriff vorzunehmen. Als es aber immer klarer wurde, daß es sich bei der Eiterung aus der Tiefe der Wundhöhle um eine Eiternng aus dem Hirn handelte und wir dem Kranken einen neuen operativen Eingriff vorschlugen, band er uns durch seine Verweigerung der Operation die Hände. Erst später gab er dann seine Einwilligung zur Operation.

Wir legten den Sohläfenlappen von unten ans frei und fanden einen sehr großen Abszeß in ihm.

In den nächsten zwei Wochen scbien sich auch der Zustand des Patienten bedeutend zn bessern. Als er dann aber wieder über heftigere Kopfschmerzen klagte, sein Sensorium etwas benommen war und seine bis dahin normale Körpertemperatur bis auf $39,4^{0}$ stieg, mußten wir damit rechnen, daß entweder 
noch ein zweiter Hirnabszeß vorlag oder daß von dem alten. Abszeß her eine eitrige Leptomeningitis hervorgerufen war.

Da die Lumbalpunktion eine Punetio sieca war, konnten wir in differentialdiagnostiseher Beziehung keinen Aufsehlub bekommen. Wir fahndeten in erster Linie auf den vermuteten zweiten Abszeß. Wir legten den Schläfenlappen von der Seite aus in großer Ausdehnnng frei und als wir nach sorgfältiger Exploration desselben keinen zweiten AbszeB fanden, suchten wir auch im Kleinhirn nach einem solchen, aber vergeblich.

Nach der Operation verschlechterte sich der Zustand des Patienten immer mehr. Im Laufe des Tages nahm die Benommenheit stetig zu, um in der Nacht in völliges Coma überzugehen, der Patient ließ öfter Urin unter sich, die Pupillen wurden reaktionslos. Der Tod trat am Tage nach der Operation ein und zwar an diffuser eitriger Leptomeningitis, welehe dureb eine Ventrikelmeningitis vermittelt worden war.

Bei der Sektion des Schläfenbeins fanden wir nur eine geringe Trübung der Labyrinthflüssigkeit. Hätte die nach der ersten Operation beobachtete profuse Eiterung in der Tiefe der Operationswunde aus dem Labyrinth gestammt, so wäre sicherlich von derselben nicht mehr viel bei der Sektion zu finden gewesen. Was nun den Sehläfenlappenabszeß anbetrifft, so ist derselbe von der Caries des Tegmen antri ausgegangen. Die Dura zeigte an dieser Stelle die tuberkulöse Granulation und von hier aus war eine Infektion des Schläfenlappens per contiguitatem erfolgt. Wenn wir auch nicht eine direkte Wegleitung vom Hirnabszeb in den Ventrikel finden konnten, so war doch das Gewebe zwischen Ventrikel und Abszeßwand so erweicht, daß wohl sicher von hier aus die Ventrikelmeningitis und weiter die diffuse eitrige Leptomeningitis ihren Weg genommen hat.

11. Ro bert Trümper, 10 Jahre alt, Bergmannssohn aus Westeregeln. Aufgenommen am 21. Oktober 1904, gestorben am 2. November 1904.

Anamnese: Patient ist bereits im Jahre 1901 wegen einer rechtsseitigen akuten Eiterung in der hiesigen Poliklinik behandelt worden und als geheilt entlassen worden.

Seit 9 Tagen klagt Patient über Schwindelgefühl, seit 5 Tagen über Schmerzen in der linken Kopfseite mit dumpfem Sausen im Ohre. In den letzten 4 Tagen Erbrechen. Ein zu Rate gezogener Arzt verordnete einen Blutegel hinter das $0 \mathrm{hr}$.

Status praesens: Schlanker Knabe in mittlerem Ernăhrungszustand. Lungen freí. Herztöne rein. Puls kräftig, regelmäßig, 110. Temperatur $38,5^{\circ}$. Keine Milzvergrößerung. Augenhintergrund normal. Pupillen gleichweit, reagieren prompt. Oscillierender Nystagmus beim Blick nach rechts, Sensibilität und Motilităt erhalten. Bauchdecken- und Cremaster- 
reflexe erhalten. patellarreflexe fehlen. Schwindel objektiv nachweisbar; Patient schwankt beim Stehen mit geschlossenen Augen stark nach links. Urin frei von Eiweiß und Zucker.

Umgebung des Ohres: Über dem Planum mastoideum kein Oedem und keine Drackemptindlichkeit. An der Spitze des Warzenfortsatzes ein Blutegelstich. Geschwellte und druckempfindliche Lymphkn oten am Kieferwinkel.

Gehörgang* und Trommelfellbefund: Rechts: Hinten oben trockene Perforation.

L i n ks: Gehörgang gerötet und mäßig geschwellt. Trommelfell stark gerötet; vorn unten quillt reichlich foetider Eiter hervor. Vorn oben eine kleine Granulation.

$\mathrm{H}$ ö r prü fu ng: Flüstersprache rechts in $10 \mathrm{~cm}$ Entfernung, links direkt nichts gehört. $\mathrm{C}_{1}$ nach rechts lateralisiert. Fis 4 rechts normal, links bei Metallanschlag.

Therapie und Krankheitsverlauf: 22. Oktober. Lumbalpunktion: Cerebro-Spinalfiussigkeit kristallklar.

Totala ufmeifolung: Weichteile und Corticalis normal. Bei den ersten Meißelschlägen quillt Eiter von vorn unten hervor. Großes zerfallenes Cholesteatom freigelegt und entfernt. Fistel im horizontalen Bogen, kein Eiter in ihr. Dänner foetider Eiter quillt sowohl von oben hinten und unten aus der Schädelhöhle. Extraduraler Abszeß hinten oben. Dura von dickem etwas mißfarbenem Polster bedeckt; hier keine Fistel in der Vura. Dura bis ins Gesunde freigelegt. Extrasinnöser Abszeß. Bei weiterer Freilegung des Sinus mit der Knochenzange Sinusverletzung und starke Blutung, die auf Tamponade steht. Beim Abheben der Dura ron der hinteren Pyramidenfläche quillt dünne braungelbe Jauche hervor. In der Dura eine Fistel. Durch die Fistel gelangt man mit der Sonde nach hinten unten in eine große aber leere Kleinhirnabszeßhöble, welche nach Erweiterung der Eingangsöffnung von der Ohroperationshöhle aus mit Jodoformgaze tamponiert wird. Während der Operation einmal Facialisspasmas. Spaltung, Verband.

Nach der Operation Kopfschmerzen besser. Temperatur $38,3^{\circ}-38,3^{\circ}-$ $37,1^{\circ}-38,0^{\circ}-37,5^{\circ}-38,5^{\circ}$. Puls $132-101-86-116$.

23. Oktober. Patient hat in der Nacht sehr gut geschlafen. Sensorium frei. Reflexe unverändert.

Verbandwechsel: Paukenhöhle frei. Aus dem Abszeß entleeren sich einige Tropfen freien Eiters. Temperatur $37,5^{\circ}-37,5^{\circ}-37,3^{\circ}-37,2^{\circ}-$ $37,3^{\circ}-37,0^{\circ}$. Puls $72-90$. $96-72$

24. Oktober. Temperatur $37,1^{0}-37,2^{0}-36,8^{\circ}-36,8^{\circ}-37,0^{\circ}$. Puls

25. Oktober. Allgemeinbefinden sehr gut. Nahrungsaufnahme zufriedenstellend. Kein Nystagmus. Beim Verbandwechsel wird in der Kleinhirnabszeßhöhle kein freier Eiter gefunden. Temperatur $37,5^{\circ}-37,3^{\circ}-$ $36,9^{\circ}-36,7^{\circ}-37,3^{\circ}$. Puls $88-76$.

26. Oktober. Temperatur $37,0^{\circ}-36,5^{\circ}-36,7^{\circ}-37,1^{\circ}$. Puls $88-76$.

28. Oktober. Befinden gut. Keine Kopfschmerzen mehr. Der Versuch, den im verletzten Sinus steckenden Tampon zu lösen, gelingt nicht, da der Tampon sebr fest sitzt. Der in die Wundhöhle ragende Teil des Tampons wird mit der Scheere entfernt. Temperatur $37^{\circ}, 1^{\circ}-37,0^{\circ}-36,66^{\circ}-37,7^{\circ}$. Puls 92-76.

28. Oktober. Morgentemperatur gegen 6 Uhr $39,3^{\circ}$. Verbandwechsel. Der Tampon im Sinus sieht milfarben aus und stinkt. Bei Entfernung des Tampons im Sinus dünntlüssiger mißfarbener Eiter. Jugularisunterbindung. Sinusoperation. Weitere Ereilegung des Sinus nach dem Bulbus zu. Spaltung des völlig thrombosierten Sinus. Entfernung der eitrig zerfallenen Thrombenmassen mit dem Löffel. Vom Sinus transversus her mäßige Blutung, vom Bulbus her keine.

Nach der Operation große Schwăche. Patient trinkt mehrere Tassen Milch und heilen Wein. Darauf erholt er sich wieder etwas. Sensorium vollständig frei. Augenhintergrund normal. Reflexe unverändert. Rohe Kraft erhalten. Temperatur $37^{7} 7^{0}-38,1^{\circ}-38,6^{\circ}-37,3^{6}-37,4^{\circ}$. Puls $96-128$. 
29. Oktober. Temperatur $36.8^{\circ}-37,3^{\circ}-39,1^{0}-37,9^{\circ}-37,8$. Puls $98-101$.

30. Oktober. Temperatur $37,8^{\circ}-38,6^{\circ}-38,3^{\circ}-38,6^{\circ}-38,7^{\circ}$. Puls 84 .

Verbandwechsel: Lösung der Sinustampons. Vom Sinus transversus her geringe Blutung. Der zentrale Sinus ist frei von Sekret, auch bei Druck auf die Jugularis bemerkt man kein Sekret im Sinus.

Sensorium frei. Appetit gut.

31. Oktober. Morgentemperatur $38,7^{\circ}$. Spaltung der Jugularis äber der Unterbindungsstelle und Versuch einex Durchspülung nach oben. Dieselbe gelingt gut, es werden mehrere gröfere Thrombenstucken durch die Spülfü̈ssigkeit entfernt. Temperatur $38,0^{\circ}-39,1^{\circ}-39,7^{\circ}-39,3^{\circ}-40,1^{\circ}-$ $39,2^{\circ}$. Puls $96-102$.

1. November. In der Nacht läßt Patient einmal Urin unter sich. Am Morgen liegt er apathisch da. Trepanation auf das Kleinhirn und weite Freilegung desselben vonder Schädelbasisher. Spaltung der Dura und des Abszesses. Abszel leer. Am Nachmittage zunehmende Somnolenz. Pupillenreaktion träge. Patient läst Urin unter sich. Temperatur $39,0^{\circ}-38,5^{\circ}-37,8^{\circ}-37,5^{\circ}-37^{3}, 3^{\circ}-37,4^{\circ}$. Puls $116-120$.

2. November. Patient liegt in tiefem Coma. Pupillen über mittelweit, starr. Patient läßt Stuhl und Urin unter sicb. Atmung oberflächlich, 24 . Puls $116-108$.

Temperatur $38,4^{\circ}-39,2^{\circ}-40,1^{\circ}-40,7^{\circ}$.

Tod gegen Abend.

Sektionsprotokoll.

Jugendliche männliche Leiche in mäßìg gutem Ernährungszustande. Totenstarre und Flecken vorhanden. In der Umgebung des linken Proc. mastoid. findet sich eine gr oße Trepanationswunde. Die Wunde ist tamponiert. Nach Herausnahme der Tampons erscheint ein prolabirender Teil des Kleinhirns. An der linken Halsseite, am vorderen Rande des Sterno-cleidomastoidens eine $z$ weite reaktionslose Wunde. Darmserosa glänzend; kein fremder Inbalt im Abdomen. Zwerchfellstand beiderseits IV. Intercostalraum. Lungen collabiren, kein fremder Inbalt in den Pleuraböhlen. Herzbeutel liegt in der Ausdehnung eines Handtellers trei. Seine Innenfläche glatt und glänzend. Inhalt einige Tropten klares Serum.

Gebirn: Schädeldach ziemlich dunn, mit der Dura etwas verwachsen. Dura etwas gespannt, von normaler Dicke. Im Sinus longitudinalis wenig geronnenes Blut. Innenfläche der Dura trocken. Weiche Hāute nicht getrübt. Suberachnoideale Flüssigkeit nicht vermehrt Die Gefäße der Pia nur wenig injizirt. Gyri stark abgeplattet. Basis und Fossa Sylvii ohne Besonderheit. Die Ventrikel etwas erweitert, ihr klarer Inhalt war wenig vermehrt. Ependym glatt. Auf der Oberfäche des Kleinhirns sind die weichen Hirnhäute gelblich verfärbt und einige hirsekorngroBe Fibrinfocken liegen auf. Das Kleinhirn ist etwas vergrößert. Die bintere Hälfte der linken Hemisphäre ist in einen Abszeß verwandelt, der sich zur Operationswunde bin offtnet. Die vordere Hälfte ist im Zentrum erweicht. Zwischen beiden befindet sich ein $1 / 2 \mathrm{~cm}$ breiter hämorrhagischer Streifen. Großhirn von guter Consistenz; mittlere Partien wieder etwas weicher. Schnittläebe anämisch und feucht.

Racben und Halsorgane: Schleimhaut blaß. Tonsillen vergrößert und beide besonders rechts mit Eiter durchsetzt, sonst ohne Besonderheit

Milz: $12: 71 / 2: 3 \mathrm{~cm}$. Oberfläche glatt, bellviolett. Parenchym hellbraunrot, Follikel vergrößert, Trabekel ziemlich deutlich, Consistenz ein wenig weich.

Linke Niere entsprechend grob, fibröse Kapsel leicht löslich. Das umgebende Gewebe etwas durchblutet Oberfläche glatt, Parenchym etwas dunkelrot, Pyramiden etwas dunkler. Zeichnung dentlich. Parenchym quillt etwas hervor. Nierenbecken obne Besonderheit.

Rechte Niere gleicht der linken.

Da rmschleimhaut größtenteils blaß. In den unteren Teilen des Dünndarms finden sich reichliche injizierte Stellen, zum Coecum bin ziemlich ausgedehnte Blutungen. 
Die übrigen Organe ohne Besconderheit.

Diagnosis post mortem: Kleinhirnabszeß. Circumscripte fibrinös-eitrige Leptomeningitis an der Oberflache desKleinhirns. Hirndruck, Hydrocephalus internus. Anamie und ôdem des Gehirns. Unterbindung der linken Vena jugularis. Mäßiges Lungenödem. Abszedierende Angina tonsillaris. Septischer Milatumor. Mäßige Blutungen in der Umgebung der linken Niere und in der Schleimhaut des Ileum.

Sektion des Schläfenbeins.

Sinus sigmoideus vom Sinus transversus bis $1^{1 / 2} \mathrm{~cm}$ ron dem Bulbus venae jugularis eitrig infiltriert. Innenwand des Bulbus venae jugularis braunot verfarbt; im Bulbus einige schwarz-rote Thrombustücke. Die übrigen Sinus frei. Fistel im horizontalen Bogengang. Labyrinthwasser klar.

Epikrise. Der Patient zeigte bei seiner Aufnahme Symptome, welehe wir sowohl auf eine Beteiligung des Labyrinths allein, als auch auf eine schon bestehende intraeranielle Complication, Hirnabszef oder eitrige Leptomeningitis, zurückführen konnten. Die Symptome bestanden in halbseitigem Kopfschmerz, Schwindel, Nystagmus, Erbrechen und Temperatursteigerung. Das Ergebnis der Lumbalpunktion, kristallklarer Liquor eerebrospinalis, lieb eine diffuse eitrige Leptomeningitis ausschließen. Bei der Operation fanden wir außer einer Bogengangfistel größere extradurale Eiteransammlungen in der mittleren Schädelgrube und in der hinteren am Sinus sigmoidus und weiter noeh in der Tiefe. An letzterer Stelle konnten wir auch eine Fistel entdecken, welche in einen Kleinhirnabszeß führte. Wir legten den Abszeß von der Operationshöble aus frei und tamponierten ihn. Während der Operation kam beim Abkneifen der Sulcuswand mit der Knochenzange durch eine Splitterverletzung eine Sinusblutung zu Stande, welche aber auf Tamponade sofort stand.

Gleich nach der Operation konnten wir eine deutliche Besserung im Befinden des Kranken konstatieren, denn die Kopfschmerzen, thber welche er bei der Aufnahme sehr geklagt hatte, waren fast vollständig geschwunden. Diese Besserung machte in deu nächsten Tegen zusehends Fortsehritte. Die Temperaturen blieben normal, Nystagmus, Kopfschmerzen und Schwindelgefühl hörten gänzlich auf. Der Versuch, den im verletzten Sinus steckenden Tampon am.7. Tage nach der Operation zu lösen, gelang noch nicht; das in der Wundhöhle hängende Stück des Tampons entfernten wir mit der Scheere, da es durch Beeinträchtigung der Übersichtlichkeit die Behandlung der Operationswunde und besonders der Abszebhöhle erschwerte. Am nächsten. Morgen trat plötzlich eine Temperatursteigerung auf $39,3^{\circ}$ ein. Als wir an diesem Tage den Tampon aus dem Sinus lösten, fanden

Archí f. Ohrenheilkunde. Bd. LXV. 
wir in letzterem dünnflüssigen mißfarbenen Eiter, während der Tampon selbst einen sehr üblen Geruch zeigte. Wir fanden hier also die Erklärung für die Temperatursteigerung. Bei der nun folgenden Sinusoperation fanden wir reichliche Mengen eitrig zerfallener Thromben. Fragen wir uns nun, woher die so späte infectiöse Thrombose des Sinus sigmoideus gekommen ist, so scheint folgende Erklärung etwas für sich zu haben. Der in dem verletzten Sinus steckende Tampon wurde ununterbrochen von dem aus dem Kleinhirnabszeß in seiner Nähe kommenden Eiter überrieselt. Bei der Entfernung des überflüssigen Teiles des Tampons mit der Scheere, welehe bekanntlich nicht schneidet, sondern quetscht, wurde nun das infectiöse Material direkt in den bis dahin gutartigen Thrombus hineingepreßt. Auch der Umstand, daß das Fieber ungefähr 20 Stunden nach dem vorhergehenden Verbandswechsel aufgetreten war, läßt sich mit unserer Annahme gut in Einklang bringen.

Nach der Sinusoperation fiel das Fieber wieder sichtlich ab. Als aber zwei Tage später wiederum Temperatursteigerungen auftraten, nahmen wir an, daß sich im Bulbus venae jugularis, aus dem wir bei der Sinusoperation keine Blutung erzielt hatten, noch Infectionsstoffe befänden. Eine Durchspülung durch die Vena jugularis gelang uns gut; wir beförderten so noch mehrere größere Thrombenpartikel aus dem Bulbus.

Als trotzdem auch jetzt kein Temperaturabfall eintrat, mußten wir die Ursache für das Fieber an anderer Stelle suchen. Bei der Eröffnung des Kleinhirnabszesses waren wir ausnahmsweise gleich von der Operationshöble und nicht von der Schädelbasis aus vorgegangen. Vielleicht war also hierdurch eine weniger günstige Abflubedingung geschaffen worden, so daß die Möglichkeit einer Retention von Sekret in der Abszeßhöhle vorliegen konnte. Aus diesem Grunde gingen wir noch einmal von der Schädelbasis aus gegen das Kleinhirn vor, fanden den Cerebellarabscess aber vollständig leer.

Das Befinden des Patienten wurde aber von Stunde zu Stunde schlechter; es trat bald Somnolenz auf, welche in vollständiges Coma überging, er ließ Urin unter sich, die Pupillen wurden reaktionslos. Der Tod trat am nächsten Tage ein.

Der Kranke ist, wie die Sektion ergab, nicht an den Folgen des Hirnabszesses gestorben, denn außer einer geringen circumseripten Meningitis in der Nachbarsehaft desselben fanden wir 
keine Veränderung am Gehirn. Der Tod ist vielmehr an der von der sekundären Sinusthrombose induzierten Sepsis erfolgt.

12. Marie Bendler, 24 Jahre alt, aus Blankenburg a. H. Aufgenommen am 19. November 1904 , gestorben am 23. Novomber 1904.

Anamnese: Chronische Eiterung beiderseits seit Jahren. Ursache unbekannt. Jetzt diffuser Kopfschmerz, Schmerz hinter dem rechten Ohre. Patientin ist seit etwa 14 Tagen poliklinisch behandelt worden.

Status praesens: Temperatur $40,1^{\circ}$, Puls 120 , Atmung 30 . Kräftig, gut genährt. Hautdecken etwas schlaff und trocken. Herz und Lungen ohne Besonderheiten. Somnolenz.

Umgebung des rechten Ohres: Druckemptindlichkeit über der Spitze des proc. mast. Hautdecken ohne Besonderheiten.

Gebörgang- und Trommelfell lbefund: Gehörgang weit. Beiderseits zentrale Perforation von je etwa Linsengröße. Paukenhöhlenschleimhaut gerötet und geschwellt, Sekretion mäßig stark, njcht foetid.

Hörprüfung: Die somnolente Patientin ist selbst für Konversationssprache schwerhörig and versteht nur Lautgesprochenes.

19. November. Temperatur $40,1,40,7,40,4,40,4$. Mäbige Somnolenz, diffuser Kopfschmerz. 1. Halswirbel druckempfindlich. Schmerz beim Drehen des Kopfes. Pupillen reagieren prompt. Beiderseits Nystagmus leichten Grades nach beiden Seiten. Bauchdecken- und Patellarreflexe normal.

20. November. Temperatur 40,5,40,7,40,4, 40,5,40,3, 39,5, 39,5 . Die rechte Pupille etwas weiter als die linke. Patellarreflexe abgeschwächt. Empfindlichkeit des Nackens stârker, bis zum 4. Halswirbel herabreichend. L $\mathrm{nmbalpunktion} \mathrm{ergibt} \mathrm{unter} \mathrm{mäßig} \mathrm{erböhtem} \mathrm{Druck} \mathrm{stehenden,} \mathrm{kristall-}$ klaren Liquor, der "abgesehen von einer geringen Verunreinigung steril ist." $\mathrm{A}$ bends Puls 116, Atmung 23, Sensoriumfreier, etwas verlangsamte Leitung. Der Kopfschmerz ist nach der Punktion wesentlich geringer geworden. Patellarreflex rechts erloschen, links nur angedeutet, Bauchdeckenreflex nicht nachweisbar. Zunge weniger trocken, oedematös. Foetor ex ore. Keine allgemeine Hyperaesthesie. Augenhintergrund normal. Pupillen reagieren prompt. Kein Milz- oder Lebertumor. Appetitlos. Obstipation, Empfindlichkeit des Nackens wie am Vormittage.

21. November. Temperatur $39,9,39,9,38,8,38,6,38,7,38,9,39,0^{\circ}$.

Totalaufmeiblung rechts, Trepanation auf das Kleinhirn. Weichteile und Corticalisoberfäche von normalem Aussehen. Der ganze Warzenfortsatz besteht aus elfenbeinhartem, osteosklerotischem Knochen, Antrum erhalten, mit schmierigem, schwärzlich-gränem Kiter gefullt. Aditus und Atticwandungen sind größtenteils zerfressen. Vom Antrum aus, dicht hinter dem Facialiskanal, eine Anzahl mit schwarz-grünem Sekret gefüllter Zellen in die Tiefe führend. Die unterste Zelle ist erbsengroß und hat ulceröse Wandungen.

Sinus und Dura der mittleren Schädelgrube freigelegt, beide von normalem Anssehen. Trepanation a u das Kleinhirn. Kleinhirndura, von normalem Aussehen, wird durch einen Krenzschnitt gespalten. Meningen stärker injiziert, jedoch ohne Belag. Kein nennenswerter Abfluß von Liquor Punktion des Kleinhirns ergibt keinen Eiter, Tamponade.

22. November. Temperatur $39,1,39,0,39,8,39,7,39,5,40,2,39,5$. Die Kranke ist sehr unklar, Halluzinationen angenehmen Charakters. Auf energische Fragen gibt sie jedoch Antworten. Kein Erbrechen, Stuhlgang auf Einlauf, Urin spontan, Pupillen sehr weit, reagieren schwach aber prompt. Augenhintergrund normal. Patellarreflexe fehlen, Bauchdeckenreflexe angedeutet. Strabismus durch Paresen beider Abdncens. Starker Nystagmus. Schmerzen im linken Arm, Gelenke jedoch gut und ohne Schmerz beweglich. Sonst keine Hyperästhesie.

23. November. Temperatur $39,5,39,9,40,3,40, \tilde{y}, 40,7,42,0$. Sensorium 
völlig getrübt, Patientin läßt unter sich, phantasiert beständig. Starker Nystagmus, weite, fast reaktionslose Pupillen. Abends exitus letalis.

Sektionsprotokolla uszug. Weibliche kräftige Leiche, Hautfarbe blaß, Starre und Totenflecke vorhanden. Hinter dem rechten Ohre eine etwa $6 \mathrm{~cm}$ lange, tamponierte Trepanationswunde. Wirbelkanal ohne Veränderung, die spannung der Dura spinalis kaum erhöht. Die Innenfläche der Dura spinalis ist etwas trübe und mit der Arachnoidea teilweise zart verklebt. Die Subarachnoidealräume sind besonders in der Brustmarkgegend durch eitrig sulzige Massen ausgefült, sodal die weichen Häute dadurch getrübt erscheinen. Die Piavenen sind stärker gefällt, besonders in der Lendenmarkgegend. Die sulzigen Massen in den Subarachnoidealräumen sind von fester Consistenz. Nirgends lät sich freier Eiter herausdrücken. Die graue Substanz, insbesondere die Vorderbörner im Lendenmark etwas rosig gefärbt, sonst ohne Veränderungen. Die weiße Substanz blaß und von guter Konsistenz.

Schädeldach entsprechend dick, Diploe mäßig dentlich und von mittlerem Blatgehalt. Die Dura des Gehirns ist etwas byperâmisch und zeigt in den hinteren Partien etwas vermehrte Spannung. Das Schädeldach ist längs des Sinus longitudinalis superior mit der Dura verwachsen. Im Sinus longitudinalis reichlich Fibringerinnsel. Die Innenfiäche der Dura zeigt überall ziemlich fest anhaftende hämorrhagische Membranen, aufgelagert in Fleckenform, recbts wie links. Die Dura darunter ist etwas matt, zwischen den Autlagerungen glatt und glänzend. Dir Arachnoidea ist im Verlaufe der starken Gefäbe etwas getrubt. Die subarachnoideale Flüssigkeit ist nicht vermehrt. Die Gefăße der Pia sind stärker gefüllt. Bei Heransnahme des Gehirns zeigt sich in der mittleren Schădelgrube die Dura von lockeren hämorrhagischen Membranen bedeckt. Die linksseitigen Hirnsinus sind frei, die rechtsseitigen werden nicht eröffnet. An der Basis des Hirns finden sich am Anfangsteil beider Art. fossae Sylvii, weiterhin besonders deatlich binter dem Chiasma, an der Brücke und an den Pedunculi cerebelli ad pontem etwas sulzige, gelbliche Trübungen, die jedoch dentliche graue Knötchen nicht erkennen lassen. Abstrichpräparat von der Hirnkonvexität läßt deutlich Eỉterkörperchen erliennen. Die Gefäße der Basis zart. Die Ventrikel nicht erweitert, das Ependym zart. Plexus und Tela sind blutreicher. Die Zentralganglien von deatlicher Zeichnung. Kleinhirn ohne Besonderheiten, ebenso Brücke und Medulla. Die Konsistenz des Hirns ist gut. Die Blutpunkte etwas vermehrt. In den Ventrikeln einige Tropfen klaren Serums. Rinde gran-rötlich. Dicht neben dem rechten. Sinus sigmoideus findet sich eine etwa $1 \mathrm{~cm}$ lange Incision in der Dura.

Diagnosis post mortem: Eitrige sulzige Basilar- und Spinalmeningitis. Pachymeningitis bămorrhagicainterna. Oedem und Hyperamie der Lungen. Atelektase der unteren Partien. Akuter Milztumor.

Sektion des Schläfenbeins.

Beide Labyrinthe intakt, keine Wegleitung nach der Schädelböhle gefunden.

Epikrise: Bei ihrer Aufnahme in die Klinik batte die Kranke ansgesprochene meningitische Erseheinungen (Somnolenz, diffusen Kopfschmerz, Druekempindlichkeit des 1. Halswirbels, gleichmäßig hohes Fieber ete.). Am Tage nach der Aufnahme wurde zur Lumbalpunktion gesehritten, die einen unter mäßig erböhtem Druck stehenden kristallklaren Liquor ergab, der, wie das hygienisehe Institut nach der Untersuchung tags darauf mitteilte, ,abgesehen von einer geringen Verunreinigung steril ist". Es waren nämlich nur 1 bis 2 Kolonieen gewachsen und zwar von Staphylococcus albus, von denen angenommen 
war, daß sie durch sekundäres Hineingelangen von einzelnen Staphylocoecen in den Liquor zu Stande gekommen wären. Diese Annahme war deshalb verständlich, weil der Liquor kristallklar war und keinen erhöhten Leukocytengehalt aufwies. Hatte nach unseren bisherigen Erfahrungen die kristallklare Besehaffenheit des Liquor uns als strikter Gegenbeweis gegen eine diffuse eitrige Meningitis gegolten, so wurden wir desgleichen dureh das bakteriologische Untersuchungsresultat mit dem Ergebnis "steriler Liquor abgesehen von einer geringen Verunreinigung" vielmehr zu einem noch zu wagenden Operationsversuche ermuntert, als davon abgeschreckt. DaB wir nach der Totalaufmeißlung, die eine diffuse Caries der Mittelohrräume feststellte, explorativ auf die hintere Schädelgrube eingingen, hat seinen Grund darin, weil wir auf Grund der Nackenempfindlichkeit mit der Annahme rechneten, daß möglicherweise ein ausgedehnter Extraduralabszeb in der hinteren Schädelgrube vorläge, und daß das hohe Fieber möglicherweise abhängig wäre von einem Heranreichen des supponierten Extraduralabszesses bis an den Sinus. Daß wir schließlich, als wir keine extradurale Eiteransammlung fanden, die Kleinhirndura spalteten, und das Kleinhirn punktierten, als wir dessen weiche Meningen stärker als gewöhnlich injiziert fanden, ist mehr aus dem Wunsche heraus, unbedingt einen zirkumskripten Eiterherd zu finden, nachdem das Lumbalpunktionsergebnis gegen das Vorhandensein einer diffusen eitrigen Leptomeningitis gesprochen hatte, zu verstehen, als daß es aufzufassen wäre als Folge streng logischer diagnostischer Erwägungen.

Die Kranke ist an einer diffusen eitrig-sulzigen Basilarund Spinalmeningitis zu Grunde gegangen. Der Tod ist unabhängig von den Operationsversuchen erfolgt, denn das Gesehick der Kranken war bereits dureh das Vorhandensein dieser Meningitis vor der Operation besiegelt.

Daß bei der Lumbalpunktion ein kristallklarer Liquor entleert wurde, ist entweder so zu erklären, daß der gewonnene Liquor nur ans dem unteren Teile des Spinalkanals herrührte, der durch das sulzige plastische Exsudat in der Brustmarkgegend (ef. Sektionsprotokoll) nach oben hin abgesehlossen war. Bei dieser Erklärung wären die bei dem Kulturverfahren gewonnenen 1-2 Staphylococcenkolonieen als "Verunreinigung des Liquor" anfzufassen. Die andere in Betracht kommende Erklärung der kristallklaren Punktionsflüssigkeit wäre die, dab es bisher uns 
noch unbekannte Fälle von diffuser eitriger Leptomeningitis gibt, bei denen die Punktionsflitssigkeit kristallklar ist, keine Leukocytenvermehrung zeigt und nur spärliche Mikroorganismen aufweist (bier Staphylococcen). Leider ist der meningeale Eiter nicht bakteriologiseh untersucht, so dah wir nicht wissen, ob die Meningitis eine Staphylococeenmeningitis gewesen ist.

13. Carl Friedrich Wurmstich,53 Jahre alt, Gemeindediener aus Kotchendorf.

Aufgenommen am 9. Juli 1904, gestorben am 3. August 1904.

Anamnese: Patient will früber nie obrenkrank gewesen sein. Vor einem Monate bekam er Schmerzen im linken Ohre, welche angeblich so heftig waren, daß er mebrere Nächte nicht schlafen konnte. Er schreibt diese Schmerzen den kalten Umschlägen $\mathrm{zu}$, die er sich am Tage vorber wegen Kopfschmerzen auf den Kopf appliziert hatte. Einige Tage darauf reichliche Eiterung aus dem Obre. Vor 4 Tagen bemerkte Patient zam ersten Male, daß er nicht mebr pfeifen konnte, und daß sein Gesicht schief sei.

Status praesens: Kräftiger, gesund aussehender Mann in gutem Ernährungszustande. Innere Organe gesund. Puls kräftig, regelmäßig. Pupillen gleichweit, reagieren prompt; kein Nystagmus. Augenhintergrund normal. Schwindel objeltiv nicht nachweisbar. Deutlich ausgesprochene Facialisparese; das rechte Auge kann nicht geschlossen werden, der Mundwinkel steht schief. Urin frei von EiweiB und Zucker.

U m gebung des Ohres: Leichte Druckemptindlichkeit in der Gegend des Emissarium mastoideum. Oedem oder Infiltration nicht nachweisbar.

Gehörgang- und Trommelfellbefund. Gehörgang weit. Im Gehörgang mäßige Mengen foetiden Eiters. Großer Defekt des Trommelfelles, welcher den hinteren, oberen und unteren Quadranten einnimmt. Krater nach hinten oben. Mit der Sonde kommt man hier auf rauhen Knochen. Hammergriff retrahiert, das Ende scheint mit der Promotoriumwand verwachsen $z u$ sein. Paukenschleimhaut entzündlich gerötet.

Höprüfung: Flüstersprache rechts direkt. links in $5 \mathrm{~m}$ Entfernung gehört. $\mathrm{C}_{1}$ vom Scheitel nach links lateralisiert. Fis 4 stark herabgesetzt. Rinne rechts -, links + .

Therapie und Krankheitsverlauf:

14. Juli. Totalaufmei $\{l u n g$. Weichteile normal. Corticalis des Planum mastoideum an einer kleinen Stelle verfärbt, im übrigen ohne Besonderheiten. Caries im Antrum. Von Ossiculis $A m b \rightarrow B$ am langen Schenkel carios. Am Canalis Fallopii ist nichts zu finden, was die Facialisläbmung erklāren könnte. Spaltung, Plastik, Tamponade, Verband.

Guter Heilungsverlauf. In den letzten beiden Tagen hat Patient über Kopfschmerzen in der rechten Stirngegend und uber leichten Schwindel geklagt.

2. August. Morgens gegen 6 Vhr plötzlich eintretende Benommenheit. Flockenlesen Puls verlangsamt, 60 . Patient giht auf Fragen keine Antwort, vermag seine Umgebung nicht zu erkennen Pupillen gleichweit, reagieren gut. Augenhintergrund normal. Temperatur $41, ; 3^{\circ}$ Lumbalpunktior. Liquor cerebrospinalis steht unter hohem Druck, sehr trübe. Im Ausstrichpräparat werden Streptococen und Diplococcen nachgewiesen, Freilegung der hinteren Schädelgrube. Eröfnung des Labyrinths; kein Eiter gefunden. Kein Eiter an Porus acusticus internus. Exploration von Schlätenlappen und Kleinhirn; Eiter nicht gefunden. Injektion von $5 \mathrm{ccm}$. Streptococcenserum Menzer.

3. August. Schlaf sehr unruhig. Patient vollstandig benommen, nimmt keine Nahrung zu sich. Nacken sebeinbar sebr druckempfindlich. Pupillen mittelweit, reagieren träge. Kein Nystagmus. Gegen Mittag deutlicher Nystagmus. Haut- und Sehnenreflexe erloschen. Patient läßt wiederholt Urin unter 
sich. Starkes Trachealrasseln. Atmung beschleunigt, oberflächlich. Puls unregelmäßig, fliegend, über 150 . Temperatur $39,8-40,8^{\circ}$.

Gegen Abend Exitus.

Sektionsprotokoll.

Kräftig gebaute, männliche Leiche in gutem Ernährungszustande. Totenflecke und Starre vorhanden. Hinter dem rechten $\mathrm{Ohr}$ findet sich eine sebr ausgedehnte, mit Gaze tamponierte Trepanationswunde. Das Felsenbein ist bîs zum inneren $\mathrm{Ohr}$ eröfifnet. Die Wunde führt von dem Felsenbein in die mittlere Schädelgrube. An der entsprechenden Stelle liegen zerfetzte Gehirnmassen vor. Auch die hintere Schädelgrube ist in einer Ausdehnung von Zweimarkstückgröbe eröfnet. In dieser Wunde liegen prolabierte Kleinhirnteile. Schädeldach von mittlerer Dicke. Diploe ohne Besonderheiten. Dura von erhöhter Spannung und mittlerem Blutgehalt. Der Innenfläche liegen feine dünnflüssige Beläge auf, jedoch nur rechterseits, Innenflăche links matt. Die weichen Hirnhäute der rechten Hemisphäre sind getrübt, besonders in der Gegend der Gefäße. Pia mit gelblichem gallertigen Eiter durchsetzt. Blutgefäße der Pia mäßig injiziert. Gyri abgeflacht. Die linke Seite verhält sich fast ebenso wie die rechte, nur zeigt die subarachnoideale Flüssigkeit einen gelblichen Schimmer. In der Gegend des rechten Schläfenlappens ist das Gehirn in der Ausdehnung etwa einer Wallnuß zertrümmert und blutig durchtränkt. Derselbe Befund an der rechten unteren Seite des Kleinhirns. Auch an der Basis zeigen die weichen Hirnhăute die gelbliche Verfärbung und zwar bis in die Fossa. Sylvii hinein. Ventrikelinhalt vermehrt, aber klar. Die Ventrikel, besonders der dritte, dilatiert. Ependym glatt. Rautengrube ohne Besonderheiten. Desgleichen das Kleinhirn, nur ist die Umgebung der zertrümmerten Partien injiziert. Die Substanz der Hemisphären etwas feucht, etwas hyperämisch, von sehr guter Konsistenz, sonst ohne Besonderheiten. Die Sinus der Hirnbasis enthalten frische Gerinnsel.

Das Netz im oberen Drittel des Abdomens. Kein fremder Inhalt im Abdomen. Zwerchfellstand beiderseits unterer Rand der 4. Rippe.

Herz schlecht kontrabiert. Klappenapparat intakt. Muskulatur braunrot, schlaff, mit weißlichen Streifchen. Die lntima der Coronararterien zeigen zahlreiche, gelblich weiße Verdickungen.

Linke Lunge von etwa entsprechendem Volumen. In Bereich des Unterlappens von etwas erhöhtem Gewicht. Aus dem Bronchus entleert sich auf Druck reichlich seröse Flüssigkeit. Schleimhaut ein wenig injiziert. Pulmonalis frei. Pleura im wesentlichen glatt und glänzend, nur am Oberlappen einige fibröse Auflagerungen Lunge überall nachgiebig, lufthaltig. Pleura an der Spitze etwas verdickt. Schnittlläche etwas trocken. Blut- und Saftgehalt kaum erhöht. Im Unterlappen sind Blut- und Saftgebalt bedeutend erböht. Farbe dunkelrot.

Rechte Lunge gleicht im wesentlichen der linken Lunge im äuBeren Befund. Oberlappen ist blut- und saftreicher als links. Im Unterlappen ist der größte Teil luftleer. Farbe dunkelbraunrot. Schnittläche leicht uneben. Konsistenz ziemlich fest. Der Rand des Unterlappens etwas oedematős. Bronchiale Lymphknoten sind pigmentiert, sonst ohne Veränderungen.

Milz 17:10:4 cm. Kapsel ziemlich glatt. Konsistenz schlecht. Parenchym von duneklbraunroter Farbe und undeutlicher, sehr verwaschener Zeichnung.

Linke Niere: Konsistenz ziemlich gut. Blutgehalt etwas erhöht. Rinde und Mark wenig deutlich gesebieden. Rinde nicht verbreitert; in ihr einige gelbliche Herdchen. Nierenbecken etwas injiziert.

Rechte Niere gleicht im wesentlichen der linken.

Die übrigen Organe ohne wesentlichen Befund.

Diagnosis post mortem: Trepanationswunde. Prolabieren von Gehirnteilen in dieselbe. Eitrige Meningitis rechterseits Hydrocephalus internus. Hyperämie und Oedem der Gehirnhäute und des Gehirns. Leichte Myocarditis fibrosa und braune Atrophie des Herzmuskels. Leichte Coronarsclerose. Hypostatische Pneumonie im rechten Unterlappen. Beginnen- 
de Infiltration des linken. Lungenodem. Septischer Milztumor. Leichte Hyperamie der Nieren. Cystitis catarrhalis part. hâmorrhagica.

Sektion des Schläfenbeins.

Im Canalis Fellopii dicker Eiter, welcher den Nervus facialis vollstandig durchsetzt hat. Der Eiter ist bis zum Por us acusticus internus zu verfolgen. DieNerven hier eitrig infiltriert. Labyrinthwasser eitig getrübt. Sinus frei.

Epikrise. Wir führten in diesem Falle die Totalaufaufmeißlung aus, waren aber nicht in der Lage, trotz ausgedehnter Freilegung des Canalis Fallopii eine Ursache für die Facialislähmung za finden.

Die Heilung machte, abgesehen von der Facialislähmung, welche unverändert bestehen blieb, gute Fortschritte. Plötzlich, fast drei Wochen nach der Operation, traten bei dem Patienten die bedrohliehsten Erscheinungen auf. Er wurde benommen, der Puls verlangsamte sich, es trat Flockenlesen auf, die Temperatur stieg bis auf $40,3^{\circ}$. Wir konnten also wohl kaum an einer diffusen eitrigen Leptomeningitis zweifeln. Die Lumbalpunktion, welche unter hohem Druck stehende, getrubte Cerebrospinalflüssigkeit mit Streptococeen und Diplococen ergab, bestätigte unsere Diagnose.

Wenn wir trotz letaler Prognose es noch unternahmen, auf eine tiefliegende extradurale Eiterung oder auf einen Hirnabszeß zu fahnden, so ist dies wohl mehr als ein letzter verzweifelter Versuch der Rettung des Patienten anzusehen. Tatsächlich brachte die Nachoperation dem Patienten keine Rettung mehr; er starb sehon am nächsten Tage, nachdem die Erscheinungen der Meningitis noeh ausgesprochener geworden waren.

Die diffuse eitrige Leptomeningitis war in diesem Falle von einer eitrigen Entzindung des Nervus facialis ansgegangen. Die primäre Infektionsstelle am Canalis Fallopii konnten wir trotz eifrigen Suchens nicht feststellen. Auf ihrem Wege dureh das Labyrinth hatte die Eiterung dann den Nervus acustieus und das Labyrinth in Mitleidensehaft gezogen und war dann weiter durch beide Nerven des Porns acusticus internus in die Schädelhöhle fortgeleitet worden.

14. Willy Heermann, 19 Jahre alt, Kaufmannsgebilfe aus Halle. Aufgenommen am 27 . Februar, gestorben am 12. April 1904.

An amnese: Patient leidet seit 8 Jahren an Ausfub aus dem linken Ohre, welcher im Anschluf an Masern aufgetreten ist. Rechterseits besteht auch seit einigen Jahren Ausfluf. Schmerzen sollen zuweilen im rechten Ohr aufgetreten sein. - Vor 6 Wochen hatte Patient einen so starken Schwindelanfall, daß er hinfiel.

Status praesens: Schlanker, mittelkräftiger junger Mann. Innere 
Organe gesund. Puls kräftig, regelmäßig, 75. Pupillen gleichweit, reagieren prompt; kein Nystagmus. Reflexe normal. Urin frei von Eiweil und Zucker.

Omgebung des Ohres: Rechts: Spitze des Proc. mast. ein wenig druckemptindlich. Lymphdrüsen unterhalb der Spitze und vor dem Tragus. Links: Eine geschwollene, nicht druckempfindliche Drüse auf dem Proc. mast. Spitze ganz wenig druckempfindlich.

Gebörgang- und Trommelfellbefund: Rechts: Medialer Teil des Gehörgangs geschwollen, Trommelfell diffus gerötet, verdickt. Im Hintergrunde macerierte Epidermis. Perforation im vorderen nnteren Quadranten. Reichliche fötide Eiterung. - Links: Trommelfell getrübt. Im vorderen unteren Quadranten Perforation mit granulierten Rändern. Fistel über dem Proc. brevis, ans der sich schmierige Massen mit der Sonde entfernen lassen. Beiderseits kein rauher Knochen zu fühlen.

Hörprü fung: Flüstersprache rechts in $2 \mathrm{~m}$ Entfernung gehört, links direkt nicht gehört. $C_{1}$ vom Scheitel und rechts lateralisiert. Fis 4 rechts normal, links stark herabgesetzt. Rinne rechts --, links -

Ergebnis beim Catheterismus tubae: Rechts Perforationsgeräusch, links Blasegerăusch.

Therapie und Krankheitsverlan: Links Hammer-AmboBexcision vom Gebörgange aus. Hammer am Kopf cariös. Ausspritzungen des rechten Ohres und Spülungen per tubam. Eintäufelung von Natr. tetraboric.

29. Februar. Beim Verbandwechsel entleeren sich reichliche Mengen Eiter. Yormaler Heilungsverlauf.

14. März. Der mediale Gehörgangsabschnitt links ist noch byperämisch und geschwollen, so dab man den Annulus tympan. nur in seiner oberen Hălfte sehen kann. Schleimhaut vom Promontorium hyperämisch und mäßig geschwollen. Nur noch geringe fötide Sekretion. Rechts nur noch ganz geringe Eiterung, Patient wird auf eigenen Wunsch als gebessert entlassen und weiterhin ambulant behandelt.

15. März. Der hintere obere und untere Quadrant des rechten Trommelfells gerötet und vorgewölbt. Paracentese; es entleert sich reichlich rahmiger Eiter. Verband. Dem Patienten wird Bettruhe verordnet.

18. März. Patient klagt uber rechtsseitigen Kopfschmerz. Geringe Druckempfindlichkeit über dem Plan. mastoid. und der Spitze.

19. März. Temperatur $38,1^{\circ}$, Puls 100. Patient hat die ihm verordnete Bettruhe nicht eingebalten; er wird wieder aufgenommen. Rechtes Trommelfell vorgewölbt. Paracentese. Eisblase. Bettruhe. Abendtemperatur $39,3^{\circ}$.

20. März. Zustand unverändert. Temperatur $37,1-38,7-38,6-38,3-$ $37,9-37,6-37,5-37,5^{\circ}$.

21. Mărz. Kopfschmerzen fast gänzlich geschwunden. Temperatur schwankt zwischen 37,1 und $38,0^{\circ}$. Links nur noch geringe Sekretion.

24. März. Nur geringe Druckempfindlichkeit in der Gegend des Emissarium mastoideum. Allgemeinbefinden gut.

3. April. Gestern und heute wieder geringe Temperatursteigerung. Stärkere Druckempfindlichkeit über dem Planum mastoid. und in der Gegend des Emissariums. Eisblase.

Der Patient, dem bestăndige Bettruhe verordnet war, ist wiederholt aufgestanden.

9. April. Gestern Abend Temperatursteigerung auf $38,1^{\circ}$. In der Nacht große Unruhe. Flache teigige Schwellung in der Gegend des Emissarium mastoideum.

Total a ofmeiß elung. In den Weichtellen einige geschwellte Lymphknoten. Corticalis sehr blatreich. Dach des Kuppelraumes und des Aditus cariös. Antrum, Aditus und gesamte Paukenhöhle von blutreichen Granulationen ausgefüllt. Amboß intakt, Hammerkopf zeigt nur stellenweise oberflächliche Caries. Fast der ganze Hammer und ebenso der lange AmboBschenkel mit Granulationen bedeckt. Der Proc. mastoid ist von einer etwa kirschgroßen Höhle eingenommen, die mit dem Antrum communiziert, mit schwärzlich roter, geschwellter Schleimbaut lausgefüllt ist, und deren Wandung in Sulcus sigmoideus einen gut erbsengroben Defekt zeigt, in dem der 
Sinus vorliegt. Dessen Wand ist mit derben, oberflächlich trüb durchscheinenden Granulationen bedeckt. Der Sinus wird auf eine Länge von $3 \mathrm{~cm}$ freigelegt. Er fühlt sich derb und hart an, pulsiert nicht. Hinter dem Facialiswulst und hinten oben einige mit trüber, geschwellter Schleimhaut gefüllte Zellen. Resektion der Spitze. Spaltung, Plastik, Tamponade, Verband. Temperatur $37,3-40,2-40,6-40,5-40,3-40,4-40,4^{\circ}$.

Das Krankheitsbild verschlimmert sich rapide. In der Nacht erbricht Patient wiederholt. Große Unruhe, lautes Aufschreien. Klage über Kopfschmerz und Schwindel. Morphiuminjektion.

10. April. Klage über heftige Kopfschmerzen. Leichter Opisthotonus, ohne Contraktur der Nackenmuskulatur. Cremasterreflexe fehlen, Patellarreflexe stark herabgesetzt. Pupillen reagieren. Sensorium getrübt.

Jugularisunterbindung. Sinusoperation. Sinuswand stark verdickt. Im Sinus obturierender mißfarbener Thrombus. Aus dem peripheren Sinusende spärliche, aus dem zentralen Ende reichliche Blutung. Tamponade. Verband.

Nach der Operation große Schwäche.

Temperatur $40,4-40,5-40,8-40,9-41,0-40,6-39,0-38,0^{\circ}$.

11. April. In der Nacht war Patient wieder sehr unruhig; Morphiuminjektion. Sensorium völlig getrübt. Patient läßt Stuhl und Urin unter sich. Patellar- und Cremasterreflexe fehlen. Pupillen eng, reaktionslos. Bei Druck auf die Halswirbelsäule schreit Patient lant auf. Puls sehr klein, dikrot, 126; gegen Abend unzäblbar, häufig aussetzcnd. Temperatur 37,4-40,0$39,9-40,2-40,0-39,5-39,4-39,0^{\circ}$.

Tod in der Nacht unter zunehmender Herzschwäche.

Sektionsprotokoll.

Jugendliche kräftige, männliche Leiche. Fettpolster mäBig. An der rechten Halsseite Unterbindungswunde der Jugularis. Hinter dem Ohre größere tamponierte Wunde. Hautdecken leicht gelblich. Zwerchfellstand beiderseits 4. Rippe. Leber überragt um 3-4 Finger den Rippenbogen. Darmserosa glatt und glänzend. Kein fremder Inhalt im Abdomen. Lunge nirgends verwachsen. Keine Flussigkeit in der Pleurahöhle. Lungen collabieren.

$\mathrm{Sebab}$ eldach entsprechend dick. Diploe gering. Dura leicht gelblich gefärbt, in den hinteren Partien gespannt, vorn gefaltet, zeigt nicht erböhten Blutgehalt. Innenfläche der Dura glatt und glänzend. Die weichen Häute getrübt. Subarachnoideale Flüssigkeit vermebrt. Pia von mittlerem Blutgehalt. Bei Herausnahme des Gehirns entleert sich reichlich etwas trübe, doch seröse Flüssigkeit. Fossae Sylvii frei. Gefäße der Basis zart. In den Ventrikeln, die nicht erweitert sind, einige Tropfen klaren Gerinnsels. 3. und 4. Ventrikel und Kleinbirn ohne Besonderheiten. Großhirnganglien von mäßjig deutlicher Zeichnung, ohne Besonderheiten. Ebenso Brücke und Medulla. Gehirnsubstanz von ziemlich schlechter Consistenz. Schnittläche feucht. Substanz ziemlich blaß. Hemisphären ohne Besonderheiten. Rinde blaß.

Herzbeutel in fast ganzer Ausdehnung frei. Einige Kubikzentimeter klaren Serums in ihm. Herz entsprechend groß, ziemlich gut contrahiert. Tricuspidalis für drei, Mitralis für zwei Finger durchgängig. Wenig epicardiales Fett. Arterielle Klappe schlußfähig. Nach Herausnahme des Herzens ca. $400 \mathrm{ccm}$ flüssigen Blutes im Herzhentel. Klappen des rechten Herzens zart und glatt, ebenso Mitralis, deren Sehnenfäden tellweise verdickt sind. Auf dem Epicard punktförmige Blutaustritte. Klappen des linken Herzens intakt. Muskulatur von mäßiger Consistenz, blaßbrauner Farbe, gelblichen Streifen. Elastizität der Aorta gut. Intima und Coronararterien ohne Besonderheiten.

Linke Lunge von entsprechendem Gewicht, etwas vergrößertem $\mathrm{V}_{0-}$ lumen. Pleura des Unterlappens zeigt teils punktförmige, teils flächenhafte Blutaustritte, die nur subpleural gelegen sind. Alus dem Bronchus entleert sich auf Druck keine Flässigkeit. Bronchialschleimhaut schwach violett injiziert. Pulmonalis frei. Pleura im wesentlichen glatt und glänzend. Oberlappen uberall lufthaltig; an der Spitze etwas lufthaltiger als im übrigen Parenchym, das mehr gelblichrot ist. Luftgebalt etwas vermebrt. Unterlappen etwas mehr lufthaltig Blut- und Saftgebalt vermebrt. 
Rechte Lunge: Ekchymosen an der Pleura sehr gering vorhanden. Im übrigen gleichen Bronchus, Pulmonalis, Pleura der linken Seite. Lunıen uberall nachgiclig. Ober- und Mittellappen gleichen den Oberlappen der anderen Seite. Rănder etwas geblăht. Unterlappen wie links.

Tonsille etwas vergrößert. In beiden ein mit miBfarbenem Eiter gefüllter AbszeB.

Mil z 16:10:5 cm. Kapsel glatt, Parenchym dunkelrotbraun. Fullikel ziemlich deutlich. Consistenz ziemlich schlecht.

Die ubrigen Organe obne Besonderheiten.

Diagnosis post mortem: Sepsis. Anämie und Ödem des Hirns. Thrombosedes Sinus transversus dext. Unterbindung der Vena jugularis. Angina necrotica. Subpleurale Blutungen der linken Lunge. Anämie und Verfettung des Herzmaskels. Septischer Milztumor. Fettleber. Leichter Ikterus.

Sektion des Schlafenbeins.

Der Sinus sigmoideus in $\mathrm{Ausdehnung} \mathrm{von} \mathrm{ungefăhr} 5 \mathrm{~cm}$ eitrig infiltriert. Im Sinus transversus bis zum Torcular Herophili ein dunkelrotes weiches Blutgerinnsel. Innenwand des Sinus transversus sieht gut aus. Bulbus venaejugularis und Vena jugularis bis zur Unterbindungsstellegesund. Die übrigen Sinus frei. Labyrinth intakt.

Epikrise. In diesem Falle stellten wir eine beiderseitige chronische Eiterung fest. Während wir auf der linken Seite die Hammer-Amboßexcision ausführten, glaubten wir rechts mit einer palliativen Behandlung anskommen zu können. Die Sekretion lieb anf beiden Seiten bald nach, und war nach 14 Tagen nur noeh in ganz geringem Grade vorhanden, so dah wir den Patienten auf sein dringendes Verlangen nach Hause entließen, um ihn von da ab ambulant zu behandeln.

Schon am nächsten Tage klagte er aber wieder tiber Schmerzen im rechten Ohre. Wir fanden ein stark gerötetes Trommelfell und führten die Paracentese aus. Da wir trotz energisehen Zuredens den Patienten nicht veranlassen konnten, sich wieder in die Klinik aufnehmen zu lassen, mußten wir ihn wieder fortsehicken, uachdem wir ihm strenge Bettruhe verordnet batten.

Als aber nach einigen Tagen Kopfschmerzen eingetreten waren und die Temperatur bei der sogleich vorgenommen Messung $38,1^{\circ}$ betrug, ließen wir uns auf eine weitere ambulante Behandlung nicht mehr ein, sondern veranlaßten den Patienten zu sofortiger Aufnahme, zumal wir auch in Erfahiung gebracht hatten, daß er in keiner Weise die ihm verordnete Bettruhe zu Hause eingehalten hatte. Wir führten nochmals die Trommelfellparacentese aus und applizierten dem Patienten eine Eisblase hinter das Ohr. Nach zwei Tagen waren die entzündlichen Erscheinungen wieder zurïckgegangen.

Der weitere Verlauf der Erkrankung war, abgesehen von einer ganz geringen Temperatursteigerung in den ersten Tagen 
des April, ein zufriedenstellender. Am Abend des 8. April trat jedoch wieder eine Temperatursteigerung bis $38,1^{\circ}$ ein, auberdem fanden wir eine flache teigige Sehwellung in der Gegend des Emissarium mastoideum. Bei der nun vorgenommenen Totalaufmeißelung fanden wir eine ausgedehnte Caries sämtlicher Mittelohrräume und einen großen perisinuösen Abszeß. Da wir durch die Operation keinen Abfall der Temperatur erzielt hatten, dieselben vielmelr während des ganzen Tages und der folgenden Nacht stets über $40,0^{\circ}$ betragen hatten, führten wir am folgenden Tage die Jugularisunterbindung und Sinusoperation aus. Wir fanden hierbei einen obturierenden mibfarbenen Thrombus im Sinus sigmoideus.

Trotz dieser Operation blieben die hohen Temperaturen unverändert. Der Zustand des Patienten verschlimmerte sich in rapider Weise. Er wurde so unruhig, daß wir ihm eine Morphiuminjektion machen mußten. Das Sensorium wurdevollständig getrübt, er lieb Stuhl und Urin unter sich. Der Puls wurde ganz klein und fast unzähibar. Der Tod trat unter den Zeichen zunehmender Herzsehwäche in der Nacht des zweiten Tages nach der Sinusoperation ein.

Wie die Sektion ergab, ist der Patient an der ausgedehnten Sepsis, welehe durch die Blutleiterthrombose vertursacht war, gestorben.

15. Id a Töp fer, 6 Jahre alt, Bergmannskind aus Siersleben.

Aufgenommen am 17. November 1904, gestorben am 10. Dezember 1904 .

Anamnese: Am 14. November begann das Kind über Schmerzen in beiden Ohren zu klagen. Die Schmerzen waren so heftig, dab es in den nächsten Nächten nicht schlafen konnte. Am nächsten Tage beiderseits AusfluB. Das Kind fieberte, der Appetit war sebr scblecht.

Status praesens: Sehr blasses Kind; Knochen grazil, Muskulatur und Fettpolster dürtig entwickelt. Das Kind macht einen schwerkranken Eindruck. Pupillen gleichweit, reagieren prompt. Kein Nystagmus. Schwindel objektiv nachweisbar; das Kind fällt beim Laufen nach links. Puls regelmäßig, nicht besonders kräftig, 100 . Temperatur $38,7^{\circ}$. Urin frei ron Eiweiß und Zucker.

Umgebung des Ohres. Rechts: Die Gegend hinter dem Obre, besonders an der Spitze, ist stark druckempfindlich. Oedem nicht nachweisbar. Auf dem Planum mastoideum einige infiltrierte Lymphdrüsen. Links: Ganz geringes Oedem über dem Planum mastoideum. Druckempfindlichkeit des ganzen Warzenfortsatzes, hauptsächlich an der Spitze. Hier keine Infiltration.

Gehörgang-and Trommelfellbefund. Rechts: Gehörgang weit, in ihm reichliche Mengen schleimigen Eiters. Trommelfell hinten oben stark vorgewölbt, gelb. Perforation nicht sichtbar. Li nks: Derselbe Befund wie rechts. werden.

Hörprüfung konnte bei der Schwäche des Kindes nicht ausgeführt

Therapie und Krankheitsverlauf: Beiderseits Paracentese. Verband. Eisblase hinter die Ohren.

$8^{15}$ Uhr p. m. starker Schüttelfrost von 10 Minuten Dauer; darauf Tempera tur $40,2^{\circ}$. 
18. November. Typische A ufmeißlung beiderseits wegen spărlichen akuten Empyems. Weichteile speckig. Corticalis sebr blutreich. Links perisinuöse Eiterung. Rechts nur Eiter in den peripheren Zellen und im Antrum. Verletzung. des stark prominierenden Sinus rechts. Die Blutung steht auf lamponade.

19. November. Höchste Tagestemperatur $38,5^{\circ}$. Nabrungsaufnahme zufriedenstellend. Sensorium vollständig frei. Puls 100-132.

21. November, In der vergangenen Nacht höchste Temperatur $39,4^{\circ}$. Verbandwechsel. Versuch, den im verletzten Sinus steckenden Tampon zu lösen. Blutung. Die Wunde am linken Ohre sieht besser aus.

23. November. Der Sinustampon wird ohne Blutung gelöst. Allgemeinbefinden gut. Das Kind nimmt gut Nahrung zu sich. Sensorium frei. Patientin richtet sich von selbst im Bett hoch and unterbält sich mit seiner Umiebung.

25. November. In der Nacht Temperatursteigerung bis $40,1^{\circ}$. Versuch, von der Öff̈ung im rechten Sinus mit dem Löffel einzugehen, um eventuell Thrombenmassen zu entfernen, gelingt nicht; man stölst auf beiden Seiten auf festen Verschlnß. Der Sinus der anderen Seite mit frischen Granulationen bedeckt. Puls 92-116. Atmung 24 .

26. November. Andauernd hohe Temperatur. Puls 104. Atmung 30. An der Linge nichts pathologisches nachweisbar.

28. November. Puls 128. Atmung 45. Das Kind sieht sehr anămisch aus und ist sehr schwach. Nahrungsaufnahme gut. Zeitweilig Hustenreiz. Auf der rechten Lungenseite unten eine schmale Dämpfungszone von drei Querfingez Breite. An dieser Stelle ahgeschwächtes Atmen. Probepunktion. Es wird eitrig getrübte Flüssigkeit aspisiert. Rippensektion nach Schleich'scher Anăsthesie Fs wird eine măBige Menge eitriger Flüssigkeit, vermischt mit viel Fibrinfäden, entleert.

Nach der Operation große Schwäche. Heiße Milch und heißer Wein wird dem Kinde eingefiößt.

2. Dezember. Kein Temperaturabfall nach der Operation. Atmung 36. Puls 150 , sehr klein. Täglicher Verbandwechsel an der Brustwunde. Die Wunde am linken Ohre zeigt überall frische Granulationsbildung Rechts in der Gegend des Sinus graue Verfärbung. Versuch, den Sinus zu spalten. Da der Sinus vollständig obliteriert ist und einen bindegewebigen Strang bildet, gelangt man mit dem Schnitt direkt anf die Kleinhirnsubstanz.

8. Dezember. Im Urin Spuren von Eiweil. Das Kind liegt apathisch da; das Sensorium ist vollständig frei. Puls klein, kaum fühlbar, über 150.

10. Dezember. Puls bäufig aussetzend, unzählbar. Respiration ganz oberflächlich, 60. Kleinhirnprolaps rechts. Tod an zunehmender Herzschwäche um 2 Uhr p. m.

Der Temperaturverlauf

wird durch beifolgende Temperaturkurve demonstriert. Sektions protokoll.

Weibliche kindliche Leiche von zartem Körperbau, in schleohtem Ernăhrungszustand. Haut sehr blaß. Unterhalb der Scapula eine $4 \mathrm{~cm}$ lange, $3 \mathrm{~cm}$ breite, schmierig belegte drainierte Rippenresektionswunde.

Schadeldach ohne Besonderbeiten. Dura zart, AuBenfiäche glatt. Gefäßfüllung gering. Innenfläche glatt, zeigt einige, zum Teil abspülbare, zum Teil festhaftende, dunkelrote, zarte Auflagerungen. Weiche Hänte zart, durchsichtig. Subarachnoideale Flüssigkeit wenig vermehrt. Pialgefäße mäßig injiziert. Weiche Häute der Basis getrübt. Bei Herausnahme des Kleinhirns reißt die rechte Kleinhirnhemisphäre etwas ein Dieselbe ist entsprechend der durch den Schädel führenden Operationswunde schmierig belegt und erweicht. Weiche Häute der Umgebung nicht getrübt. Seitenventrikel nicht erweitert, enthalten wenige Tropfen klaren Serums. Ependym glatt. Rautengrube ohne Besonderheiten. Kleinhirn sehr weich. Weile Substanz in der Umgebung der oben beschriebenen erweichten Stelle blutig gesprenkelt. Die großen Ganglien des Stammes, Brücke und Meduila von entsprechender Zeichnung, sehr saftreich. Großhirnhemisphären ebenfalls sehr saftreich und 


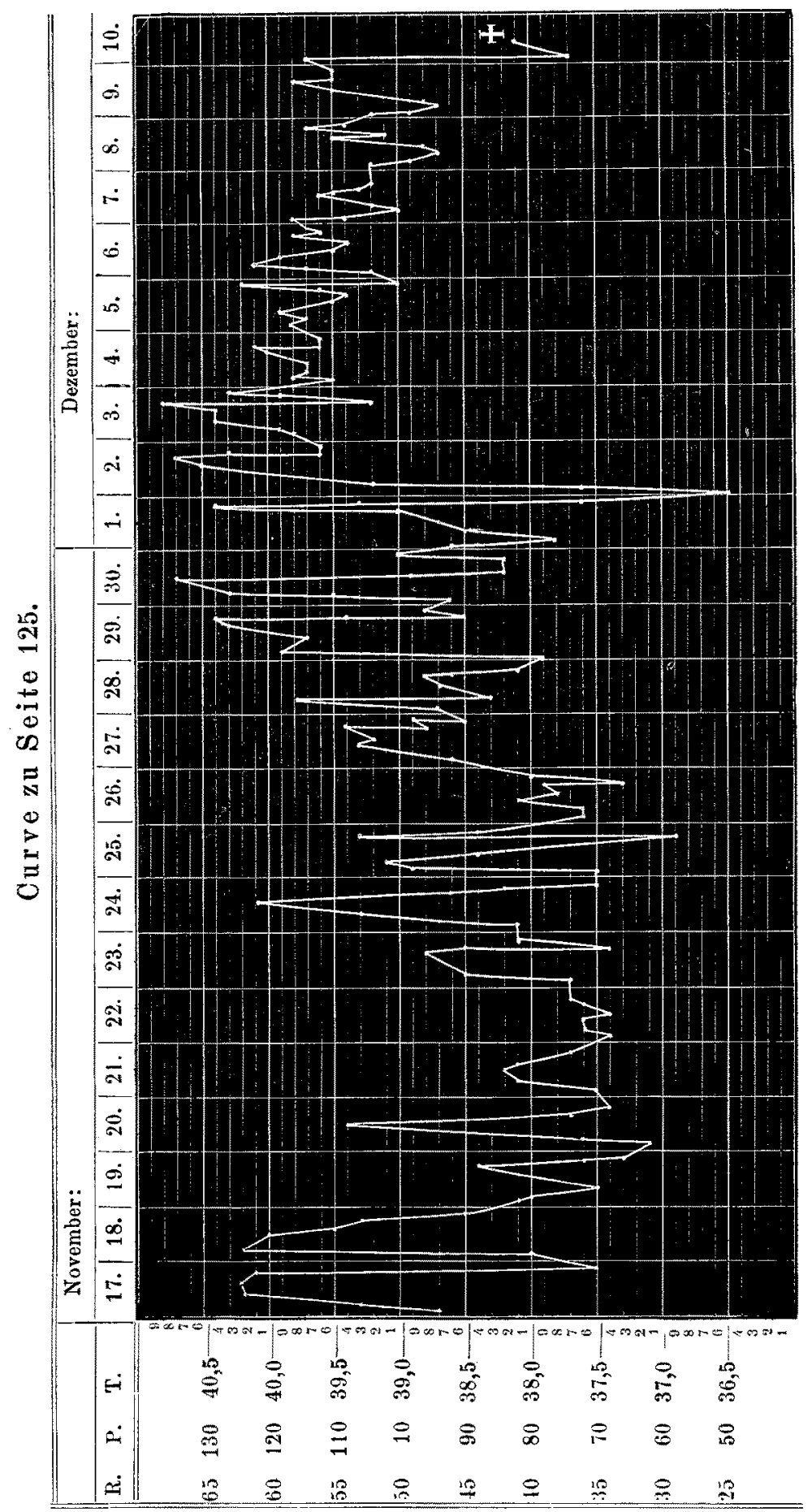


mäßig blutreich. Rinde atich des rechten Hinterhauptlappens nicht verschmälert, grau-rosa.

Fettpolster der Brust- und Bauchwand sehr gering. Muskulatur blaß. Die 5. Rippe ist an der Knorpelknochengrenze gelöst Auf Druck entleert sich aus einem feinen, für eine Sonde durchgängigen Kanal dicker, rahmiger Eiter. Die Umgebung der Fistel schmierig eitrig belegt. Zwerchfellstand rechts 5, links unterer Rand der 5. Rippe. Die Fistel an der 5. Rippe führt in eine abgekapselte, von schmieriger Pleura ausgekleidete Höhle. Rechte Lunge sinkt nicht zurücls; sie ist am seitlichen Rande des Unterlappens mit der Brustwand fest verwachsen. Rechte Brusthöhle enthält 150 ccm dünnflüssige, trübe, von dicken Eiterflocken durchsetzte, schmutzigrötlichgelbe Flüssigkeit. In der linken Pleurahöhle $250 \mathrm{ccm}$ ähnliche Flüssigkeit wie rechts. Herzbeutel liegt in Fünfmarkstücksgröße frei, enthält $40 \mathrm{ccm}$ klare Flüssigkeit, Innenfläche glatt.

Herz gut kontrahiert, etwas größer als die Faust der Leiche, enthält reichlich Blut- und Speckgerinnsel. Tricuspidalis für 2, Mitralis für 1 Finger durchgängig. Arterielle Klappen schlußfähig. Klappenapparate zart. Endocard glatt, Myocard lehmfarben, sehr bla $\beta$, zeigt deatlich gelbe Streifung, auch an den Papillarmuskeln. Aorta und Kranzgefä $\beta_{e}$ ohne Besonderheiten.

Linke Lunge: Aus dem Bronchus entleert sich wenig schaumige Flüssigkeit. Pulmonalis frei. Peribronchiale Lymphknoten markig geschwollen. Pleura trübe, mit teils frischen, teils älteren Fibrinbelăgen bedeckt. Lunge im ganzen von herabgesesetztem Volumen und Gewicht, mäßig saftreich, blutarm. Oberlappen von graurötlicher Schnittlläche, glatt und feucht. Unterlappen etwas blutreicher, jedoch überall nachgiebig. Unter der Pleura ein linsengroßer, mit rahmigem Eiter gefüllter AbszeB.

Rechte Lunge: Aus dem Bronchus entleert sich auf Druck etwas Schaum. Pulmonalis, peribronchiale Lymphknoten wie links. Pleura von einer, einige $\mathrm{mm}$ dicken, fibrinös eitrigen Schwiele bedeckt. Oberlappen ziemlich derb, überall nachgiebig, sehr saft-, wenig blutreich, graurot. Mittellappen blutreicher. Unterlappen zeigt am seitlichen stumpten Rande eine haselnußgroße mit dickem, rahmigem Eiter gefüllte Höble, deren Wand sehr derb ist. Sonst keine Abszesse. Gewebe mälig blut-, sebr saftreich, überall nachgiebig.

Milz $7^{1 / 2}: 4^{1}, 2: 2^{1 / 2} \mathrm{~cm}$. Oberfanche glatt, Parenchym dunkelblaurot. Follikel deutlich, Trabekel zart. Palpa ziemlich derb.

Linke Niere: Fettkapsel mäBig, fibröse zart. Gewebe blaB, quillt uber derselben vor. Die leicht getrübte, entsprechend breite Rinde grenzt sich nicht scharf von der blassen Marksubstanz ab. Nierenbecken und Nebennieren ohne Besonderbeiten.

Rechte Niere etwas blutreicher, gleicht im wesentlichen der linken.

Leber entsprechend groß. Oberfläche glatt. Zeichnnng des blutarmen Parenchyms deutlich. Farbe etwas gelbbraun.

Gallen blase ohne Besonderheiten.

Magen durch Gas aufgetrieben. Schleimhaut kaum gefaltet, blaß.

Darm obne Besonderkeiten.

Harn und Geschlechtsorgane ohne Besonderheiten.

Große Gefäße ohne Besonderheiten.

Diagnosis post mortem: Resektionswundeander 5. rechten Rippe. Hydrocephalus ext. Kleinhirnprolaps. Empyem der rechten Plenra. Plearitis serofibrinosabeiderseits. Lungenabszesse. Anämie und fettige Degeneration des Herzmuskels. Anämie und Oedem der Nieren.

\section{Sektion der Schlafenbeine.}

Rechts: Sinus sigmoideus inganzer Ausdehnung vom sinus transversus bis zum Bulbus venae jugularis obliteriert und in einen bindegewebigen strang verwandelt. Die übrigen sinus gesund und mit frischen Blutgerinnseln gefült. Foramen jugulare und Bulbus venae jugularis sehr klein Inneres und mittleres $0 \mathrm{hr}$ ohne Besonderbeiten. Links: Sämtliche Sinus 
sebr grok, besonders Sinus sigmoideus. Bulbus venaejugula. ris sebr weit. In dem Sinns frische Blutgerinnsel. Mittelohr und Labyrintb obne Besonderheiten.

Epikrise: Wie man schon aus der beigegebenen Temperaturkurve ersehen kann, handelt es sich in diesem Falle um eine Pyaemie, wie sie heftiger wohl kaum denkbar ist. Wundern kann man sich nur, daß ein so schwächliches Kind im Stande war, über drei Wochen im Kampfe gegen diese schwere Erkrankung auszuhalten, ehe der Körper erlahmte.

Am Tage der Aufnahme beobachteten wir bei dem Kinde gegen Abend einen Schüttelfrost mitfolgender Temperatursteigerung auf 40,20. Da der otoskopische Befund auf beiden Ohren ungefähr derselbe war, mubten wir natürlich auch beide Seiten operieren, und beiderseits auf eine Sinuserkrankung fahnden. Wir fanden auf der linken Seite eine perisinuöse Eiterung. Als wir nun auch die rechte Seite freilegen wollten, entstand eine Verletzung des abnorm vorgelagerten, gesund aussehenden Sinus. Dies war im vorliegenden Falle ein um so bedauerlicherer Zufall, als gerade auf dieser Seite der Hauptabflub des Blutes stattfinden mußte, wenn wir eventuell genötigt waren, eine Ausräumung des erkrankten Sinus auf der anderen Seite vorzunehmen.

In den nächsten Tagen trat ein deutlicher Temperaturabfall ein, welcher fünf Tage anhielt, so daß wir uns achon der Hoffnung hingaben, daß wir mit unserer Operation die drohende Pyaemie beseitigt hätten. Am folgenden Tage stieg die Temperatur jedoch wieder auf 40,10. Wir versuchten an dem verletzten rechten Sinus von der Verletzungsstelle aus mit dem seharfen Löffel einzugehen, um eventuell vereiterte Thrombenmassen entfernen zu können, stießen aber nach beiden Seiten auf festen Widerstand. Den linken Sinus wagten wir nicht zu öffnen, zumal der Sinus sich sehon mit gesunden Granulationen bedeckt hatte, und wir deshalb zweifelhaft sein mußten, ob wir hier überhaupt einen Thrombus finden würden.

Die Pyaemie nahm nun ihren stetigen Fortgang. Am 28. November diagnostizierten wir ein rechtsseitiges Pleuraempyem, welches wir unter Schleich'scher Anästhesie eröffneten, da das Kind so schwach war, daß wir ihm eine Narkose nicht mehr, zumuten konnten. Auch dieser Eingriff brachte nicht den gewünsehten Erfolg. Schließlich versuchten wir noch einmal gegen den rechten Sinus vorzugehen, fanden aber nur einen völlig obliterierten Strang, so daß wir bei der Inzision direkt anf das Kleinhirn kamen. 
In den letzten Tagen nahm die Herzschwächē rapide zu. Das Kind starb an den Folgen der Pyaemie, wachdem es über drei Wochen in unserer Klinik ununterbrochen in hohem Fieber gelegen hatte.

Bei der Sektion der Schläfenbeine fanden wir den rechten Sinus sigmoideus vollständig obliteriert und in einen bindegewebigen Strang verwandelt. Auf der linken Seite konnten wir keinen Thrombus finden; wir konnten nicht einmal feststellen, wo eventuell die wandständige Thrombose, die zweifellos bei der Aufnahme bestanden hatte, gesessen hatte. Vielleicht läßt dies sich dadurch erklären, daß der wandständige Thrombus in dem Augenblicke, als durch den Sinusverschlub der anderen Seite ein stärkerer Blutstrom in dem betreffenden Sinus stattfand, von der Wand abgerissen wurde und so den übrigen Körper mit infektiösem Material überschwemmte.

16. Fritz Braune, 3 Jahre alt, Bergmannskind aus Wansleben. Akute Mittelohreiterung. Tod an tuberkulöser Basilarmeningitis und Miliartuberkulose Wird noch ansführlich mitgeteilt werden.

17. Wilhelm Müller, 52 Jahre alt, Zimmerpolierer aus Oechlitz. Beiderseitige Pneumococcenotitis. Tod an apoplectiform einsetzender diffuser, eitriger Leptomeningitis.

Dieser Fall ist von Dallmann (,Beitrag zur Casuistik der Pneumococcenotitis") in diesem Archiv, Bd. 64, S. 147 ausführlich mitgeteilt worden.

18. Willi Ochse, 6 Jahre alt, Arbeiterkind aus Querfurt. Chronische Eiterung mit Cholesteatom links, Sinusthrombose. Totalaufmeißlung, Jugularisunterbindung, Sinusoperation. Zwei Tage später Bulbusoperation. Tod kurze Zeit $\mathrm{n}$ ach der Operation. Wird besonders mitgeteilt werden.

19. R obert Sondershausen, 37 Jahre alt, Maurer aus Halle. Chronische Eiterung links mit Caries. Klage über Kopfschmerzen und Schwindel. Totalaufmeiliung. Ulcus am hinteren Bogengang. Am folgenden Tage Temperatursteigerung und unerträgliche Kopfschmerzen. Tod 5 Tage nach der Operation an diffuser eitriger Leptomeningitis. Das Schläfenbein wird zur mikroskopischen Untersuchung vorbereitet. Der Fall wird eingehender anderweitig mitgeteilt werden. 


\section{Mastoidoperationen:}

(In den mit $\mathrm{T}$ bezeichneten Fallen ist die TotalaufmeiBlung gemacht worden.)

\begin{tabular}{|c|c|c|c|c|c|c|c|}
\hline 至. & Name & $\Xi g$ & Diagnose, & der $\begin{array}{c}D \\
\mathrm{Be}\end{array}$ & lung & Bespltat & Bemerknnoren \\
\hline z & & 营焉 & & $\begin{array}{l}\text { in der } \\
\text { Klinik }\end{array}$ & aberhaupt & & 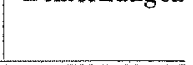 \\
\hline 1 & $\begin{array}{l}\text { Willi Haar- } \\
\text { mann. } \mathrm{T} \text {. }\end{array}$ & 19 & $\begin{array}{l}\text { Chron, Eiterung rechts } \\
\text { mit Caries. }\end{array}$ & 6 Woch. & 6 Woch. & Gestorben. & $\begin{array}{l}\text { Sinusoperat., } \\
\text { Jugul.-Unterb }\end{array}$ \\
\hline 2 & $\begin{array}{l}\text { Oscar Sohön- } \\
\text { feld. }\end{array}$ & 9 & $\begin{array}{l}\text { Akute Eiterung links } \\
\text { mit Empyem. }\end{array}$ & 3 Mon. & 3 Mon. & Geheilt. & Bulbusoperat. \\
\hline 3 & $\begin{array}{c}\text { Oswald } \\
\text { Quinque. }\end{array}$ & 19 & $\begin{array}{l}\text { Links akutes hellbränn- } \\
\text { liches klares Exsudat in } \\
\text { den Mastoidealräumen. }\end{array}$ & 4 Woch. & 4 Woeh. & Geheilt. & $\begin{array}{l}\text { Gehörgangs- } \\
\text { furunkel. }\end{array}$ \\
\hline 4 & $\begin{array}{l}\text { Auguste Holz- } \\
\text { sohumacher. }\end{array}$ & 4 & $\begin{array}{l}\text { Akute Eiterung rechts } \\
\text { mit Empyem. }\end{array}$ & 8 Mon. & 10 Mon. & Geheilt. & $\begin{array}{l}\text { Fistel in der } \\
\text { Dura. }\end{array}$ \\
\hline 5 & $\begin{array}{c}\text { Bertha } \\
\text { Liesohke. T. }\end{array}$ & 49 & $\begin{array}{l}\text { Chron. Eiterung rechts } \\
\text { mit Cholesteatom. }\end{array}$ & - & 14 Tage. & Gestorben. & $\begin{array}{l}\text { An acciden- } \\
\text { tellem Erisyp. }\end{array}$ \\
\hline 6 & Erich Rothe. & 18 & Akate Eiterung links, & 4 Woeh. & 7 Wooh. & Geheilt. & $\begin{array}{c}\text { In der Filiale } \\
\text { gelegen. }\end{array}$ \\
\hline 7. & Willi $\underset{T}{\text { Hippler. }}$ & 22 & $\begin{array}{l}\text { Chron. Eiterung rechts } \\
\text { mit Cholesteatom. }\end{array}$ & 8 Tage. & 7 Mon. & Geheilt. & - \\
\hline 8 & $\underset{\mathrm{T} .}{\text { Anna Herde. }}$ & 12 & $\begin{array}{l}\text { Chron. Eiterung reehts } \\
\text { mit Caries. }\end{array}$ & - & 3 Mon. & Geheilt. & $\begin{array}{c}\text { In der Filiale } \\
\text { gelegen. }\end{array}$ \\
\hline 9 & $\begin{array}{l}\text { Wilhelm } \\
\text { Schulze. T. }\end{array}$ & 36 & $\begin{array}{l}\text { Chron. Eiterung links } \\
\text { mit Cholesteatom. }\end{array}$ & - & 4 Mon. & Geheilt. & $\begin{array}{l}\text { In der Filiale } \\
\text { gelegen. }\end{array}$ \\
\hline 10. & Eduard Bock. & 28 & $\begin{array}{l}\text { Akute Fiterung links } \\
\text { mit Empyem. }\end{array}$ & 8 Woeb. & - & Geheilt. & - \\
\hline 11 & $\begin{array}{c}\text { Otto Bartsch. } \\
\text { T. }\end{array}$ & 12 & $\begin{array}{l}\text { Chron. Eiterung rechts } \\
\text { mit Cholesteatom. }\end{array}$ & 3 Mon. & 5 Mon. & Geheilt. & - \\
\hline 12 & $\begin{array}{c}\text { Friederike } \\
\text { Grey. T. }\end{array}$ & 20 & do. & $4 / 2$ Mon. & - & Geheilt. & 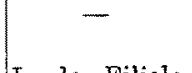 \\
\hline 13 & Hans Wust. & 2 & $\begin{array}{l}\text { Akute Eiterning rechts } \\
\text { mit Empyem und supra- } \\
\text { mastoidealem Abszeß. }\end{array}$ & 一 & 6 Woch. & Gebeilt. & $\begin{array}{c}\text { In der Filiale } \\
\text { gelegen. }\end{array}$ \\
\hline 14 & Minna Seidel. & 23 & $\begin{array}{l}\text { Akute Eiterung links } \\
\text { mit Empyem. }\end{array}$ & 3 Mon. & 3 Mon. & Geheilt. & Sinusoperat. \\
\hline 15 & $\begin{array}{c}\text { AnnaWalther. } \\
\text { T. }\end{array}$ & 32 & $\begin{array}{l}\text { Chron. Eiterung links } \\
\text { mit Caries. }\end{array}$ & 6 Woch. & - & $\begin{array}{l}\text { Noch in } \\
\text { Behandlg. }\end{array}$ & $\begin{array}{l}\text { In der Filiale } \\
\text { gelegen. }\end{array}$ \\
\hline 16 & $\begin{array}{c}\text { Cort Kalbitz. } \\
\mathrm{T} .\end{array}$ & 13 & $\begin{array}{l}\text { Chron. Eiterung reehts } \\
\text { mit Cholesteatom. }\end{array}$ & 6 Woeh. & 6 Mon. & Geheilt. & Sinusoperat. \\
\hline 17 & $\begin{array}{c}\text { Franz Baer. } \\
\text { T. }\end{array}$ & 12 & do. & 3 Mon. & 4 Mon. & Geheilt. & - \\
\hline 18 & Carl Berger. & 36 & $\begin{array}{l}\text { Akute Eiterung links } \\
\text { mit Empyem. }\end{array}$ & 4 Mon. & - & Gebeilt. & $\begin{array}{l}\text { Sinus-Bulbus- } \\
\text { operation. }\end{array}$ \\
\hline 19 & $\begin{array}{l}\text { Arno Muller. } \\
\text { T. }\end{array}$ & 22 & $\begin{array}{l}\text { Chron. Eiterung rechts } \\
\text { mit diffuser Caries. }\end{array}$ & 3 Mon. & - & Gebeilt. & - \\
\hline 20 & $\begin{array}{l}\text { Ella Kaet- } \\
\text { seher. }\end{array}$ & 5 & $\begin{array}{l}\text { Akut. Soharlacheiternng } \\
\text { mit Mastoiditis. }\end{array}$ & - & 8 Woch. & Geheilt. & $\begin{array}{l}\text { Poliklinisch } \\
\text { operiert. }\end{array}$ \\
\hline 21 & $\begin{array}{l}\text { Hermann } \\
\text { Elias. } \mathrm{T} \text {. }\end{array}$ & 6 & $\begin{array}{l}\text { Chron. Eiterung rechts } \\
\text { mit Cholesteatom. }\end{array}$ & 4 Mon. & 一 & Geheilt. & - \\
\hline 22 & Wilh. Hahn. & 2 & $\begin{array}{l}\text { Aknte Eiterung links } \\
\text { mit Empyem }\end{array}$ & - & 7 Woch. & Geheilt. & $\begin{array}{c}\text { In der Filiale } \\
\text { gelegen. }\end{array}$ \\
\hline
\end{tabular}




\begin{tabular}{|c|c|c|c|c|c|c|c|}
\hline \multirow{2}{*}{$\stackrel{\text { 岁 }}{\Xi}$} & \multirow{2}{*}{ Name } & \multirow{2}{*}{ 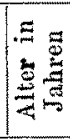 } & \multirow{2}{*}{$\begin{array}{l}\text { Diagnose, } \\
\text { resp. Befund }\end{array}$} & \multicolumn{2}{|c|}{$\begin{array}{l}\text { Dauer der } \\
\text { Behandlung }\end{array}$} & \multirow{2}{*}{ Resultat } & \multirow{2}{*}{ Bemerkungen } \\
\hline & & & & $\begin{array}{l}\text { in der } \\
\text { Klinik }\end{array}$ & Uberhaupt & & \\
\hline 23 & $\begin{array}{l}\text { Margarete } \\
\text { Herbst. }\end{array}$ & 1 & $\begin{array}{l}\text { Akute Eiterung reehts } \\
\text { mit Empyem. }\end{array}$ & 1 Woch. & 6 Woch. & Geheilt. & - \\
\hline 24 & Paul Lorengel. & 2 & $\begin{array}{l}\text { Akute Eiterung rechts } \\
\text { mit Empyem. }\end{array}$ & - & 3 Tage. & Gestorben. & $\begin{array}{l}\text { Seharlach- } \\
\text { station der }\end{array}$ \\
\hline 25 & Derselbe. & 2 & $\begin{array}{l}\text { Akute Eiterung links } \\
\text { mit Empyem. }\end{array}$ & - & 3 Tage. & Gestorben. & med. Flin. \\
\hline 26 & Bruno Zerner & 10 & $\begin{array}{l}\text { Akute Eiterung links } \\
\text { mit Mastoiditis. }\end{array}$ & 3 Woch. & 3 Woch. & Gestorben. & $\begin{array}{l}\text { Pachymenin- } \\
\text { gitis externa, } \\
\text { Sehläfenlap- } \\
\text { penabszeß. }\end{array}$ \\
\hline 27 & Ida Semmler. & 8 & $\begin{array}{l}\text { Akute Eiterung links } \\
\text { mit Mastoiditis. }\end{array}$ & - & 21/2 Mon. & Gebeilt. & $\begin{array}{l}\text { Scharlachsta- } \\
\text { tion der med. } \\
\text { Klinik. }\end{array}$ \\
\hline 28 & $\begin{array}{l}\text { Reinhold } \\
\text { Elimm. T. }\end{array}$ & 3 & $\begin{array}{l}\text { Akute Eiterung rechts } \\
\text { mit Empyem. }\end{array}$ & 11 Mon. & - & $\begin{array}{l}\text { Nooh in } \\
\text { Behandlg. }\end{array}$ & $\begin{array}{l}\text { Diphtherie. } \\
\text { Nephritis. }\end{array}$ \\
\hline 29 & $\begin{array}{l}\text { Louis } \\
\text { Schröter. }\end{array}$ & 59 & $\begin{array}{l}\text { Akute Eiterung links } \\
\text { mit Empyem. }\end{array}$ & 3 Woch. & 5 Woch. & Geheilt. & - \\
\hline 30 & $\begin{array}{l}\text { Pauline } \\
\text { Engelhard. }\end{array}$ & 8 & dto. & 一 & 7 Woeb. & Geheilt. & $\begin{array}{l}\text { Sebarlachsta- } \\
\text { tion der Med. } \\
\text { Klinik. }\end{array}$ \\
\hline 31 & $\begin{array}{c}\text { Anna Wilhelm. } \\
\text { T. }\end{array}$ & 15 & $\begin{array}{l}\text { Chron. Eiterung links } \\
\text { mit Caries. }\end{array}$ & 3 Mon. & 4 Mon. & Geheilt. & - \\
\hline 32 & Dieselbe. T. & 15 & $\begin{array}{l}\text { Chron. Kiterung rechts } \\
\text { mit Cholesteatom. }\end{array}$ & 3 Mon. & 6 Mon. & Geheilt. & - \\
\hline 33 & $\begin{array}{l}\text { Reinhold. } \\
\text { Klimm. T. }\end{array}$ & 3 & $\begin{array}{l}\text { Chron. Eiterung links } \\
\text { mit Caries. }\end{array}$ & 11 Mon. & 一 & $\begin{array}{l}\text { Noch in } \\
\text { Behandlg. }\end{array}$ & cf. 28. \\
\hline 34 & $\begin{array}{c}\text { Robert Zebler. } \\
\text { T. }\end{array}$ & 7 & $\begin{array}{l}\text { Chron. Eiterung rechts } \\
\text { mit, Cholesteatom. }\end{array}$ & 6 Woch. & 5 Mon. & Geheilt. & - \\
\hline 35 & $\underset{\mathrm{T} .}{\text { Emma Staat. }}$ & 5 & $\begin{array}{l}\text { Chron. Eiterung rechts } \\
\text { mit Caries. }\end{array}$ & - & 5 Mon. & Geheilt. & $\begin{array}{c}\text { In der Filiale } \\
\text { gelegen. }\end{array}$ \\
\hline 36 & $\begin{array}{l}\text { Mathilde } \\
\text { Hoppe. T. }\end{array}$ & 12 & $\begin{array}{l}\text { Chron. Eiterung links } \\
\text { mit Caries. }\end{array}$ & 4 Mon. & 6 Mon. & Geheilt. & - \\
\hline 37 & $\begin{array}{l}\text { Margarete } \\
\text { Olbricht. } \mathrm{T} .\end{array}$ & 10 & $\begin{array}{l}\text { Chron. Eiterung links } \\
\text { mit Cholesteatom. }\end{array}$ & 2 Mon. & 4 Mon. & Geheilt. & - \\
\hline 38 & Gustav Bock. & 24 & $\begin{array}{l}\text { Akute Eiterung rechts } \\
\text { mit Cholesteatom. }\end{array}$ & 3 Woch. & 7 Woch. & Gehoilt. & - \\
\hline 39 & $\begin{array}{l}\text { Karl Friedrich } \\
\text { Wurmstieh. } T \text {. }\end{array}$ & 53 & $\begin{array}{l}\text { Chron. Fiterung reehts } \\
\text { mit Caries. }\end{array}$ & 2 Tage. & 3 Woch. & - & Gestorben. \\
\hline 40 & Frau Grobe. & 24 & $\begin{array}{l}\text { Akute Eiterung reehts } \\
\text { mit Mastoiditis. }\end{array}$ & 3 Wooh. & 7 Woch. & Geheilt. & - \\
\hline 41 & $\begin{array}{c}\text { Lonny Kranz. } \\
\text { T. }\end{array}$ & 3 & $\begin{array}{l}\text { Chron. Eiterung links } \\
\text { wit Caries. }\end{array}$ & 6 Woch. & - & $\begin{array}{l}\text { Erfolg un- } \\
\text { bekannt. }\end{array}$ & $\begin{array}{l}\text { Der Behandlg. } \\
\text { entzogen. }\end{array}$ \\
\hline 42 & $\begin{array}{l}\text { Otto Deutsch- } \\
\text { mann. T. }\end{array}$ & 13 & $\begin{array}{l}\text { Chron. Eiterung rechts } \\
\text { mit Caries. }\end{array}$ & $3^{1 / 2}$ Mon. & 6 Mon. & Geheilt. & - \\
\hline 43 & $\begin{array}{c}\text { Friedrich } \\
\text { Obrach. }\end{array}$ & 59 & $\begin{array}{l}\text { Akute Eiterung links } \\
\text { mit Mastoiditis. }\end{array}$ & 4 Woch. & 7 Woch. & Geheilt. & - \\
\hline 44 & $\begin{array}{c}\text { Hermann } \\
\text { Bergmann. }\end{array}$ & 35 & $\begin{array}{l}\text { Akute Eiterung rechts } \\
\text { mit Empyem. }\end{array}$ & - & 8 Woch. & Geheilt. & $\begin{array}{l}\text { In der Filiale } \\
\text { gelegen. }\end{array}$ \\
\hline 45 & $\begin{array}{l}\text { Hermann } \\
\text { Conrad. }\end{array}$ & 35 & $\begin{array}{l}\text { Akute Eiterung links } \\
\text { mit Empyem. }\end{array}$ & 6 Woch. & - & Geheilt. & - \\
\hline
\end{tabular}




\begin{tabular}{|c|c|c|c|c|c|c|c|}
\hline \multirow{2}{*}{ 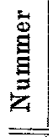 } & \multirow{2}{*}{ Name } & \multirow{2}{*}{$\frac{\pi}{5}$} & \multirow{2}{*}{$\begin{array}{l}\text { Diagnose, } \\
\text { resp. Befund }\end{array}$} & \multicolumn{2}{|c|}{$\begin{array}{c}\text { Dauer } \\
\text { der Behandlung }\end{array}$} & \multirow{2}{*}{ Resultat } & \multirow{2}{*}{ Bemerkungen } \\
\hline & & & & $\begin{array}{l}\text { in der } \\
\text { Klinik }\end{array}$ & wberhaupt & & \\
\hline 46 & Emma Staats. & 5 & $\begin{array}{l}\text { Akute Eiterung links } \\
\text { mit Nekrose. }\end{array}$ & - & $41 / 2$ Mon. & Geheilt. & $\begin{array}{l}\text { In der Filiale } \\
\text { gelegen. }\end{array}$ \\
\hline 47 & $\begin{array}{c}\text { Albert Poppe, } \\
\text { T. }\end{array}$ & 12 & $\begin{array}{l}\text { Chron. Fiterung rechts } \\
\text { mit Cholesteatom. }\end{array}$ & 3 Woch. & 5 Mon. & Geheilt. & - \\
\hline 48 & Otto Kuffel. T. & 10 & dto. & 4 Woch. & 6 Mon. & Geheilt. & - \\
\hline 49 & $\begin{array}{c}\text { Alfred Aeble. } \\
\text { T. }\end{array}$ & 27 & $\begin{array}{l}\text { Chron. Eiterung rechts } \\
\text { mit Caries. }\end{array}$ & 6 Woch. & 3 Mon. & Geheilt. & - \\
\hline 50 & Frau Soyka. & 34 & $\begin{array}{l}\text { Aknte Eiterung links } \\
\text { mit Empyem. }\end{array}$ & 3 Woch. & - & Gebessert. & $\begin{array}{l}\text { Auf eigenen } \\
\text { Wunseh entl. }\end{array}$ \\
\hline 51 & $\begin{array}{c}\text { Karl Grimm. } \\
\text { T. }\end{array}$ & 6 & $\begin{array}{l}\text { Chron. Eiterung rechts } \\
\text { mit Cholesteatom. }\end{array}$ & 3 Mon. & - & $\begin{array}{c}\text { Noch in } \\
\text { Behnndlg. }\end{array}$ & - \\
\hline 52 & $\begin{array}{l}\text { Lina } \\
\text { Michaelis. }\end{array}$ & 5 & $\begin{array}{l}\text { Akute Eiterung rechts } \\
\text { mit Empyem. }\end{array}$ & - & 6 Woch. & Geheilt. & $\begin{array}{c}\text { Ambulatoriseh } \\
\text { operiert. }\end{array}$ \\
\hline 53 & $\begin{array}{l}\text { Wilhelmine } \\
\text { Bercki. T. }\end{array}$ & 37 & $\begin{array}{l}\text { Chron. Eiterung rechts } \\
\text { mit Caries. }\end{array}$ & - & 5 Mon. & Geheilt. & $\begin{array}{l}\text { In d. Fil. ge- } \\
\text { legen. Nachtr. } \\
\text { taub geword. }\end{array}$ \\
\hline 54 & $\begin{array}{l}\text { Heinrich } \\
\text { Hoppe. T. }\end{array}$ & 64 & $\begin{array}{l}\text { Chron. Eiterung links } \\
\text { mit Caries, Labyrinthei- } \\
\text { terung und tiefem Extra- } \\
\text { duralabszeb. }\end{array}$ & 5 Tage. & 5 Tage & Gestorben. & $\begin{array}{l}\text { Labyrinther- } \\
\text { offung von d. } \\
\text { hinteren Pyra- } \\
\text { midenfl, aus. }\end{array}$ \\
\hline 55 & $\begin{array}{c}\text { Karl Wacker. } \\
\mathrm{T} \text {. }\end{array}$ & 63 & $\begin{array}{l}\text { Chron. Eiterung rechts } \\
\text { mit Cholesteatom. }\end{array}$ & 10 Tage. & 10 Tage. & Gestorben. & - \\
\hline 56 & $\begin{array}{c}\text { Emma Huth. } \\
\mathrm{T} .\end{array}$ & 6 & $\begin{array}{l}\text { Chron. Biterung rechts } \\
\text { mit Nekrose. }\end{array}$ & 7 Wooh. & 一 & Geheilt. & - \\
\hline 5 & Emma Buthe. & 6 & $\begin{array}{l}\text { Akute Eiterung links } \\
\text { mit Nekrose. }\end{array}$ & 21/2 Mon. & 4 Mon. & Geheilt. & - \\
\hline 58 & $\begin{array}{c}\text { Max Peuschel. } \\
\text { T. }\end{array}$ & 4 & $\begin{array}{l}\text { Chron. Eiterung links } \\
\text { mit Caries. }\end{array}$ & 3 Woch. & - & $\begin{array}{l}\text { Noch in } \\
\text { Behandlg. }\end{array}$ & - \\
\hline 59 & $\begin{array}{c}\text { Christian } \\
\text { Paulens. T. }\end{array}$ & 35 & $\begin{array}{l}\text { Chron. Eiterung rechts } \\
\text { m. Cholesteatom u. Car- } \\
\text { cinom. }\end{array}$ & $2^{1 / 2}$ Mon. & - & $\begin{array}{l}\text { Noch in } \\
\text { Behandlg. }\end{array}$ & Carcinom. \\
\hline 60 & $\begin{array}{c}\text { Franz Scbulze. } \\
\text { T. }\end{array}$ & 7 & $\begin{array}{l}\text { Chron. Eiterung rechts } \\
\text { mit Cholesteatom. }\end{array}$ & 3 Mon. & 3 Monat. & Geheilt. & - \\
\hline 61 & $\begin{array}{l}\text { Wilhelm } \\
\text { Falke. T. }\end{array}$ & 13 & $\begin{array}{l}\text { Chron. Eiterung rechts } \\
\text { mit Caries. }\end{array}$ & 4 Mon. & - & $\begin{array}{l}\text { Noeh in } \\
\text { Behandlg. } \\
\text { Gebessert. }\end{array}$ & $\begin{array}{l}\text { Pachymenin- } \\
\text { gitis externa. }\end{array}$ \\
\hline 62 & $\begin{array}{c}\text { Eranz Sehulze. } \\
\mathrm{T} .\end{array}$ & 7 & $\begin{array}{l}\text { Chron. Eiterung links } \\
\text { mit Cholesteatom. }\end{array}$ & $3 / 2$ Mon. & $3 / 2$ Mon. & Geheilt. & Sinusoperat, \\
\hline 63 & $\begin{array}{c}\text { Martha } \\
\text { Ebersbaoh. T. }\end{array}$ & 10 & dto. & - & - & Gebeilt. & - \\
\hline 64 & $\begin{array}{c}\text { Karl Grimm. } \\
\mathrm{T} .\end{array}$ & 6 & dto. & 3 Mon. & 5 Mon. & Geheilt. & c. \\
\hline 65 & Otto Planert. & 22 & $\begin{array}{l}\text { Alkute Eiterung links } \\
\text { mit Empyem. }\end{array}$ & 2 Mon. & 2 Mon. & Geheilt. & $\begin{array}{l}\text { Sinusverletz. } \\
\text { Sinusthromb. } \\
\text { danach, durch } \\
\text { Operation geh. }\end{array}$ \\
\hline 66 & $\underset{\text { Wawrzik. T. }}{\text { Kurt }}$ & 11 & $\begin{array}{l}\text { Curon. Eiterung links } \\
\text { mit Caries. }\end{array}$ & 9 Woeb. & - & $\begin{array}{l}\text { Noch in } \\
\text { Behandlg. }\end{array}$ & $\begin{array}{c}\text { Geringe Sekr. } \\
\text { in der Tuben- } \\
\text { gegend. }\end{array}$ \\
\hline
\end{tabular}


Jahresbericht der Kgl. Universităts-Ohrenklinik zu Halle a. S. 133

\begin{tabular}{|c|c|c|c|c|c|c|c|}
\hline 离 & Name & 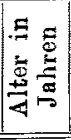 & $\begin{array}{l}\text { Diagnose, } \\
\text { resp. Befund }\end{array}$ & $\begin{array}{l}\quad \mathrm{Da} \\
\text { der } \mathrm{Bel} \\
\text { in der } \\
\text { Klinik }\end{array}$ & $\begin{array}{l}\text { uer } \\
\text { aandlung } \\
\text { uberhaupt }\end{array}$ & Resultat & Bemerkungen \\
\hline 67 & Franz Rösner. & 3 & $\begin{array}{l}\text { Akute Eiterung reohts } \\
\text { mit Fmpyem. }\end{array}$ & 2 Mon. & 3 Mon. & Geheilt. & - \\
\hline 68 & $\begin{array}{c}\text { Rosa } \\
\text { Hermann. T. }\end{array}$ & 3 & $\begin{array}{l}\text { Chron. Fiterung rechts } \\
\text { mit Caries. }\end{array}$ & 8 Mon. & - & $\begin{array}{l}\text { Noch in } \\
\text { Beliandlg. }\end{array}$ & - \\
\hline 69 & Otto Potsch. & 6 & $\begin{array}{l}\text { Akute Eiterung reehts } \\
\text { mit Empyem. }\end{array}$ & 6 Wooh. & - & Geheilt. & - \\
\hline 70 & $\stackrel{\text { Rosa }}{\text { Hermann. T. }}$ & 3 & $\begin{array}{l}\text { Chron. Eiterung links } \\
\text { mit Caries. }\end{array}$ & 31/2 Mon. & - & Geheilt. & - \\
\hline 71 & $\begin{array}{c}\text { Robert Zehler. } \\
\text { T. }\end{array}$ & & dto. & 4 Woch. & $6 \mathrm{Mat}$ & Geheilt. & - \\
\hline 72 & $\begin{array}{c}\text { Liesbeth } \\
\text { Ziesing. }\end{array}$ & 3 & $\begin{array}{l}\text { Akute Eiterung links } \\
\text { mit Empyem. }\end{array}$ & - & 4 Tage. & $\begin{array}{l}\text { D. Weiter- } \\
\text { behandlg. } \\
\text { entzogen. }\end{array}$ & $\begin{array}{l}\text { Scharlaclstat. } \\
\text { der med. Klin. }\end{array}$ \\
\hline 73 & $\begin{array}{c}\text { Alfred Weber. } \\
\text { T. }\end{array}$ & 8 & $\begin{array}{l}\text { Chron. Eiterung links } \\
\text { mit Cholesteatom. }\end{array}$ & - & 4 Mon. & Geheilt. & $\begin{array}{l}\text { Ambulatoriseh } \\
\text { operiert. }\end{array}$ \\
\hline 74 & $\begin{array}{c}\text { Friederike } \\
\text { Buchbolz. T. }\end{array}$ & 39 & dto. & 4 Woch. & 5 Mon. & Geheilt. & - \\
\hline 75 & $\begin{array}{c}\text { Friedrich } \\
\text { Kretschmann. } \\
\text { T. }\end{array}$ & 28 & $\begin{array}{l}\text { Chron. Eiterung rechts } \\
\text { mit Caries. }\end{array}$ & 一 & 6 Mon. & Geheilt. & $\begin{array}{l}\text { In der Filiale } \\
\text { gelegen. }\end{array}$ \\
\hline 76 & Rob. Zepulka. & 1 & $\begin{array}{l}\text { Akute Eiterung links } \\
\text { mit Caries. }\end{array}$ & - & 5 Woch. & Geheilt. & $\begin{array}{l}\text { Poliklinisch } \\
\text { operiert. }\end{array}$ \\
\hline 77 & Carl Stops. $\mathbf{T}$ & 44 & $\begin{array}{l}\text { Chron. Eiterung rechts } \\
\text { mit Caries a. Cholesteat. }\end{array}$ & 2/2 Mon. & 4 Mon. & Gehoilt. & - \\
\hline 78 & $\begin{array}{c}\text { Alwine } \\
\text { Boobach. }\end{array}$ & 41 & $\begin{array}{l}\text { Akute Biterung rechts } \\
\text { mit Empyem. }\end{array}$ & 3 Woeh. & 5 Mon. & Geheilt. & Sohwangerseh. \\
\hline 79 & $\begin{array}{c}\text { Moritz Bölume } \\
\text { T. }\end{array}$ & 39 & $\begin{array}{l}\text { Chron. Eiterung rechts } \\
\text { mit Caries. }\end{array}$ & 1/2 Mon. & 11/2 Mon. & Gestorben & - \\
\hline 80 & Fritz & 13 & $\begin{array}{l}\text { Chron. Eiterung links } \\
\text { mit Caries. }\end{array}$ & - & 4 Mon. & Geheilt. & $\begin{array}{l}\text { In der Filiale } \\
\text { gelegen. }\end{array}$ \\
\hline 81 & $\begin{array}{c}\text { Charlotte } \\
\text { Bicker. T. }\end{array}$ & 4 & $\begin{array}{l}\text { Chron. Eiterung rechts } \\
\text { mit Cholest. nach Scarlat. }\end{array}$ & 2 Woch. & 5 Mon. & Geheilt. & - \\
\hline$\$ 2$ & $\begin{array}{l}\text { Martha } \\
\text { Bartsch. T. }\end{array}$ & 16 & $\begin{array}{l}\text { Chron. Eiterung reehts } \\
\text { mit Caries. }\end{array}$ & 3 Mon. & - & Gebessert. & $\begin{array}{l}\text { Jugularis- } \\
\text { unterbindung. } \\
\text { Sinusoperat. }\end{array}$ \\
\hline 83 & Fr. Porst. & 29 & $\begin{array}{l}\text { Akute Eiterung rechts } \\
\text { mit Empyem. }\end{array}$ & - & 7 Woch. & Geheilt. & $\begin{array}{l}\text { In der Filiale } \\
\text { gelegen. }\end{array}$ \\
\hline 84 & $\begin{array}{c}\text { Carl } \\
\text { Engelhard. }\end{array}$ & 22 & dto. & 3 Woch. & $\cdots$ & $\begin{array}{l}\text { Nooh in } \\
\text { Behandlg. }\end{array}$ & - \\
\hline 85 & $\begin{array}{l}\text { Else Henne- } \\
\text { mann. T. }\end{array}$ & 19 & $\begin{array}{l}\text { Chron. Eiterung links } \\
\text { mit Caries. }\end{array}$ & 4 Mon. & - & $\begin{array}{l}\text { Noch in } \\
\text { Behandl. }\end{array}$ & - \\
\hline 86 & Elseschalling. & 4 & $\begin{array}{l}\text { Akute Eiterung links } \\
\text { mit Empyem. }\end{array}$ & - & 8 Wooh. & Geheilt. & $\begin{array}{l}\text { Scharlachstat. } \\
\text { der med. Klin. }\end{array}$ \\
\hline 87 & Paul Jentsch. & 26 & $\begin{array}{l}\text { Akute Eiterung links } \\
\text { mit Caries. }\end{array}$ & 6 Woch. & 9 Woch. & Geheilt. & Sinusblutung. \\
\hline 88 & $\underset{\text { T. }}{\text { Martha Beek. }}$ & 5 & $\begin{array}{l}\text { Chron. Eiterung rechts } \\
\text { mit Cholesteatom. }\end{array}$ & 5 Woch. & - & $\begin{array}{l}\text { Noch in } \\
\text { Behandl. }\end{array}$ & - \\
\hline 89 & $\begin{array}{c}\text { Gustav Heidel. } \\
\text { T. }\end{array}$ & 22 & $\begin{array}{l}\text { Chron. Eiterung reehts } \\
\text { mit Caries. }\end{array}$ & 3 Wooh. & $4^{1 / 2}$ Mon. & Geheilt. & - \\
\hline
\end{tabular}




\begin{tabular}{|c|c|c|c|c|c|c|c|}
\hline 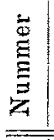 & Name & 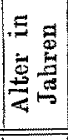 & $\begin{array}{l}\text { Diagnose, } \\
\text { resp. Befund }\end{array}$ & $\begin{array}{l}\text { Dau } \\
\text { der Beha } \\
\text { in der } \\
\text { Klinik } \\
\end{array}$ & $\begin{array}{l}\text { uer } \\
\text { tandlung } \\
\text { uiberhaupt }\end{array}$ & Resultat & Bemerkungen \\
\hline 90 & Emma Keller. & 5 & $\begin{array}{l}\text { Akute Eiterung links } \\
\text { mit Mastoiditis. }\end{array}$ & 3 Woch. & 7 Woch. & Geheilt. & - \\
\hline 91 & $\begin{array}{c}\text { Rober } \\
\text { Trümper. T. }\end{array}$ & 10 & $\begin{array}{l}\text { Chron. Eiterung links } \\
\text { mit Cholesteatom. }\end{array}$ & 12 Tage. & 12 Tage. & Gestorben. & $\begin{array}{l}\text { Extradu ralab- } \\
\text { sceh. Klein- } \\
\text { hirnabszef. } \\
\text { Sinusoperat. }\end{array}$ \\
\hline 92 & $\begin{array}{l}\text { Wilhelm } \\
\text { Scherlitzke. }\end{array}$ & 36 & $\begin{array}{l}\text { Akute Eiterung rechts } \\
\text { mit Mastoiditis. }\end{array}$ & 8 Woch. & 10 Woch. & Geheilt. & - \\
\hline 93 & Frau Zabel. T. & 41 & $\begin{array}{l}\text { Chron. Eiterung links } \\
\text { mit Cholesteatom. }\end{array}$ & $21 / 4$ Mon. & $4^{1 / 2}$ Mon. & Geheilt. & - \\
\hline 94 & Alma Kittler. & 9 & $\begin{array}{l}\text { Akute Eiterung rechts } \\
\text { mit Empyem. }\end{array}$ & 4 Woch. & 6 Woch. & Gebeilt. & - \\
\hline 95 & $\begin{array}{l}\text { Gottlieb } \\
\text { Schallas. T. }\end{array}$ & 49 & $\begin{array}{l}\text { Chron. Eiterung links } \\
\text { mit Caries tuberculosa. }\end{array}$ & 6 Woch. & - & $\begin{array}{l}\text { D. Bebnal. } \\
\text { entzogen. }\end{array}$ & - \\
\hline 96 & Paul Heger. & 10 & $\begin{array}{l}\text { Akute Eiterung rechts } \\
\text { mit Empyem. }\end{array}$ & 6 Woch. & 3 Mon. & Geheilt. & - \\
\hline 97 & $\begin{array}{l}\text { Friedr. } \\
\text { Richter. } \mathrm{T} \text {. }\end{array}$ & 20 & $\begin{array}{l}\text { Chron. Eiterung links } \\
\text { mit Caries. }\end{array}$ & 6 Woch. & 5 Mon. & Geheilt. & - \\
\hline 98 & Anna Peter. & 1 & $\begin{array}{l}\text { Akute Eiterung links } \\
\text { mit Caries. }\end{array}$ & 4 Tage. & - & $\begin{array}{l}\text { D. Behndl. } \\
\text { entzogen. }\end{array}$ & 一 \\
\hline 99 & Frieda Klee. & 6 & $\begin{array}{l}\text { Akute Eiterung links } \\
\text { mit Mastoiditis. }\end{array}$ & $41 / 2$ Woch. & 3 Mon. & Geheilt. & - \\
\hline 100 & $\begin{array}{l}\text { Martha } \\
\text { Krenzer. }\end{array}$ & 9 & $\begin{array}{l}\text { Akute Eiterung links } \\
\text { mit Mastoiditis und Sear- } \\
\text { latina. }\end{array}$ & 2 Mon. & 4 Mon. & Geheilt. & - \\
\hline $101:$ & AgatheGerber. & 12 & $\begin{array}{l}\text { Akute Eiterung links } \\
\text { mit Empyem. }\end{array}$ & 一 & 6 Woch. & Geheilt. & $\begin{array}{l}\text { In der Filiale } \\
\text { gelegen. }\end{array}$ \\
\hline 102 & $\begin{array}{l}\text { Friedrich } \\
\text { Rettig. T. }\end{array}$ & 27 & $\begin{array}{l}\text { Chron. Eiterung reehts } \\
\text { mit Cholesteatom. }\end{array}$ & 1 Mon. & - & $\begin{array}{c}\text { D. Behndl. } \\
\text { entzogen. }\end{array}$ & - \\
\hline 103 & Ida Krenzer. & 7 & $\begin{array}{l}\text { Akute Eiterung rechts } \\
\text { mit Caries. }\end{array}$ & 2 Mon. & - & Ungeheilt. & $\begin{array}{l}\text { Scharlach- } \\
\text { nekrose. }\end{array}$ \\
\hline 104 & $\begin{array}{l}\text { Carl Ficken- } \\
\text { seher. T. }\end{array}$ & 46 & $\begin{array}{l}\text { Chron. Eiterung links } \\
\text { mit Cholesteatom. }\end{array}$ & 5 Tage, & 5 Tage. & Gestorben. & $\begin{array}{l}\text { Sinus cavern.- } \\
\text { thrombose. }\end{array}$ \\
\hline 105 & $\begin{array}{c}\text { Willy Oohse. } \\
\text { T. }\end{array}$ & 6 & $\mathrm{dto}$ & 5 Tage. & - & Gestorben. & $\begin{array}{c}\text { Jugularis- } \\
\text { unterbindung. } \\
\text { Sinusoperat. } \\
\text { Bulbusoperat. }\end{array}$ \\
\hline 106 & Ida Töpfer. & 6 & $\begin{array}{l}\text { Akute Eiterung rechts } \\
\text { mit Empyem. }\end{array}$ & $31 / 2$ Wooh. & - & Gestorben. & Rippenresect. \\
\hline 107 & Dieselbe. & 6 & $\begin{array}{l}\text { Akute Eiterung links } \\
\text { mit Empyem. }\end{array}$ & s. $3^{1 / 2}$ Woch. & - & Gestorben. & \\
\hline 108 & $\begin{array}{c}\text { Karl Kauf- } \\
\text { mann. T. }\end{array}$ & 26 & $\begin{array}{l}\text { Chron. Eiterung links } \\
\text { mit Cholesteatom. }\end{array}$ & 7 Wooh. & 5 Mon. & Geheilt. & - \\
\hline 109 & $\begin{array}{c}\text { Marie Bendler. } \\
\text { T. }\end{array}$ & 24 & $\begin{array}{l}\text { Chron. Eiterung rechts } \\
\text { mit Caries. }\end{array}$ & 4 Tage. & 3 Woch. & Gestorben. & $\begin{array}{l}\text { Trepanation } \\
\text { a. d. Eleinh. } \\
\text { Kein Eiter } \\
\text { gefunden. }\end{array}$ \\
\hline 110 & Otto Sohmidt. & 8 & dto. & & - & $\begin{array}{l}\text { Noch in } \\
\text { Bebandlg. }\end{array}$ & - \\
\hline 111 & Marie $\underset{\mathrm{T}}{\mathrm{B}}$. & 19 & $\begin{array}{l}\text { Chron, Eiterung links } \\
\text { mit Cholesteatom. }\end{array}$ & s $31 / 2$ Mon. & 5 Mon. & Geheilt. & 一 \\
\hline
\end{tabular}




\begin{tabular}{|c|c|c|c|c|c|c|c|}
\hline 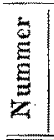 & Name & 是 & $\begin{array}{l}\text { Diagnose, } \\
\text { resp. Befund }\end{array}$ & $\begin{array}{l}\text { Da } \\
\text { der Beh } \\
\text { in der } \\
\text { Klinik }\end{array}$ & $\begin{array}{l}\text { ner } \\
\text { haudlung } \\
\text { uberhaupt }\end{array}$ & Resultat & Bemerkungen \\
\hline 112 & Olga Ilgen. & 13 & $\begin{array}{l}\text { Akute Eiterung links } \\
\text { mit Empyem. }\end{array}$ & 2 Mon. & 一 & Geheilt. & $一$ \\
\hline 113 & $\begin{array}{c}\text { Bertha Moritz. } \\
\text { T. }\end{array}$ & 15 & $\begin{array}{l}\text { Chron. Eiterung reehts } \\
\text { mit Caries. }\end{array}$ & 3 Mon. & $4^{1 / 2}$ Mon. & Geheilt. & - \\
\hline 114 & $\frac{\text { Emma Riedel. }}{\text { T. }}$ & 8 & dto. & - & - & $\begin{array}{l}\text { Nooh in } \\
\text { Behandlg. }\end{array}$ & $\begin{array}{l}\text { In der Filiale } \\
\text { gelegen. }\end{array}$ \\
\hline 115 & Carl Freiberg. & 24 & Akute Eiterung links. & 4 Woch. & 一 & Gestorben. & $\begin{array}{l}\text { In der med. } \\
\text { Klinik an Tu- } \\
\text { berkulose der } \\
\text { Lunge n. des } \\
\text { Kehlkopfes } \\
\text { gestorben. }\end{array}$ \\
\hline 116 & $\underset{\mathrm{T} .}{\text { Hedwig Rost. }}$ & 18 & $\begin{array}{l}\text { Chron. Eiterung rechts } \\
\text { mit Caries. }\end{array}$ & 4 Woch. & 4 Mon. & Geheilt. & - \\
\hline 117 & $\begin{array}{l}\text { Frau Pauline } \\
\text { Lieferentz. T. }\end{array}$ & 36 & $\begin{array}{l}\text { Chron. Eiterung links } \\
\text { mit Cholesteatom. }\end{array}$ & 6 Woch. & 5 Mon. & Geheilt. & - \\
\hline 118 & Max Prange. & 5 & $\begin{array}{l}\text { Akute Eiterung liuks } \\
\text { mit Caries. }\end{array}$ & - & - & $\begin{array}{l}\text { Noch in } \\
\text { Behandlg. }\end{array}$ & $\begin{array}{l}\text { Seharlachstat. } \\
\text { d. med. Klinik. }\end{array}$ \\
\hline 119 & Fritz Krey. T. & 6 & $\begin{array}{l}\text { Chron. Eiterung reehts } \\
\text { mit Cholestetom. }\end{array}$ & 4 Mon. & - & $\begin{array}{l}\text { Noch in } \\
\text { Behandlg. }\end{array}$ & $\begin{array}{c}\text { Extradural- } \\
\text { absze日. }\end{array}$ \\
\hline 120 & $\begin{array}{l}\text { Margarethe } \\
\text { Luther. }\end{array}$ & 12 & $\begin{array}{l}\text { Akute Eiterung links } \\
\text { mit Caries. }\end{array}$ & 2 Mon. & 3 Mon. & Geheilt. & - \\
\hline 121 & Anna Mobius. & 1 & $\begin{array}{l}\text { Akute Eiterung links } \\
\text { mit Empyem. }\end{array}$ & $2^{1} 2$ Woch. & - & Gestorben. & Diphtherie. \\
\hline 122 & $\begin{array}{l}\text { Trangott } \\
\text { Günther. }\end{array}$ & 38 & $\begin{array}{l}\text { Akute Eiterung rechts } \\
\text { mit Empyem. }\end{array}$ & 3 Woch. & - & Gebessert. & - \\
\hline 123 & $\begin{array}{l}\text { Margarete } \\
\text { Luther. }\end{array}$ & 12 & dto. & 2 Mon. & 3 Mon. & Geheilt. & 一 \\
\hline 124 & Fritz Hamel. & 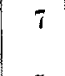 & dto. & - & 14 Tage. & Gestorben. & $\begin{array}{l}\text { Seharlach- } \\
\text { nephritis. }\end{array}$ \\
\hline 125 & Hans Stork. & 5 & dto. & 2 Mon. & 3 Mon. & $\begin{array}{l}\text { D. Behndl. } \\
\text { entzogen. }\end{array}$ & $\begin{array}{l}\text { Seharlach- } \\
\text { nekrose. }\end{array}$ \\
\hline 126 & $\begin{array}{c}\text { Otto Köchel. } \\
\text { T. }\end{array}$ & 13 & $\begin{array}{l}\text { Chron. Eiterung links } \\
\text { mit Cholesteatom. }\end{array}$ & 4 Woch. & - & $\begin{array}{l}\text { Noch in } \\
\text { Behandlg. }\end{array}$ & - \\
\hline 127 & $\begin{array}{c}\text { Johannes Bias. } \\
\mathrm{T} .\end{array}$ & 9 & $\begin{array}{l}\text { Chron. Eiterung rechts } \\
\text { mit Caries. }\end{array}$ & 4 Tage. & 4 Tage. & Gestorben. & $\rightarrow$ \\
\hline 128 & Elise Stietz. & 17 & $\begin{array}{l}\text { Akute Eiterung links } \\
\text { mit Empyem. }\end{array}$ & $2^{1 / 2}$ Mon. & - & $\begin{array}{l}\text { Noch in } \\
\text { Behandlg. }\end{array}$ & - \\
\hline 129 & Gertrud Kahl. & 6 & $\begin{array}{l}\text { Akute Eiterung rechts } \\
\text { mit Empyem. }\end{array}$ & 2 Woch. & 6 Woch. & Geheilt. & - \\
\hline 130 & $\begin{array}{l}\text { Otto } \\
\text { Bernbardt. }\end{array}$ & 3 & $\begin{array}{l}\text { Akute Eiterung links } \\
\text { mit Empyem. }\end{array}$ & 11 Tage & - & $\begin{array}{l}\text { Noch in } \\
\text { Bebandlg. }\end{array}$ & - \\
\hline 131 & $\begin{array}{l}\text { Frieda } \\
\text { Koch. }\end{array}$ & $13 / 4$ & dto. & - & 6 Woch. & Geheilt. & $\begin{array}{l}\text { In der Filial } \\
\text { gelegen. }\end{array}$ \\
\hline 132 & Kurt Jordan. & 1 & $\begin{array}{l}\text { Akute Eiterung rechts } \\
\text { mit Empyem. }\end{array}$ & 8 Tage. & - & $\begin{array}{l}\text { Noch in } \\
\text { Bebandlg. }\end{array}$ & - \\
\hline 133 & $\begin{array}{l}\text { Wilhelm } \\
\text { Schmidt. T. }\end{array}$ & 32 & $\begin{array}{l}\text { Chron. Eiterung rechts } \\
\text { mit Cholesteatom. }\end{array}$ & $21 / 2$ Mon. & 4 Mon. & Geheilt. & - \\
\hline 134 & Franz Keil. & 2 & $\begin{array}{l}\text { Akute Eitcrung rechts } \\
\text { mit Caries. }\end{array}$ & 3 Woch. & - & $\begin{array}{l}\text { Noch in } \\
\text { Bebdlang: }\end{array}$ & - \\
\hline
\end{tabular}




\begin{tabular}{|c|c|c|c|c|c|c|c|}
\hline \multirow{2}{*}{ 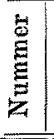 } & \multirow{2}{*}{ Name } & \multirow{2}{*}{ 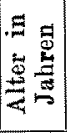 } & \multirow{2}{*}{$\begin{array}{l}\text { Diagnose, } \\
\text { resp. Befund }\end{array}$} & \multicolumn{2}{|c|}{$\begin{array}{c}\text { Daver } \\
\text { der Bebandlung }\end{array}$} & \multirow{2}{*}{ Resultat } & \multirow{2}{*}{ Bemerkungen } \\
\hline & & & & $\begin{array}{l}\text { in dex } \\
\text { Klinik }\end{array}$ & überhaupt & & \\
\hline 135 & $\begin{array}{c}\text { Frieda } \\
\text { Angermann. }\end{array}$ & 2 & $\begin{array}{l}\text { Akute Eiterung links } \\
\text { mit Empyem. }\end{array}$ & 14 Tage. & - & $\begin{array}{l}\text { D. Behdlg. } \\
\text { entzogen. }\end{array}$ & - \\
\hline 136 & o. Mainz. & 15 & do. & 5 Woch. & 5 Wooh. & Geheilt. & - \\
\hline 137 & Alfred Barth. & 4 & $\begin{array}{l}\text { Akute Eiterung rechts } \\
\text { mit Caries. }\end{array}$ & - & - & $\begin{array}{l}\text { Nooh in } \\
\text { Behandlg. }\end{array}$ & $\begin{array}{l}\text { Scharlachstat. } \\
\text { d. med. Klinik. }\end{array}$ \\
\hline 138 & $\begin{array}{l}\text { Ernst Gleits- } \\
\text { mann, T. }\end{array}$ & 16 & $\begin{array}{l}\text { Chron. Eiterung rechts } \\
\text { mit Cholesteatom. }\end{array}$ & 4 Mon. & 4 Mon. & Geheilt. & - \\
\hline 139 & Kudolf Barth. & 6 & $\begin{array}{l}\text { Aknte Eiterung links } \\
\text { mit Caries. }\end{array}$ & - & - & $\begin{array}{l}\text { Nooh in } \\
\text { Behandlg. }\end{array}$ & $\begin{array}{l}\text { Scharlachstat. } \\
\text { d. med. Klinik. }\end{array}$ \\
\hline 140 & Carl stille. $T$. & 18 & $\begin{array}{l}\text { Chron. Eiterung links } \\
\text { mit Cholesteatom. }\end{array}$ & 2 Mon. & - & $\begin{array}{l}\text { Noch in } \\
\text { Behandlg. }\end{array}$ & - \\
\hline 141 & Frieda Schatz. & 1 & $\begin{array}{l}\text { Akute Eiterung rechts } \\
\text { mit Empyem. }\end{array}$ & 6 Wooh. & 8 Woch. & Geheilt. & - \\
\hline 142 & $\begin{array}{c}\text { Anna Felgner. } \\
\mathrm{T} \text {. }\end{array}$ & 6 & $\begin{array}{l}\text { Chron. Eiterung links } \\
\text { nit Caries. }\end{array}$ & $21 / 2$ Mon. & 3 Mon. & Geheilt. & - \\
\hline 143 & $\begin{array}{l}\text { Friedrich } \\
\text { Liebelt. }\end{array}$ & 54 & $\begin{array}{l}\text { Akute Eiterung rechts } \\
\text { mit Empyem. }\end{array}$ & 7 Wooh. & 9 Wooh. & Geheilt. & - \\
\hline 144 & $\begin{array}{l}\text { Gertrud } \\
\text { Sohatz. }\end{array}$ & 1 & $\begin{array}{l}\text { Akute Eiterung links } \\
\text { mit Empyem. }\end{array}$ & - & 6 Woch. & Geheilt. & $\begin{array}{l}\text { Poliklinisch } \\
\text { operiert. }\end{array}$ \\
\hline 145 & Elise Kaiser. & $\stackrel{7}{\mathrm{M}}$. & $\begin{array}{l}\text { Akute Eiterung liniss } \\
\text { mit Caries. }\end{array}$ & - & 与े Woch. & Geheilt. & $\begin{array}{c}\text { Poliklinisch } \\
\text { operiert. }\end{array}$ \\
\hline 146 & Dieselbe. & & $\begin{array}{l}\text { Akute Eiterung rechts } \\
\text { mit Caries. }\end{array}$ & - & 6 Woch. & Gebeilt. & $\begin{array}{l}\text { Poliklinisch } \\
\text { operiert. }\end{array}$ \\
\hline 147 & Senftenberg. & 52 & $\begin{array}{l}\text { Akute Eiterung links } \\
\text { mit Mastoiditis. }\end{array}$ & 7 Woch. & 9 Woch. & $\begin{array}{l}\text { Noch in } \\
\text { Behandlg. }\end{array}$ & - \\
\hline 148 & $\begin{array}{l}\text { Ferdinand } \\
\text { Regel. T. }\end{array}$ & 16 & $\begin{array}{l}\text { Chron. Eiterung rechts } \\
\text { mit Caries. }\end{array}$ & - & - & $\begin{array}{l}\text { Noch in } \\
\text { Behandlg. }\end{array}$ & $\begin{array}{l}\text { In der Filiale } \\
\text { gelegen. }\end{array}$ \\
\hline 149 & $\begin{array}{l}\text { Johannes } \\
\text { Bernbard. }\end{array}$ & 14 & $\begin{array}{l}\text { Akute Eiterung links } \\
\text { mit Caries. }\end{array}$ & 3 Mon. & - & Geheilt. & $\begin{array}{l}\text { Sinus- Bulbus } \\
\text { operation. }\end{array}$ \\
\hline 150 & Elli Meeth. & 2 & $\begin{array}{r}\text { Akute Eiterung reobts } \\
\text { mit LymphdrusenabszeB. }\end{array}$ & 3 Woch. & 4 Woch. & $\begin{array}{l}\text { Noch in } \\
\text { Behandlg. }\end{array}$ & - \\
\hline 151 & $\begin{array}{c}\text { Elise Hirsoh. } \\
\text { T. }\end{array}$ & 6 & $\begin{array}{l}\text { Chron. Eiterung links } \\
\text { mit Caries. }\end{array}$ & $11 / 2$ Mon. & - & $\begin{array}{l}\text { Noch in } \\
\text { Behandlg. }\end{array}$ & - \\
\hline 152 & $\begin{array}{c}\text { Fran Stenzel. } \\
\text { T. }\end{array}$ & 26 & do. & 3 Woch. & - & $\begin{array}{l}\text { Nooh in } \\
\text { Behandlg. }\end{array}$ & - \\
\hline 153 & W. Zappe. T. & 5 & $\begin{array}{l}\text { Chron. Eiterung rechts } \\
\text { mit Nekrose. }\end{array}$ & $2 \%$ Mon. & - & $\begin{array}{l}\text { Nooh in } \\
\text { Behandlg }\end{array}$ & - \\
\hline 154 & Otto Mehl. & 3 & $\begin{array}{l}\text { Akute Eiterung links } \\
\text { mit Caries. }\end{array}$ & - & 8 Woch. & $\begin{array}{l}\text { Nooh in } \\
\text { Behandlg. }\end{array}$ & $\begin{array}{l}\text { Soharlachstat. } \\
\text { d.med. Klinil: }\end{array}$ \\
\hline 155 & $\begin{array}{l}\text { Wilhelm } \\
\text { Benecke. T. }\end{array}$ & 12 & $\begin{array}{l}\text { Chron. Eiterung links } \\
\text { mit Cholesteatom. }\end{array}$ & $21 / 2$ Mon. & - & $\begin{array}{l}\text { Nooh in } \\
\text { Behandlg. }\end{array}$ & - \\
\hline 156 & $\begin{array}{l}\text { Wilhelm } \\
\text { Hennig. T, }\end{array}$ & 9 & $\begin{array}{l}\text { Chron. Fiterung rechts } \\
\text { mit Cholesteatom. }\end{array}$ & $2^{1 / 2}$ Mon. & - & $\begin{array}{l}\text { Noch in } \\
\text { Behandlg. }\end{array}$ & - \\
\hline 157 & $\begin{array}{l}\text { Robert Son- } \\
\text { dershausen. } T \text {. }\end{array}$ & 38 & $\begin{array}{l}\text { Chron. Eiterung links } \\
\text { mit Cholesteatom. }\end{array}$ & 3 Tage. & 3 Tage. & Gestorben. & Meningitis. \\
\hline 158 & $\begin{array}{c}\text { Bertha } \\
\text { Schroeter. T. }\end{array}$ & 19 & $\begin{array}{l}\text { Chron. Eiterung links } \\
\text { mit Empyem. }\end{array}$ & $2^{1 / 2}$ Mon. & - & $\begin{array}{l}\text { Noch in } \\
\text { Behandlg. }\end{array}$ & - \\
\hline 159 & Bertha Lein. & 1 & $\begin{array}{l}\text { Akute Eiterung rechts } \\
\text { mit Empyem. }\end{array}$ & 5 Tage & - & $\begin{array}{l}\text { Noch in } \\
\text { Bebandlg. }\end{array}$ & - \\
\hline
\end{tabular}


Jabresbericht der Kgl. Universitäts-Ohrenklinik zu Halle a. S.

137

\begin{tabular}{|c|c|c|c|c|c|c|c|}
\hline \multirow{2}{*}{ 异 } & \multirow{2}{*}{ Name } & \multirow{2}{*}{ 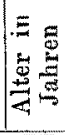 } & \multirow{2}{*}{$\begin{array}{l}\text { Diagnose, } \\
\text { resp. Befund }\end{array}$} & \multicolumn{2}{|c|}{$\begin{array}{l}\text { Daner } \\
\text { der Bebandlung }\end{array}$} & \multirow{2}{*}{ Resultat } & \multirow{2}{*}{ Bemerkungen } \\
\hline & & & & $\begin{array}{l}\text { in der } \\
\text { Klinik }\end{array}$ & iberhaupt & & \\
\hline 160 & $\begin{array}{c}\text { Käthe } \\
\text { Hesselbarth.T. }\end{array}$ & 4 & $\begin{array}{l}\text { Chron. Eiterung rechts } \\
\text { mit Caries }\end{array}$ & 2 Mon. & - & $\begin{array}{l}\text { Noch in } \\
\text { Behandlg. }\end{array}$ & - \\
\hline 161 & $\begin{array}{c}\text { Eduard } \\
\text { Rosenkranz.T. }\end{array}$ & 17 & $\begin{array}{l}\text { Chron. Eiterung links } \\
\text { mit Caries. }\end{array}$ & 2 Mon. & - & $\begin{array}{l}\text { Noch in } \\
\text { Behandlg. }\end{array}$ & - \\
\hline 162 & $\begin{array}{l}\text { Walter } \\
\text { Dötling. T. }\end{array}$ & 8 & $\begin{array}{l}\text { Chron. Eiterung links } \\
\text { mit Cholesteatom. }\end{array}$ & 2 Mon. & - & $\begin{array}{l}\text { Noch in } \\
\text { Behandlg. }\end{array}$ & - \\
\hline 163 & Frieda Mieth. & 1 & $\begin{array}{l}\text { Akute Eiterung links } \\
\text { mit Caries. }\end{array}$ & 3 Tage & - & $\begin{array}{l}\text { D. Behdlg. } \\
\text { entzogen. }\end{array}$ & - \\
\hline
\end{tabular}

